Um estudo comparativo das especificações de segurança aplicadas a uma arquitetura orientada a serviços 

SERVIÇO DE PÓS-GRADUAÇÃO DO ICMC-USP

Data de Depósito:

Assinatura:

\section{Um estudo comparativo das especificações de segurança aplicadas a uma arquitetura orientada a serviços}

\section{Douglas Rodrigues}

Orientadora: Profa. Dra. Kalinka Regina Lucas Jaquie Castelo Branco

Dissertação apresentada ao Instituto de Ciências Matemáticas e de Computação - ICMC-USP, como parte dos requisitos para obtenção do título de Mestre em Ciências - Ciências de Computação e Matemática Computacional. VERSÃO REVISADA. 
Ficha catalográfica elaborada pela Biblioteca Prof. Achille Bassi e Seção Técnica de Informática, ICMC/USP, com os dados fornecidos pelo(a) autor(a)

\begin{tabular}{|c|c|}
\hline \multirow[t]{3}{*}{$\mathrm{R} 696 \mathrm{e}$} & $\begin{array}{l}\text { Rodrigues, Douglas } \\
\text { Um estudo comparativo das especificações de } \\
\text { segurança aplicadas a uma arquitetura orientada a } \\
\text { serviços / Douglas Rodrigues; orientadora Kalinka } \\
\text { Regina Lucas Jaquie Castelo Branco -- São Carlos, } \\
\text { 2011. } \\
\quad 113 \text { p. }\end{array}$ \\
\hline & $\begin{array}{l}\text { Dissertação (Mestrado - Programa de Pós-Graduação en } \\
\text { Ciências de Computação e Matemática Computacional) -- } \\
\text { Instituto de Ciências Matemáticas e de Computação, } \\
\text { Universidade de São Paulo, } 2011 .\end{array}$ \\
\hline & $\begin{array}{l}\text { 1. Arquitetura Orientada a Serviços. 2. Avaliação } \\
\text { de Desempenho. 3. Segurança de Redes. I. Branco, } \\
\text { Kalinka Regina Lucas Jaquie Castelo, orient. II. } \\
\text { Título. }\end{array}$ \\
\hline
\end{tabular}


"Orar como se tudo dependesse de Deus. Agir como se tudo dependesse de nós." (Gilbert Chesterton) 



\section{Agradecimentos}

Gradeço, em primeiro lugar, a Deus, por me conceder a vida, saúde, paz, amor, discerni-
mento, paciência e coragem para chegar até aqui e superar mais este desafio.

Aos meus pais Célia e João e à minha namorada Maíra, pelo amor, carinho, incentivo, apoio e compreensão incondicionais.

À professora Kalinka, pela confiança, respeito, amizade, dedicação, apoio, motivação, conselhos e orientação não apenas durante o período de desenvolvimento deste trabalho, mas sim ao longo dos anos em que trabalhamos juntos.

Ao Júlio, por toda contribuição e sugestões na idealização e realização deste projeto.

Aos amigos do LaSDPC Maycon, Lourenço, Thiago, Ricardo, Edwin, Pedro Nobile, Bruno Guazzelli, Bruno (Nardone), Paulo, Kenji, Mário, Fabiano, Renê, Roni, Luis Nakamura, Pedro Prado, Alessandro, Daniel, Adriana e Dionísio pelo convívio saudável e troca de experiências. Espero ter me lembrado de todos!

Aos meus amigos de república Paulo e Danillo, pelo ambiente e convívio agradáveis, companhia e momentos de diversão. Aos meus amigos de graduação Rafael e Adriano pelas conversas e viagens descontraídas.

Aos professores do grupo de Sistemas Distribuídos e Programação Concorrente, pelas sugestões e discussões sobre o trabalho.

A todos os funcionários do ICMC-USP, em especial aos da Secretaria de Pós-Graduação, pela atenção e cordialidade no atendimento.

Ao CNPq pelo suporte financeiro.

Enfim, a todos aqueles que de alguma forma contribuíram para a realização deste trabalho. 

Este projeto é proposta uma avaliação e comparação de diretrizes e a adequação de técnicas que permitam não somente a criação de Web services seguros, mas também a validação dos serviços utilizados para determinar se a aplicação possui as características almejadas relacionadas ao desempenho e à segurança. Neste sentido, é primordial analisar as principais especificações de segurança empregadas em Web services no contexto atual, bem como avaliar os algoritmos criptográficos e o comprimento das chaves utilizadas. Os resultados obtidos permitem determinar, com base nos objetivos especificados, qual o impacto dos mecanismos de segurança utilizados no desempenho da aplicação. 

$\mathrm{N}$ this project we propose an evaluation and comparison of guidelines and appropriateness of techniques that allow not only the creation of secure Web services, but also the validation of the services used to determine whether the application has the desired characteristics related to performance and security. In this sense it is crucial to analyze the main security specifications used in Web services in the current context, as well as evaluating the cryptographic algorithms and key length used. The results obtained allow to determine, based on specified objectives, the impact of security mechanisms used in application performance. 

Resumo

$\begin{array}{lll}\text { Abstract } & \text { vii }\end{array}$

$\begin{array}{lll}\text { Lista de Siglas } & \text { xv }\end{array}$

1 Introdução $\quad \mathbf{1}$

1.1 Motivação e Objetivos . . . . . . . . . . . . . . . . . . . . 2

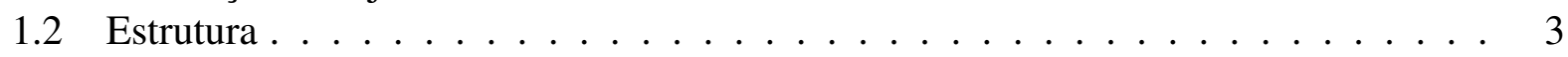

2 SOA e Web Services $\quad 5$

2.1 Arquitetura Orientada a Serviços . . . . . . . . . . . . . . . . . . . . . . 5

2.2 Visão Geral dos Web Services . . . . . . . . . . . . . . . . . . . 8

2.2.1 Pilha Conceitual dos Web Services . . . . . . . . . . . . . . . . . 9

2.3 Padrões Fundamentais dos Web Services . . . . . . . . . . . . . . . . . 11

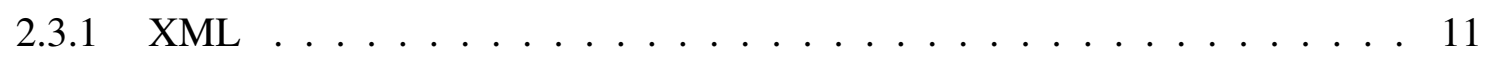

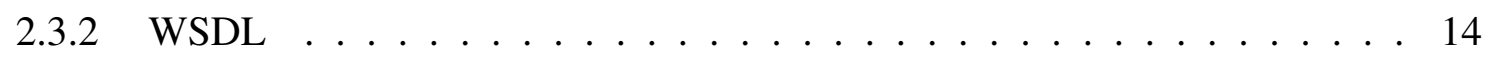

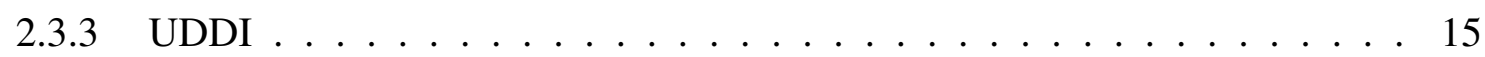

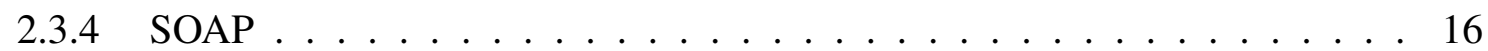

2.4 Considerações Finais . . . . . . . . . . . . . . . . . . . 18

3 Segurança em Redes de Computadores 19

3.1 Conceitos Básicos . . . . . . . . . . . . . . . . . . . 19

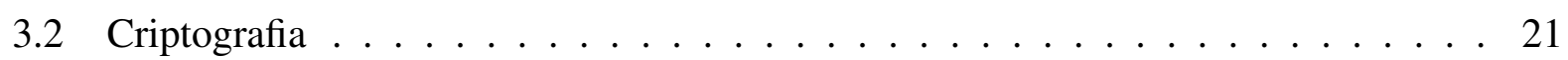

3.2.1 Criptografia de Chave Simétrica . . . . . . . . . . . . . . . 22

3.2 .2 Criptografia de Chave Pública . . . . . . . . . . . . . . 23

3.3 Assinatura Digital . . . . . . . . . . . . . . . . . . . . . 24

3.3 .1 Função de Hash . . . . . . . . . . . . . . . . . . . . . . . . 26

3.4 Gerenciamento de Chaves Públicas . . . . . . . . . . . . . . . . . . 28

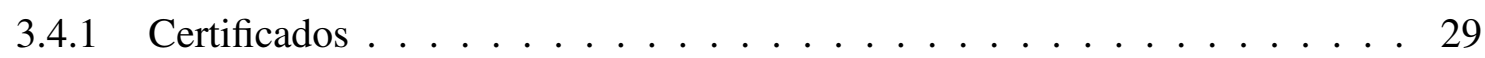

3.5 SSL e TLS . . . . . . . . . . . . . . . . . . 30

3.6 Considerações Finais . . . . . . . . . . . . . . . . . 31 
4 Especificações de Segurança em Web Services $\quad 33$

4.1 XML Encryption . . . . . . . . . . . . . . . . . . . . 33

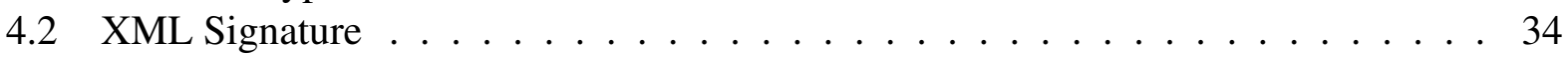

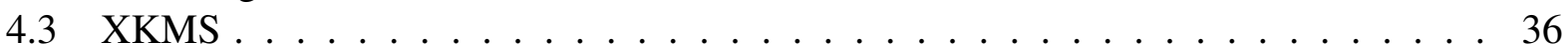

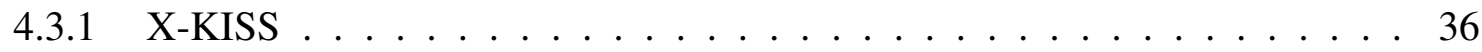

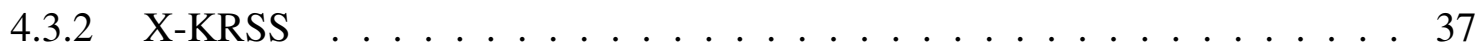

4.4 WS-Security . . . . . . . . . . . . . . . . . 37

4.5 WS-Policy . . . . . . . . . . . . . . . . . . 38

4.6 WS-SecurityPolicy . . . . . . . . . . . . . . . . . . . 39

4.7 Outras Especificações de Segurança para Web Services . . . . . . . . . . . . . . 41

4.8 Considerações Finais . . . . . . . . . . . . . . . . . . . . . . 42

5 Arquitetura de Segurança Proposta para Web Services $\quad 43$

5.1 Trabalhos Correlatos . . . . . . . . . . . . . . . . . . 43

5.2 Desenvolvimento e Implementação da Arquitetura . . . . . . . . . . . . . . . . . . . . . . . . . . . . . . . . . . . .

5.3 Funcionamento da Arquitetura . . . . . . . . . . . . . . . . . 50

5.4 Considerações Finais . . . . . . . . . . . . . . . . . . . . . 54

6 Avaliação de Desempenho de Web Services Seguros 55

6.1 Estudo de Caso $1 \ldots \ldots \ldots \ldots \ldots$

6.1 .1 Domínio da Aplicação . . . . . . . . . . . . . . . . . . 56

6.1.2 Configuração do Ambiente de Testes . . . . . . . . . . . . . . . . 56

6.1 .3 Planejamento dos Experimentos . . . . . . . . . . . . . . . 56

6.1 .4 Análise dos Resultados . . . . . . . . . . . . . . . . 59

6.2 Estudo de Caso $2 \ldots \ldots \ldots \ldots \ldots$

6.2 .1 Domínio da Aplicação . . . . . . . . . . . . . . . . . 63

6.2.2 Configuração do Ambiente de Testes . . . . . . . . . . . . . . . . 64

6.2 .3 Planejamento dos Experimentos . . . . . . . . . . . . . . . 65

6.2 .4 Análise dos Resultados . . . . . . . . . . . . . . . . . . . . 66

6.3 Considerações Finais . . . . . . . . . . . . . . . . . . . 78

7 Conclusão $\quad \mathbf{7 9}$

7.1 Dificuldades Relacionadas ao Projeto . . . . . . . . . . . . . . . . . 80

7.2 Contribuições . . . . . . . . . . . . . . . . . . 80

7.3 Produção Científica . . . . . . . . . . . . . . . . . . 81

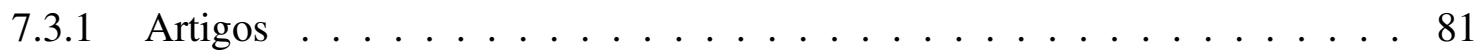

7.3.2 Capítulos de Livro . . . . . . . . . . . . . . . . . . . 81

7.3 .3 Minicursos Apresentados . . . . . . . . . . . . . . . . . 82

7.3 .4 Resumos . . . . . . . . . . . . . . . . . 82

7.4 Trabalhos Futuros . . . . . . . . . . . . . . . . 82

$\begin{array}{ll}\text { Referências } & 84\end{array}$ 


\section{Lista de Figuras}

1.1 Segurança ponto-a-ponto - Adaptado de (Microsoft, 2002) . . . . . . . . . . . . 2

1.2 Segurança fim-a-fim - Adaptado de (Microsoft, 2002) . . . . . . . . . . . . . 2

2.1 Elementos da SOA - Adaptado de $($ Erl, 2005) . . . . . . . . . . . . . . . . 6

2.2 Arquitetura dos Web services - Adaptado de (Barry e Gannon, 2003). . . . . . . . 9

2.3 Pilha conceitual dos Web services - Adaptado de (IBM, 2009). . . . . . . . . . . . 10

2.4 Exemplo de elemento e atributo. . . . . . . . . . . . . . . . . . . 12

2.5 Exemplo da estrutura hierárquica do XML . . . . . . . . . . . . . . . . . . . . . . . . . . . . . 12

2.6 Exemplo de XML Schema. . . . . . . . . . . . . . . . . . . . 13

2.7 Exemplo de XML Namespaces. . . . . . . . . . . . . . . . . . . . . . . . 14

2.8 Estrutura de um documento WSDL - Adaptado de $($ Erl, 2004). . . . . . . . . . . . 15

2.9 Estrutura da mensagem SOAP - Adaptado de (Ort, 2005) . . . . . . . . . . . . . 17

2.10 Exemplo de mensagem SOAP de requisição. . . . . . . . . . . . . . . . . . 17

3.1 Esquema geral da criptografia - Adaptado de (Rosenberg e Remy, 2004). . . . . . . 21

3.2 Criptografia de chave simétrica - Adaptado de (Rosenberg e Remy, 2004). . . . . . 22

3.3 Criptografia de chave pública - Adaptado de (Rosenberg e Remy, 2004). . . . . . . 24

3.4 Geração de assinatura digital - Adaptado de (Rosenberg e Remy, 2004). . . . . . . 26

3.5 Verificação de assinatura digital - Adaptado de (Rosenberg e Remy, 2004). . . . . . 27

3.6 Pilha de protocolos SSL - Adaptado de (Stallings, 2005) . . . . . . . . . . . . . . 30

4.1 Estrutura do XML Encryption. . . . . . . . . . . . . . . . . . . . 34

4.2 Tipos de assinaturas do XML Signature - Adaptado de (Nordbotten, 2009). . . . . 35

4.3 Estrutura do XML Signature. . . . . . . . . . . . . . . . . . 36

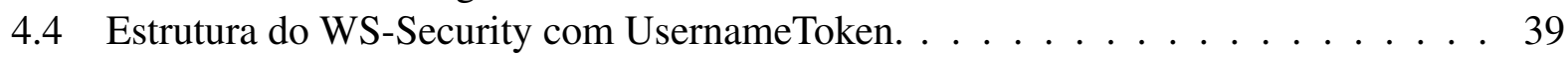

4.5 Política definida com WS-Policy. . . . . . . . . . . . . . . . . . . . . . . . . . . . . . 40

4.6 Política definida com WS-SecurityPolicy. . . . . . . . . . . . . . . . 40

4.7 Pilha de especificações de segurança para Web services - Adaptado de (Tang et al., 2006) . . . . . . . . . . . . . . . . . . . 41

5.1 Arquitetura de segurança para Web services. . . . . . . . . . . . . . . . . 50

5.2 Autoridade certificadora e os keystores do cliente e do serviço - Adaptado de (Fer-

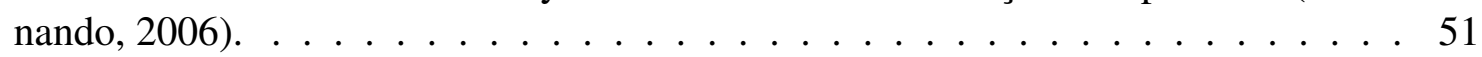

5.3 Procedimento de criptografia. . . . . . . . . . . . . . . . . . 52

5.4 Procedimento de decriptação. . . . . . . . . . . . . . . . 53 
6.1 Ambiente para execução de experimentos. . . . . . . . . . . . . . . . . . . 57

6.2 RTT -5 clientes. . . . . . . . . . . . . . . . . . 6 60

6.3 RTT -10 clientes. . . . . . . . . . . . . . . . . 61

6.4 Influência dos fatores. . . . . . . . . . . . . . . . . . . . 62

6.5 WS-Security vs. SSL . . . . . . . . . . . . . . . . . . 63

6.6 Ambiente para execução de experimentos. . . . . . . . . . . . . . . . . . . 64

6.7 Algoritmos de chave simétrica com RSA-OAEP (1 cliente) . . . . . . . . . . . . 67

6.8 Algoritmos de chave simétrica com RSA 1.5 (1 cliente). . . . . . . . . . . . . . 68

6.9 Algoritmos de chave simétrica com RSA-OAEP (3 clientes) . . . . . . . . . . . . 69

6.10 Algoritmos de chave simétrica com RSA 1.5 (3 clientes). . . . . . . . . . . . . . 69

6.11 Algoritmos de chave pública com AES 192 (1 cliente). . . . . . . . . . . . 70

6.12 Algoritmos de chave pública com AES 256 (1 cliente) . . . . . . . . . . . . 70

6.13 Algoritmos de chave pública com 3DES (1 cliente) . . . . . . . . . . . . . 71

6.14 Algoritmos de chave pública com AES 192 (3 clientes) . . . . . . . . . . . . . 71

6.15 Algoritmos de chave pública com AES 256 (3 clientes). . . . . . . . . . . . 72

6.16 Algoritmos de chave pública com 3DES (3 clientes). . . . . . . . . . . . . 72

6.17 RTT - AES192 - RSA-OAEP. . . . . . . . . . . . . . . . 73

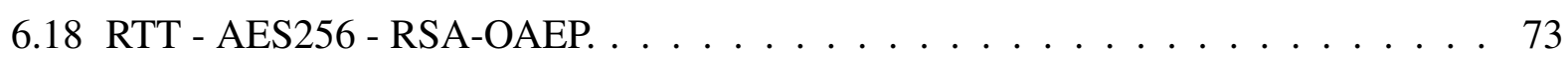

6.19 RTT - 3DES - RSA-OAEP. . . . . . . . . . . . . . . . 74

6.20 RTT - AES192 - RSA1.5 . . . . . . . . . . . . . . . . . 75

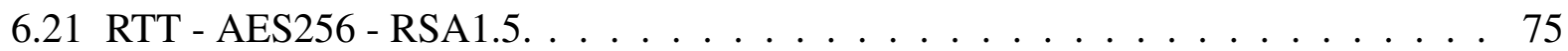

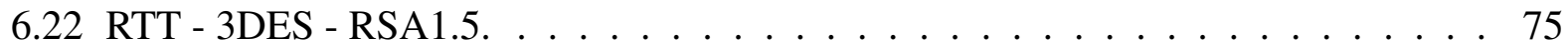

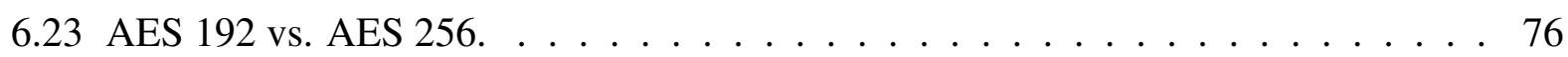

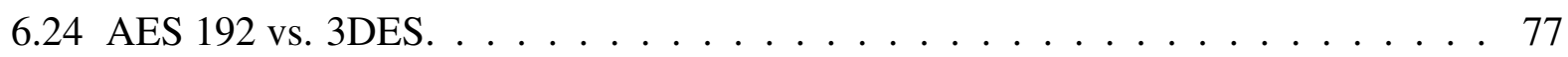

6.25 AES 256 vs. 3DES. . . . . . . . . . . . . . . . . . . 77 


\section{Lista de Tabelas}

6.1 Elementos de hardware. . . . . . . . . . . . . . . . 56

6.2 Fatores e níveis dos experimentos. . . . . . . . . . . . . . 58

6.3 Experimentos realizados. . . . . . . . . . . . . . . . 58

6.4 RTT -5 clientes. . . . . . . . . . . . . . . . . . . . . 59

6.5 RTT -10 clientes. . . . . . . . . . . . . . . . . . . 60

6.6 RTT - Web services que utilizam SSL . . . . . . . . . . . . . . . . . 62

6.7 Elementos de hardware. . . . . . . . . . . . . . . . . . . . . . 64

6.8 Fatores e níveis dos experimentos. . . . . . . . . . . . . . . . 65

6.9 Experimentos realizados. . . . . . . . . . . . . . . . . 66

6.10 Algoritmos de chave simétrica com RSA-OAEP $(1$ cliente $) \ldots \ldots$. . . . . . . . . . 67

6.11 Algoritmos de chave simétrica com RSA 1.5 (1 cliente) . . . . . . . . . . . . . 68

6.12 Algoritmos de chave simétrica com RSA-OAEP (3 clientes) . . . . . . . . . . . 68

6.13 Algoritmos de chave simétrica com RSA 1.5 (3 clientes). . . . . . . . . . . . . . 68

6.14 Algoritmos de chave pública com AES 192 (1 cliente). . . . . . . . . . . . . . . 70

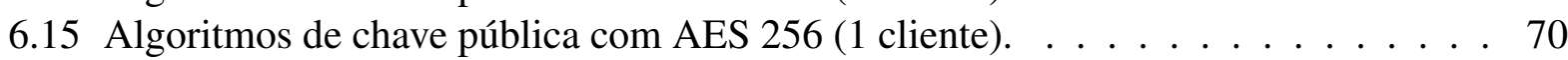

6.16 Algoritmos de chave pública com 3DES (1 cliente) . . . . . . . . . . . . . 70

6.17 Algoritmos de chave pública com AES 192 (3 clientes). . . . . . . . . . . . . . 71

6.18 Algoritmos de chave pública com AES 256 (3 clientes). . . . . . . . . . . . . . 72

6.19 Algoritmos de chave pública com 3DES (3 clientes). . . . . . . . . . . . . . 72

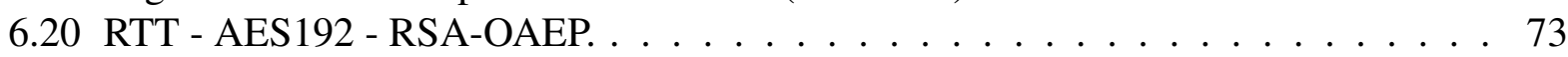

6.21 RTT - AES256-RSA-OAEP. . . . . . . . . . . . . . . . . . . . . . . . . . . . . . . . 74

6.22 RTT - 3DES - RSA-OAEP . . . . . . . . . . . . . . . . . . . . . . . . . . . . . . . . . .

6.23 RTT - AES192 - RSA1.5 . . . . . . . . . . . . . . . . . . 74

6.24 RTT-AES256-RSA1.5 . . . . . . . . . . . . . . . . . . . 74

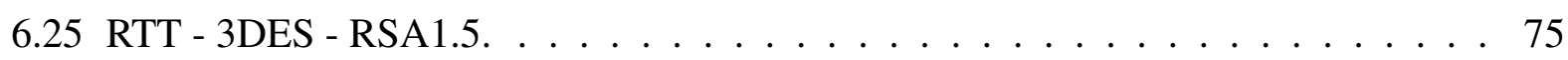



3DES Triple Data Encryption Standard

AES Advanced Encryption Standard

API Application Programming Interface

ASCII American Standard Code for Information Interchange

B2B Business-to-Business

BPEL Business Process Execution Language

CA Certification Authority

CORBA Common Object Request Broker Architecture

CPU Central Processing Unit

DES Data Encryption Standard

DoS Denial of Service

DTD Document Type Definition

FTP File Transfer Protocol

HTTP Hypertext Transfer Protocol

HTTPS Hypertext Transfer Protocol Secure

ICP Infraestrutura de Chave Pública

ITU International Telecommunication Union

JCE Java Cryptography Extension

JDK Java Development Kit

JRE Java Runtime Environment

KDC Key Distribution Center

LDAP Lightweight Directory Access Protocol 
MD5 Message-Digest Algorithm 5

MTOM Message Transmission Optimization Mechanism

NIST National Institute of Standards and Technology

OAEP Optimal Asymmetric Encryption Padding

OASIS Organization for the Advancement of Structured Information Standards

PKI Public Key Infrastructure

RMI Remote Method Invocation

RPC Remote Procedure Call

RSA Rivest, Shamir, Adleman

RTT Round Trip Time

SAML Security Assertion Markup Language

SHA-1 Secure Hash Algorithm 1

SMTP Simple Mail Transfer Protocol

SOA Service-Oriented Architecture

SOAP Simple Object Access Protocol

SSL Secure Sockets Layer

SwA SOAP with Attachments

TLS Transport Layer Security

UDDI Universal Description, Discovery and Integration

URI Uniform Resource Identifier

URL Uniform Resource Locator

W3C World Wide Web Consortium

WS Web Services

WSDL Web Services Description Language

WSDM Web Services Distributed Management

WS-I Web Services Interoperability Organization

WSIT Web Services Interoperability Technologies

X-KISS XML Key Information Service Specification

XKMS XML Key Management Specification

X-KRSS XML Key Registration Service Specification

XML eXtensible Markup Language 
O paradigma orientado a serviços torna mais ágil a criação de redes de colaboração no desenvolvimento de aplicações que ultrapassam as fronteiras das empresas, acarretando mudanças no modo como estas aplicações são construídas a partir de serviços existentes. A ideia básica da arquitetura orientada a serviço (Service-Oriented Architecture - SOA) tem recebido significante preocupação e atenção da comunidade de projeto e desenvolvimento de software. Como resultado desta atenção há a proliferação de muitas definições conflitantes sobre SOA. Desta forma, vários tipos de arquiteturas orientadas a serviço têm surgido e, entre elas, os Web services têm sido os mais comumente utilizados (Erl, 2005).

A interoperabilidade proporcionada pelos Web services é fundamental para a integração de aplicações baseadas na Web e na Internet, sendo a mesma alcançada por meio da utilização de padrões baseados em XML (eXtensible Markup Language), tais como SOAP (Simple Object Access Protocol), WSDL (Web Services Description Language) e UDDI (Universal Description, Discovery and Integration). O SOAP é utilizado para a transferência de dados entre os serviços, enquanto que a WSDL define um esquema XML para descrever os serviços disponíveis e a especificação UDDI define um modo de publicar e descobrir informações sobre um serviço específico em um diretório ou registro de serviços (Josuttis, 2007).

Ainda em relação à interoperabilidade, esta permite a integração de aplicações, entretanto, não garante a confidencialidade das informações que trafegam pela Internet, as quais podem ser sigilosas. Deste modo, garantir a segurança das informações é uma necessidade primordial quando se utiliza os Web services, uma vez que seus fluxos de negócio, processos e arquiteturas internas ficam expostos. 


\subsection{Motivação e Objetivos}

Abordadas com mais detalhes na Seção 3.5, tecnologias como o SSL/TLS (Secure Sockets Layer/Transport Layer Security) (Freier et al., 1996) (Dierks e Allen, 1999) visam prover segurança ponto-a-ponto, porém não garantem segurança fim-a-fim. Tal segurança é necessária em um ambiente de Web services, pois as mensagens SOAP podem trafegar por diversos Web services intermediários antes de atingir o destinatário final. Portanto, se a criptografia for utilizada apenas na camada de transporte, as informações serão reveladas aos Web services intermediários pelos quais as mensagens passaram, de modo proposital ou por meio de lacunas existentes entre uma sessão segura e outra (Mashood e Wikramanayake, 2007). Nas Figuras 1.1 e 1.2 são ilustrados os contextos de segurança em uma configuração ponto-a-ponto e uma configuração fim-a-fim, respectivamente.

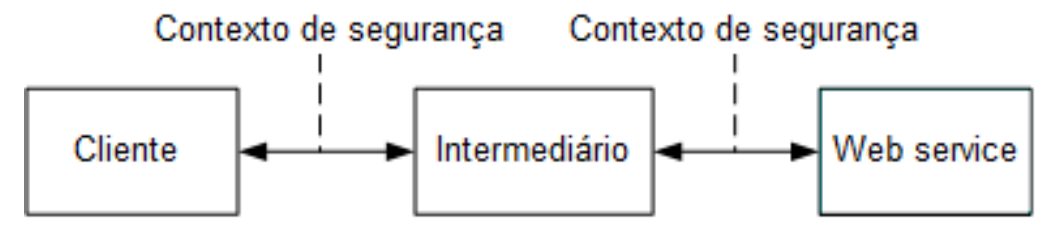

Figura 1.1: Segurança ponto-a-ponto - Adaptado de (Microsoft, 2002).

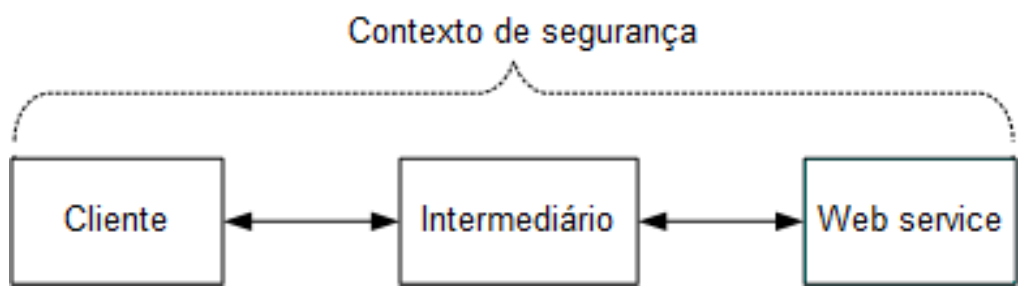

Figura 1.2: Segurança fim-a-fim - Adaptado de (Microsoft, 2002).

Para que a segurança seja garantida no ambiente de Web services novos mecanismos de segurança devem ser considerados, como, por exemplo, o WS-Security, que é um padrão da OASIS (Organization for the Advancement of Structured Information Standards) que visa à segurança fim-a-fim das mensagens SOAP, provendo confidencialidade, integridade e autenticidade para as mesmas no nível de mensagem (OASIS, 2006a).

Entretanto, a utilização de tais padrões de segurança causa significativa sobrecarga no desempenho dos Web services. A preocupação com o desempenho de Web services seguros é legitimada pelo fato de que as especificações de segurança aumentam consideravelmente o tamanho da mensagem SOAP, principalmente o cabeçalho. Além disso, a adição dos elementos XML relacionados à segurança acarreta não apenas maior consumo de largura de banda da rede para o transporte das mensagens SOAP, mas também consumo adicional de CPU para o processamento do documento XML e das operações necessárias à sua segurança (Liu et al., 2005) (Engelen e Zhang, 2008b) (Gruschka et al., 2011).

Desta forma, neste projeto é proposta uma avaliação e comparação de diretrizes e a adequação de técnicas que permitam não somente a criação de Web services seguros, mas também a validação 
dos serviços utilizados para determinar se a aplicação final possui as características desejadas no que diz respeito ao desempenho e à segurança. Neste sentido, é primordial analisar as principais especificações de segurança empregadas em Web services no contexto atual, bem como avaliar os algoritmos criptográficos e o comprimento das chaves utilizadas.

Ainda dentro deste escopo, pretende-se também determinar quais algoritmos criptográficos e suas chaves associadas impõem o menor impacto em termos de desempenho no contexto dos Web services. Tais algoritmos precisam ser estudados e discutidos de modo a determinar quais deles, ou a combinação dos mesmos, podem garantir segurança fim-a-fim com um desempenho satisfatório.

\subsection{Estrutura}

O restante deste documento está organizado da seguinte forma:

- No Capítulo 2 é apresentada uma revisão geral sobre a arquitetura orientada a serviços e os Web services, bem como os padrões que os compõem.

- No Capítulo 3 são apresentados conceitos sobre segurança em redes de computadores, bem como as técnicas de segurança existentes, tais como criptografia, assinatura digital, dentre outras.

- No Capítulo 4 são abordadas algumas especificações de segurança para XML e para Web services, tendo em vista a importância das mesmas para este projeto de pesquisa.

- No Capítulo 5 é apresentada a arquitetura de segurança proposta para Web services, bem como seus componentes e seu funcionamento.

- No Capítulo 6 são exibidos os resultados obtidos com os experimentos realizados na arquitetura de segurança.

- Finalmente, no Capítulo 7 é apresentada a conclusão desta dissertação de mestrado. 



\section{SOA e Web Services}

Este capítulo se inicia apresentando os principais conceitos sobre arquitetura orientada a serviços. Estes conceitos básicos constituem a base dos fundamentos de sua principal implementação, os Web services, os quais são abordados posteriormente. E, por fim, são discutidos os padrões fundamentais utilizados nos mesmos, tais como: XML (eXtensible Markup Language), SOAP (Simple Object Access Protocol), WSDL (Web Services Description Language) e UDDI (Universal Description, Discovery and Integration).

\subsection{Arquitetura Orientada a Serviços}

O termo "orientado a serviço" já existe há algum tempo e tem sido utilizado para diferentes contextos e diferentes finalidades. Porém, existe o consenso de que o termo "orientado a serviço" representa uma abordagem diferenciada para a separação de preocupações, ou seja, a lógica necessária para se resolver um grande problema pode ser melhor construída, realizada e gerenciada se a mesma for decomposta em uma coleção relacionada de partes menores. Cada um destes pedaços é focado em uma preocupação, isto é, em uma parte específica do problema. Assim, resumidamente, arquitetura orientada a serviços (Service-Oriented Architecture - SOA) se refere a um modelo em que a lógica de automação é decomposta em unidades menores, distintas e, geralmente, distribuídas (Erl, 2005).

Mais especificamente, SOA é uma proposta arquitetural que trata aplicações distribuídas como uma coleção de funcionalidades bem definidas em forma de serviços disponibilizados via rede, fornecendo uma infraestrutura com interfaces padronizadas. As funcionalidades do sistema são 
expostas por meio da descrição destas interfaces, permitindo a publicação, a localização e a invocação por meio de um formato padronizado (Papazoglou, 2003).

No contexto da SOA, um serviço é um componente de software que encapsula uma funcionalidade de negócio, devendo possuir uma interface bem definida e independente de implementação (Mahmoud, 2005).

Segundo (Papazoglou, 2003), a arquitetura orientada a serviços é composta de três elementos básicos:

- Registro de serviços: repositório utilizado para publicar e localizar as interfaces dos serviços, as quais são autodescritivas e baseadas em padrões abertos, definindo os métodos públicos juntamente com seus parâmetros e valores de retorno.

- Provedor de serviços: responsável pela criação do serviço e pela publicação da interface dos mesmos no registro de serviços, além de atender as requisições efetuadas pelos clientes.

- Cliente ou consumidor de serviços: pode ser uma aplicação ou outro serviço que realiza requisições a um serviço.

É importante ressaltar que cada elemento da arquitetura pode exercer um ou mais papéis, podendo ser, por exemplo, um provedor e um cliente de serviços ao mesmo tempo. Assim, um provedor de serviços pode fornecer serviços tanto para aplicações (usuários finais) quanto para outros serviços disponibilizados em uma rede, tornando possível a composição de serviços.

As interações entre os elementos apresentados envolvem as operações de publicar, localizar e invocar serviços, conforme ilustrado na Figura 2.1.

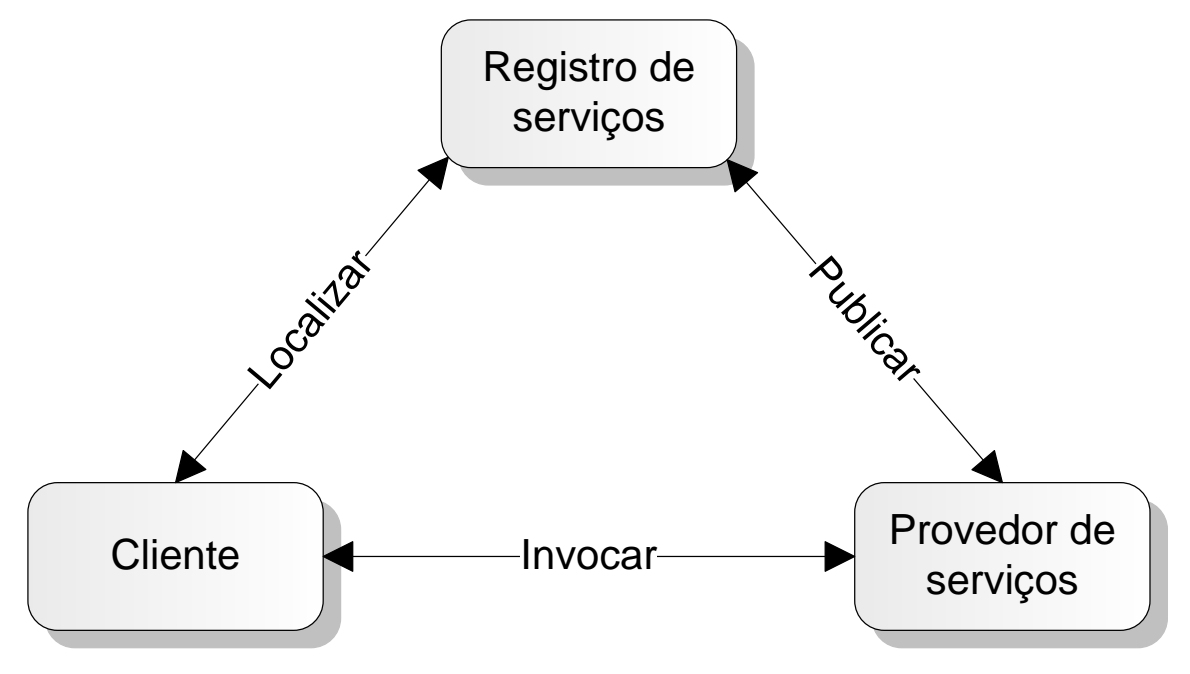

Figura 2.1: Elementos da SOA - Adaptado de (Erl, 2005).

Uma sequência normal das interações ilustrada na Figura 2.1 ocorre da seguinte maneira (Yamany et al., 2009): 
1. Publicar: o provedor de serviços desenvolve seu serviço, o implementa na linguagem e plataforma escolhidas e disponibiliza a descrição deste serviço por meio de uma interface no registro de serviços.

2. Localizar: posteriormente um cliente pode realizar uma busca por um determinado serviço no diretório de serviços, especificando características desejadas.

3. Invocar: caso o serviço exista, a interface e a localização do mesmo são retornadas para o cliente, que agora pode realizar uma invocação ao provedor de serviço.

SOA apresenta algumas características inerentes à sua arquitetura, das quais as mais importantes são: o acoplamento fraco, a transparência de localização e a independência de plataforma.

$\mathrm{O}$ acoplamento fraco refere-se ao conceito de minimizar as dependências entre as entidades participantes da arquitetura. Isto quer dizer que não existe necessidade do conhecimento de detalhes técnicos da implementação no serviço ou no cliente, como, por exemplo, a linguagem de programação ou a plataforma de implantação. A utilização de acoplamento fraco proporciona a flexibilidade de adicionar e modificar interfaces com o mínimo ou nenhum impacto de interoperabilidade entre as interfaces já existentes, ou seja, o software de um lado da comunicação pode ser modificado sem que haja impacto no software do outro lado, proporcionando assim vantagens como flexibilidade, escalabilidade e tolerância às falhas (Josuttis, 2007) (Colan, 2004) (McGovern et al., 2003).

A transparência de localização faz com que os clientes não precisem ter conhecimento sobre a localização dos serviços. Para tanto, os serviços devem ter suas definições e informação de localização armazenadas em repositórios, como o UDDI (explicado posteriormente na Seção 2.3.3), que serão acessados pelos clientes em tempo de execução com a finalidade de localizar e invocar os serviços independentemente de sua localização. A pesquisa e ligação dinâmicas a um serviço em tempo de execução permitem ainda que a implementação do serviço seja movido de um local para outro sem o conhecimento do cliente. Essa capacidade de mover os serviços pode ser, também, de grande utilidade em casos onde se pretende elevar a disponibilidade e o desempenho dos mesmos (McGovern et al., 2003).

A independência de plataforma significa que não deve haver dependência de plataforma tecnológica (hardware e software) para as funcionalidades de publicação, localização e invocação de serviços na arquitetura SOA. Isto pode ser conseguido utilizando-se padrões abertos (por exemplo, HTTP - Hypertext Transfer Protocol), descrições (por exemplo, WSDL) e mecanismos de descoberta (por exemplo, UDDI).

Uma implementação da arquitetura SOA possui como propósito a integração de negócios por meio de serviços, garantindo que os sistemas computacionais possam se adaptar às mudanças nas necessidades dos negócios de modo fácil, ágil e econômico (Papazoglou, 2003). Além disso, a arquitetura SOA também proporciona facilidade na reutilização e integração de códigos e serviços já 
oferecidos dentro de uma infraestrutura corporativa, evitando o desenvolvimento de novos códigos para prover funcionalidades já existentes.

\subsection{Visão Geral dos Web Services}

Os Web services (WS) têm sido muito abordados recentemente e são consolidados como uma implementação da arquitetura orientada a serviços (Martin-Flatin e Löwe, 2007) (Yu et al., 2007). De acordo com a definição formal contida em (W3C, 2004), um Web service é uma aplicação identificada por uma URI (Uniform Resource Identifier) e que possui interfaces bem definidas e descritas em XML. As interações com outras aplicações ocorrem por meio de trocas de mensagens XML utilizando protocolos padrões da Internet, tais como HTTP e FTP (File Transfer Protocol).

Web services também podem ser entendidos como uma unidade lógica de aplicação na qual sua funcionalidade pode ser reutilizada sem a preocupação de como a mesma é implementada, e acessada via protocolos padrões da Internet (Erradi e Maheshwari, 2005).

Os Web services são classificados como um tipo específico de serviço, sendo o mesmo identificado por uma URI e independente de arquitetura de máquinas, de sistemas operacionais e de linguagem de programação. A interoperabilidade entre clientes e provedores de serviços é alcançada devido ao uso de padrões abertos, tais como XML e HTTP. Desta forma, clientes e provedores de serviço não precisam ter conhecimento antecipado de quais são as tecnologias utilizadas em cada um dos lados. Essa característica é boa para projetos B2B (Business-to-Business) e para outras aplicações de sistemas distribuídos que requerem tecnologias integradoras por meio da Internet.

Para que as três operações fundamentais de uma arquitetura orientada a serviços (publicar, localizar e invocar) sejam possíveis, os Web services adotam os seguintes padrões baseados em XML (Erl, 2005):

- WSDL (Web Services Description Language): linguagem padrão que descreve as funcionalidades dos Web services.

- UDDI (Universal Description, Discovery and Integration): repositório onde os Web services são registrados para, posteriormente, serem descobertos pelos clientes.

- SOAP (Simple Object Access Protocol): protocolo para a troca de mensagens entre cliente e serviços, operando sobre outros protocolos de comunicação, como, por exemplo, o HTTP.

Na Figura 2.2 são ilustradas as etapas de um cenário típico de interações entre os elementos da arquitetura dos Web services. Estas etapas são:

1. Para tornar público um Web service, primeiramente o provedor de serviços descreve a interface do serviço que deseja fornecer, utilizando para isso, por exemplo, a WSDL, e em seguida publica a interface em um serviço de busca público, como, por exemplo, o UDDI. 
2. Após a publicação, o cliente pode então consultar o UDDI e localizar o serviço desejado.

3. Por meio da consulta, o cliente obtém a WSDL do serviço desejado.

4. Por fim, a comunicação entre o cliente e o provedor de serviço é realizada via troca de mensagens no formato XML encapsuladas dentro de envelopes SOAP.

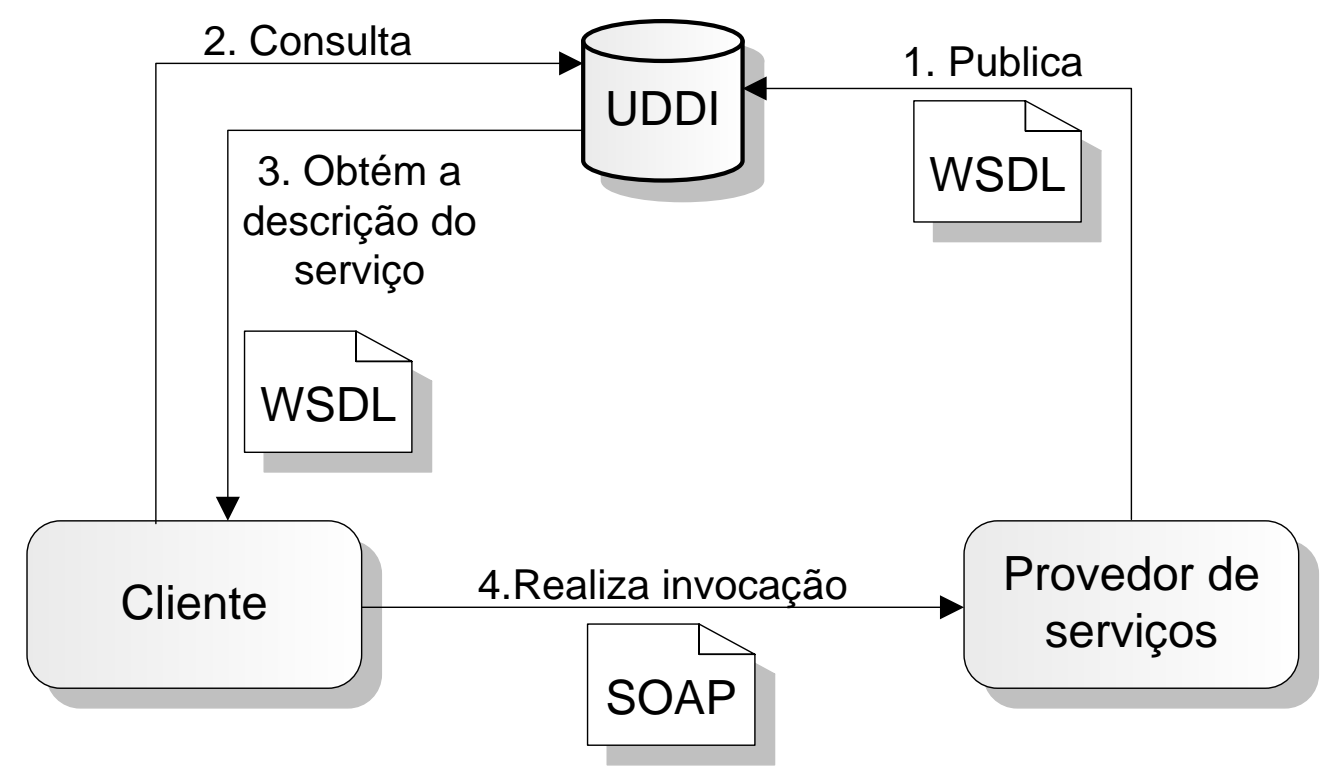

Figura 2.2: Arquitetura dos Web services - Adaptado de (Barry e Gannon, 2003).

A padronização é considerada um ponto primordial em Web services, pois assim pode-se garantir a sua característica de interoperabilidade e dinamicidade. Dentre as organizações padronizadoras, as que mais se destacam são a W3C (World Wide Web Consortium), a OASIS (Organization for the Advancement of Structured Information Standards) e a WS-I (Web Services Interoperability Organization). Vale ainda ressaltar que os padrões básicos mencionados que compõem a arquitetura dos Web services são explicados posteriormente com maiores detalhes na Seção 2.3.

\subsubsection{Pilha Conceitual dos Web Services}

As especificações pertinentes aos Web services são geralmente categorizadas em camadas de uma pilha conceitual, com a finalidade de facilitar o seu entendimento (Silva e Rosa, 2006). As camadas superiores são construídas com base nas funcionalidades fornecidas pelas camadas mais baixas. Desta forma, as camadas inferiores são mais maduras e padronizadas do que as camadas mais altas da pilha.

Na Figura 2.3 é ilustrada a pilha conceitual proposta pela IBM, a qual foi adotada neste trabalho por expor os conceitos de maneira genérica e completa, além de reunir os padrões básicos e as principais especificações emergentes (IBM, 2009).

A camada de transporte é composta de protocolos responsáveis pela transmissão de dados via rede, como, por exemplo, HTTP, FTP e SMTP (Simple Mail Transfer Protocol). O HTTP é o 


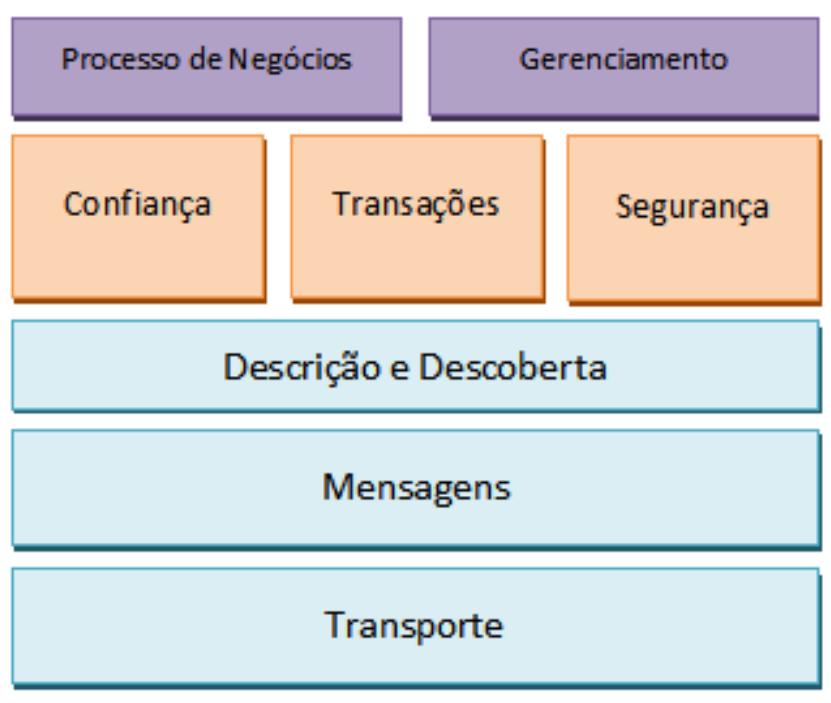

Figura 2.3: Pilha conceitual dos Web services - Adaptado de (IBM, 2009).

protocolo de comunicação mais utilizado atualmente, por isso o mesmo é recomendado como o principal protocolo de rede para os Web services na Internet. Todavia, em Web services acessados, por exemplo, dentro de uma Intranet, nada impede que sejam utilizados outros protocolos de rede.

A camada de mensagem define o formato de mensagens utilizado na comunicação entre aplicações. O padrão mais utilizado neste caso é o SOAP, objetivando a troca estruturada de informações entre nós dentro de um ambiente descentralizado e distribuído (W3C, 2007a).

A camada de descrição e descoberta oferece ao provedor de serviços uma forma de descrever as funcionalidades fornecidas pelos Web services e uma forma de publicar estas descrições em um registro central que esteja disponível publicamente para os clientes interessados. Nesta camada utiliza-se a linguagem WSDL para detalhar as características de cada serviço e o UDDI como um registro central, onde os provedores de serviços e os clientes operam em conjunto para publicar e recuperar as informações pretendidas.

Sumariamente, a WSDL define os métodos que estão presentes nos serviços, os parâmetros de entrada e saída para cada método, os tipos de dados, o protocolo de transporte utilizado e a URL (Uniform Resource Locator) da máquina onde o serviço está hospedado (W3C, 2004). Por sua vez, o UDDI tem a finalidade de representar dados e metadados sobre os Web services, provendo um mecanismo baseado em padrões para classificar, catalogar e gerenciar os Web services, permitindo que os mesmos sejam descobertos (OASIS, 2004a).

A camada de confiança visa garantir a realização de trocas de mensagens, pois sem ela não seria possível resolver questões de negócios, uma vez que os participantes não teriam certeza se esta troca de mensagens foi completada com sucesso. A especificação WS-ReliableMessaging (OASIS, 2004b) permite que as mensagens sejam entregues de forma confiável entre aplicações distribuídas na presença de falhas, como, por exemplo, falhas na rede, sendo de essencial importância para Web services. 
A camada de transações é fundamental na construção de aplicações distribuídas confiáveis. Um ambiente de Web services requer um comportamento coordenado fornecido por um mecanismo tradicional de transação para controlar as operações e os resultados de uma aplicação (IBM, 2009). Nesta camada podem-se citar as especificações WS-AtomicTransaction (OASIS, 2009a) e WSBusinessActivity (OASIS, 2009b).

A camada de segurança utiliza algumas especificações de segurança, tais como WS-Security (OASIS, 2006a), WS-SecurityPolicy (OASIS, 2007a) e SAML (Security Assertion Markup Language) (OASIS, 2008a), para que os aplicativos possam realizar uma comunicação segura. Esta camada, por tratar da segurança em Web services, é de grande interesse para o presente projeto, e algumas das especificações que a compõem são estudadas detalhadamente no Capítulo 4.

A camada de processo de negócios estabelece a ordem em que serão executadas as operações de um dado conjunto de Web services, especifica os dados compartilhados entre os mesmos, e determina quais são os parceiros e como estes estão envolvidos no processo de negócios (IBM, 2009). A especificação dos processos de negócios e o modo como eles se relacionam com os Web services são de responsabilidade da linguagem BPEL (Business Process Execution Language), também conhecida como WS-BPEL (OASIS, 2007b).

E por fim, a camada de gerenciamento disponibiliza um conjunto de capacidades para descobrir a existência, a disponibilidade, o desempenho, a utilização, o controle e a configuração de um Web service. Nesta camada pode-se destacar a especificação WSDM (Web Services Distributed Management) (OASIS, 2006b).

\subsection{Padrões Fundamentais dos Web Services}

Os Web services são baseados em um conjunto de padrões consolidados e amplamente aceitos e utilizados. Tal aceitação generalizada possibilita que serviços e clientes possuam entendimento uns dos outros e realizem comunicação independentemente de plataformas ou linguagens de programação (Ort, 2005).

As seções a seguir descrevem as tecnologias e protocolos que formam a base dos padrões dos Web services.

\subsubsection{XML}

XML (eXtensible Markup Language) é uma especificação da W3C (W3C, 2008a), utilizada em vários contextos, oferecendo um formato de dados estruturado, padronizado, flexível e extensível.

O XML provê uma linguagem padrão baseada em texto que todas as aplicações podem entender. Além disso, o XML é independente de plataforma, possui um formato de dados universal e é autodescritivo (Rosenberg e Remy, 2004).

Atualmente, o XML é o padrão mais utilizado para a estruturação de dados e conteúdo para documentos eletrônicos, sendo também amplamente aceito como a linguagem universal para troca 
de informações entre aplicações, sistemas e dispositivos por meio da Internet (Nagappan et al., 2003).

$\mathrm{O}$ aspecto mais importante do XML, no que diz respeito aos Web services, é sua sintaxe, fazendo-se uso geralmente do XML Schema e do XML Namespaces.

A sintaxe do XML permite definir um número infinito de nomeadores, conhecidos como tags. Assim, torna-se possível criar tags para descrever dados estruturados, utilizando elementos e atributos. Elementos são os nomes das tags e os atributos são definidos dentro das mesmas como um par nome/valor, representando o nome do atributo e o seu valor, conforme ilustrado na Figura 2.4. Geralmente, os atributos são utilizados para armazenar informações que não são relevantes para os dados em si, mas que são necessárias para a interpretação ou processamento dos dados (Hollar e Murphy, 2006). O conteúdo, ou o valor dos dados, é qualquer informação que esteja entre uma tag de início e uma tag de fim, podendo ser inclusive, outra estrutura XML, conforme ilustrado na Figura 2.5.

\section{1. 〈Element attribute="value">data</Element>}

Figura 2.4: Exemplo de elemento e atributo.

\begin{tabular}{|c|c|}
\hline 01. & $\langle ? \times x m 1$ version=" $1.0 " ?\rangle$ \\
\hline 02. & 〈shipOrder〉 \\
\hline 03. & $\langle$ shipTo〉 \\
\hline 64. & $\langle$ name $>$ Tove Svendson</name $\rangle$ \\
\hline 05. & 〈street>Ragnhildvei $2</$ street> \\
\hline 06. & $\langle$ address>4000 Stavanger</address〉 \\
\hline 07. & $\langle$ country $\rangle$ Norway $</$ country $\rangle$ \\
\hline 68. & $\langle/$ shipTo $\rangle$ \\
\hline 69. & $\langle$ items〉 \\
\hline 10. & 〈item> \\
\hline 11. & $\langle$ title $\rangle$ Empire Burlesque $\langle/$ title $\rangle$ \\
\hline 12. & $\langle$ quantity $\rangle 1</$ quantity $\rangle$ \\
\hline 13. & 〈price>10.90</price> \\
\hline 14. & $\langle/$ item $\rangle$ \\
\hline 15. & $\langle$ item〉 \\
\hline 16. & $\langle$ title $\rangle$ Hide your heart</title $\rangle$ \\
\hline 17. & $\langle$ quantity $\rangle 1</$ quantity $\rangle$ \\
\hline 18. & $\langle$ price $>9.90</$ price $\rangle$ \\
\hline 19. & $\langle/$ item $\rangle$ \\
\hline 20. & $\langle/$ items $\rangle$ \\
\hline 21. & $\langle/$ shipOrder $\rangle$ \\
\hline
\end{tabular}

Figura 2.5: Exemplo da estrutura hierárquica do XML.

Um esquema em documentos XML define formalmente a estrutura que os documentos XML devem ter, isto é, a ordem e o aninhamento das tags. Assim, os documentos XML podem ser validados automaticamente, de acordo com seu esquema correspondente. Isto também permite a troca de dados entre aplicações heterogêneas, sendo esta característica muito utilizada em Web services (W3C, 2008a).

Segundo (W3C, 2008a), um esquema em documentos XML pode ser de dois tipos:

- DTD (Document Type Definition): define a construção dos blocos de um documento XML, isto é, quais elementos e atributos um documento XML deve possuir e como eles devem 
estar dispostos no documento. O DTD apresenta várias limitações, as quais são corrigidas pelo padrão XML Schema.

- XML Schema: mais robusto que o DTD devido ao suporte a tipos de dados, à utilização da sintaxe da linguagem XML e por ser extensível. No padrão XML Schema o modelo do conteúdo de um elemento pode ser especificado a partir da declaração de um tipo, que pode ser simples ou complexo. Um tipo simples pode ser um atributo ou elemento simples, que possui somente texto e não possui elementos filhos. Um tipo complexo, por sua vez, é utilizado para definir quais os subelementos permitidos para um dado elemento. Na Figura 2.6 é exemplificado um XML Schema.

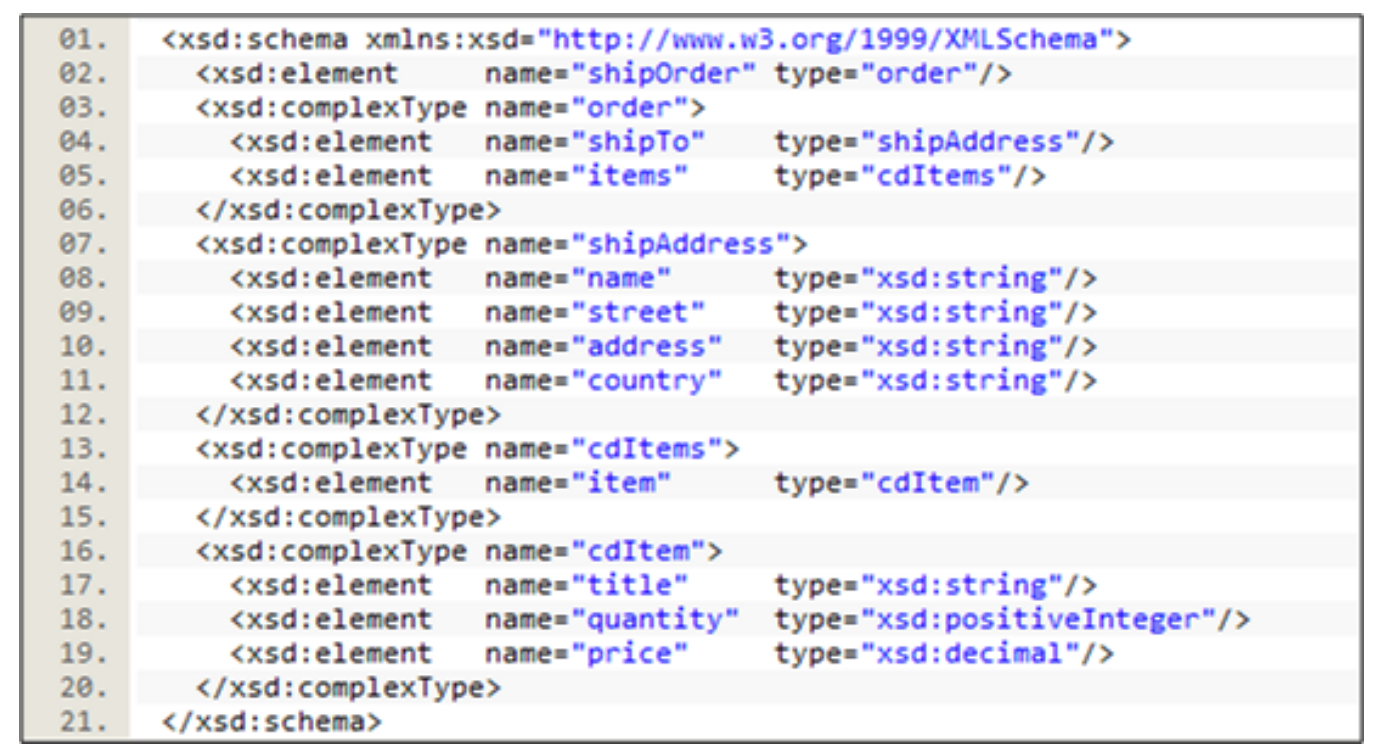

Figura 2.6: Exemplo de XML Schema.

O XML Namespaces possui a função de definir os nomes dos esquemas, isto é, identificar os nomes dos elementos e atributos para que não existam nomes repetidos, evitando assim o conflito entre eles. Um namespace é composto por um prefixo e por uma URL, a qual exerce a função de identificador único. Assim, este mecanismo permite que um documento XML utilize elementos definidos por vários esquemas XML distintos. Um namespace normalmente é referenciado em um documento XML por meio da utilização do atributo xmlns na tag. Geralmente os namespaces são longos e para evitar a repetição de uma declaração do namespace em cada elemento filho utiliza-se a declaração de um prefixo em um elemento pai, conforme ilustrado na Figura 2.7. Vale ainda observar que o uso do http na declaração do namespace é apenas uma convenção, visto que qualquer outra string poderia ser utilizada.

O XML torna-se importante neste projeto devido ao fato de que padrões básicos dos Web services, como o SOAP e a WSDL, são descritos utilizando-se XML. Do mesmo modo, padrões de segurança como o XML Encryption e o XML Signature (ambos detalhados posteriormente no Capítulo 4) também são baseados em XML. 


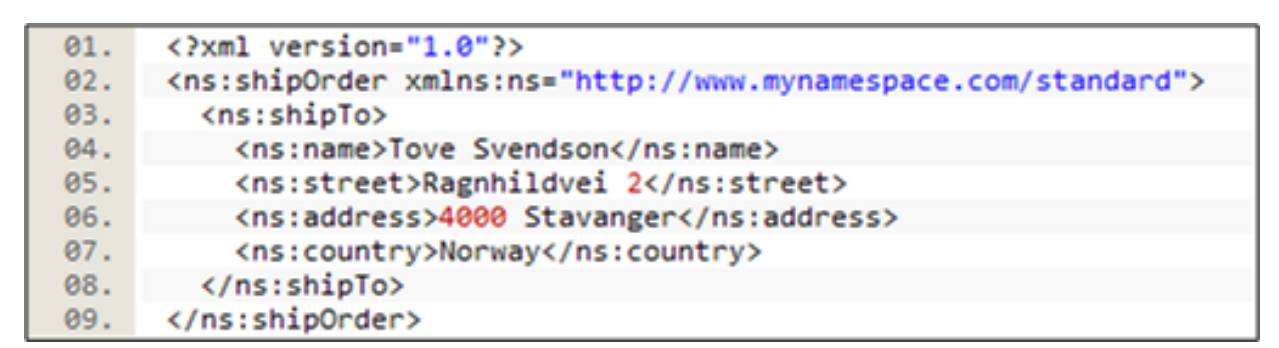

Figura 2.7: Exemplo de XML Namespaces.

\subsubsection{WSDL}

WSDL (Web Services Description Language) é um padrão da W3C (W3C, 2007b), em formato XML, extensível, que descreve as interfaces dos Web services. Um documento WSDL é independente de linguagem e de plataforma e possui a finalidade de descrever quais serviços são oferecidos, designar como os provedores de serviços e clientes irão processar as requisições e indicar o formato no qual o serviço deve enviar as informações para um cliente.

A WSDL torna possível separar a descrição das funcionalidades que são fornecidas por um serviço dos detalhes concretos da sua implementação. Além de definir o formato da mensagem, o tipo de dados, os protocolos de transporte e o formato de serialização de transporte que serão utilizados entre o cliente e o serviço, a WSDL também determina um ou mais locais de rede pelo qual o serviço pode ser invocado. Em suma, a descrição do serviço constitui um acordo que conduz as interações do cliente com o serviço.

No que diz respeito ao funcionamento, quando o cliente pretende enviar uma mensagem ao serviço, primeiramente ele deve obter a descrição do serviço localizando o respectivo documento WSDL. Então, o cliente constrói a mensagem passando os tipos de dados corretos como parâmetros, conforme a descrição da operação que será invocada. A mensagem é então enviada para o endereço onde se localiza o serviço, e este, por sua vez, recebe e valida a mensagem de acordo com as informações obtidas na WSDL, da mesma forma que obtém o conhecimento de como tratar e processar a mensagem e como construir a resposta para o cliente.

A WSDL é composta de duas partes: abstrata e concreta (W3C, 2007b). A parte abstrata representa a definição da interface de serviço, descrevendo quais as operações disponíveis, quais os parâmetros de entrada e saída determinada operação utiliza para enviar e receber mensagens e como as mensagens envolvidas são descritas. A parte concreta, por sua vez, define os detalhes para a implementação do serviço, contendo dados referentes às informações de protocolo e localizações de serviço, além de permitir vincular tais pontos de acesso sobre determinadas operações definidas na WSDL (Weerawarana et al., 2005).

Na Figura 2.8 é ilustrada a estrutura de um documento WSDL, onde os elementos que o compõem são:

\section{- Parte abstrata:}


- interface: especifica um ou mais elementos operation. Cada operação define de forma abstrata uma ação realizada pelo serviço.

- message: permite descrever as mensagens transmitidas pelos Web services. Estas mensagens são compostas por uma ou mais partes, sendo que cada parte representa um item enviado ou recebido.

\section{- Parte concreta:}

- binding: define como mapear os elementos abstratos message e operation nos protocolos de rede que serão utilizados para transportar as mensagens.

- service: declara o endereço das portas para os elementos binding, isto é, indica onde encontrar um serviço utilizando sua porta.

- endPoint: apresenta uma combinação entre o elemento binding e o endereço de rede, fornecendo assim um endereço único para acessar o serviço.

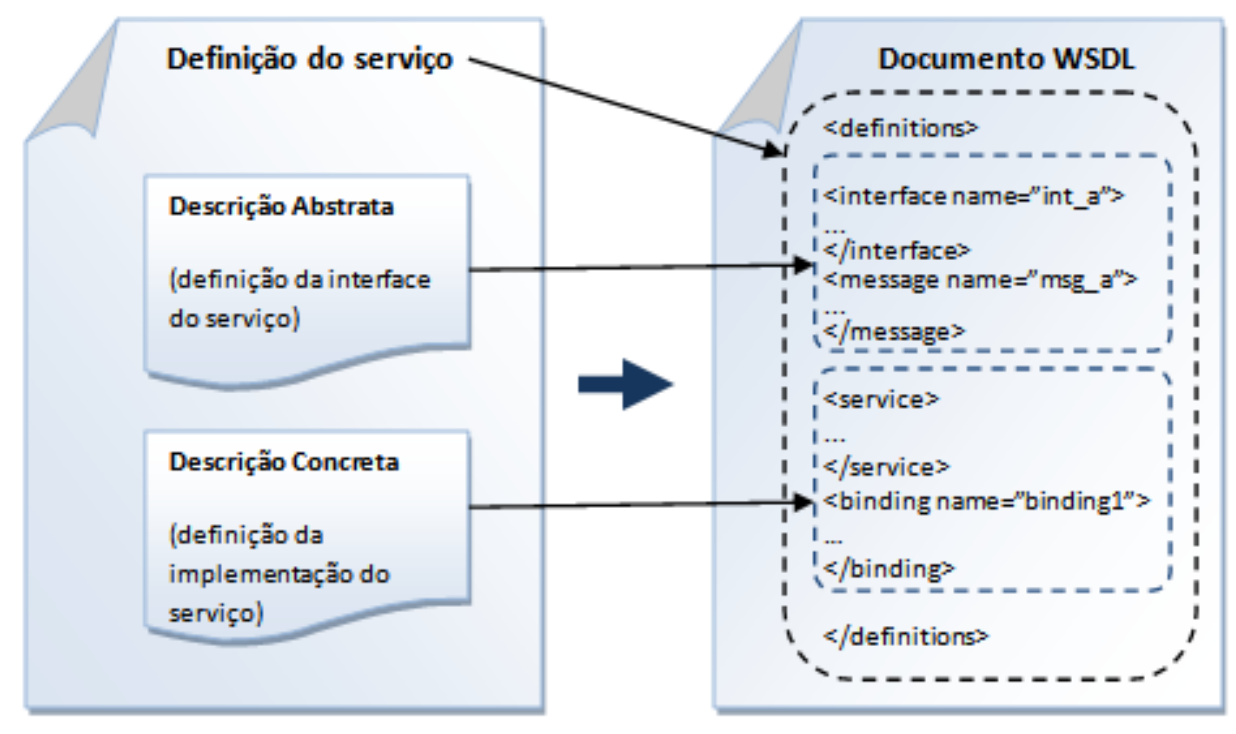

Figura 2.8: Estrutura de um documento WSDL - Adaptado de (Erl, 2004).

Existem também elementos adicionais que acrescentam novas informações e funcionalidades, como, por exemplo, os elementos types e documentation. O primeiro fornece as definições de tipos de dados utilizados na troca de mensagens e o segundo permite a inclusão de anotações no documento WSDL. Para tanto, ambos os elementos devem estar contidos no elemento raiz chamado definitions.

\subsubsection{UDDI}

UDDI (Universal Description, Discovery and Integration) é uma especificação aprovada pela OASIS (OASIS, 2004a) que define uma forma padronizada para publicação e descoberta de serviços em uma arquitetura orientada a serviços. 
A implementação de um registro UDDI é constituída por vários Web services, os quais fornecem uma interface para que os clientes tenham acesso às informações armazenadas (Yu et al., 2008). Os dados e metadados destes Web services são armazenados em registros UDDI, também conhecido como diretórios UDDI, que são documentos XML com a finalidade de descrever as informações dos Web services de maneira organizada. Um registro UDDI pode estar disponível em uma rede pública ou em uma infraestrutura interna de uma organização, sendo que cada uma destas estruturas de dados está associada a um identificador único, chamado UDDI key, gerado de acordo com as regras de classificação estipuladas por cada organização. Este mecanismo de classificação fornecido pelo UDDI permite aos clientes efetuarem consultas mais refinadas, tais como buscar por provedores de serviço que ofereçam um determinado serviço em uma determinada localização geográfica.

De forma análoga a uma lista telefônica, um registro UDDI é composto por três partes:

- Páginas brancas: contêm informações sobre nomes, endereços, números de telefones, dentre outras informações sobre os fornecedores do serviço.

- Páginas amarelas: contêm informações comerciais baseadas nos tipos de negócios, organizando-as por meio de categorias ou taxonomias.

- Páginas verdes: contêm informações técnicas sobre as funcionalidades dos Web services, fornecendo inclusive informações a respeito da interação com o serviço.

\subsubsection{SOAP}

SOAP (Simple Object Access Protocol) é um padrão da W3C (W3C, 2007a), definido com o propósito de ser um protocolo de comunicação baseado em XML para a troca de mensagens estruturadas entre cliente e provedores de serviço, independente de linguagem, que opera em diversos sistemas operacionais e sobre protocolos de aplicação consolidados, tais como o HTTP, o SMTP e o FTP.

Devido às facilidades oferecidas pelo HTTP, a utilização do SOAP tornou-se comum nas implementações atuais dos Web services. Dentre essas facilidades destacam-se a infraestrutura já existente de servidores HTTP para disponibilizar os serviços e a facilidade em atravessar limites impostos pelos firewalls, uma vez que estes servidores utilizam a porta 80 e por isso liberam o acesso à mesma.

Uma mensagem SOAP é um documento XML que estabelece o elemento Envelope como sendo o elemento raiz do documento. O Envel ope SOAP é composto pelos elementos Header e Body, e nele estão contidas todas as declarações de namespaces que serão utilizadas, assim como os detalhes de codificação para representar os dados no documento (W3C, 2007a). O elemento Header é opcional e representa o cabeçalho da mensagem, contendo informações relacionadas ao roteamento, à segurança (por exemplo, asserções de autenticação e autorização), dentre outras. 
O elemento Body, por sua vez, representa o corpo de mensagem e é obrigatório, contendo nele a mensagem propriamente dita, que pode ser qualquer tipo de informação que possa ser expressa em XML (Weerawarana et al., 2005). Na Figura 2.9 é ilustrada esta explicação e na Figura 2.10 é exibida uma mensagem SOAP como exemplo.

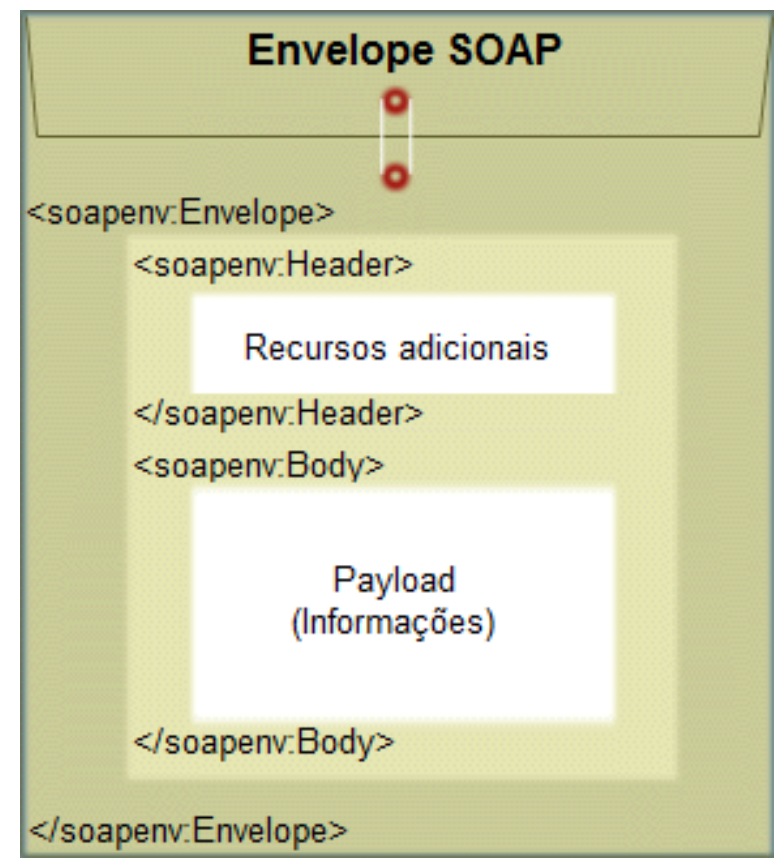

Figura 2.9: Estrutura da mensagem SOAP - Adaptado de (Ort, 2005).

Na Figura 2.10 é exibida uma mensagem SOAP de requisição, nela pode-se observar o elemento raiz Envelope na linha 1 e a declaração de seu namespace na linha 2. O corpo da mensagem se inicia na definição do elemento Body na linha 3 e termina na linha 8. Dentro do corpo da mensagem, a linha 4 indica que o método a ser acessado será o add, que por sua vez é um método que recebe dois números inteiros e retorna a soma de ambos. Estes dois números inteiros que são os parâmetros de entrada do método estão definidos nas linhas 5 e 6 . Após o processamento desta mensagem pelo servidor, uma mensagem de resposta contendo o resultado desta soma deverá ser enviada para o cliente.

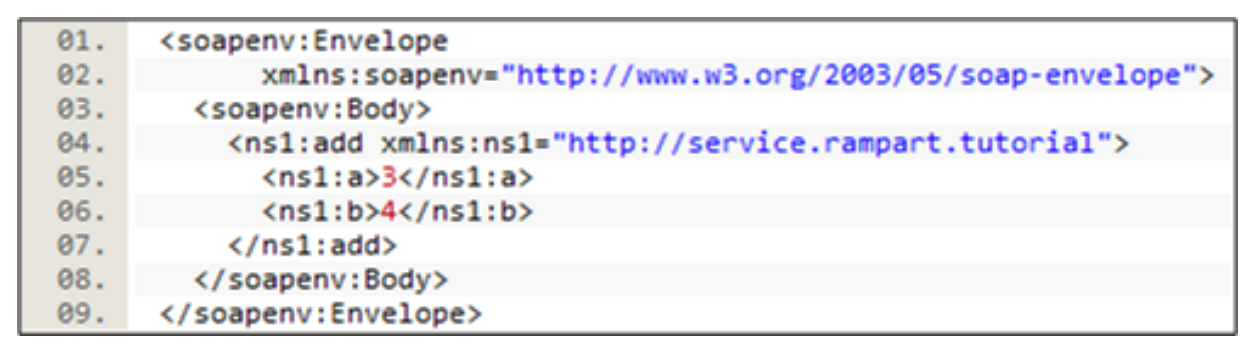

Figura 2.10: Exemplo de mensagem SOAP de requisição.

Alguns detalhes da estrutura da mensagem SOAP podem ser influenciados pelo estilo de requisição utilizado, o qual pode ser: 
- RPC (Remote Procedure Call): o estilo RPC aponta que o corpo da mensagem contém uma representação em XML da chamada do método e que as partes da mensagem representam os parâmetros do mesmo.

- Document: este estilo aponta que o corpo da mensagem contém um documento XML e que as partes da mensagem definem os elementos XML incluídos neste corpo.

Por fim é importante ressaltar também os tipos de codificação, responsáveis por compor o corpo da mensagem SOAP (Cohen, 2003). Os dois tipos principais são:

- Encoded: neste tipo as definições abstratas são traduzidas para um formato concreto utilizando as regras de codificação do SOAP.

- Literal: neste caso, as definições abstratas de tipos tornam-se concretas por elas mesmas, isto é, os tipos de dados definidos são introduzidos "literalmente" no corpo da mensagem.

\subsection{Considerações Finais}

Este capítulo apresentou os conceitos básicos relacionados à arquitetura orientada a serviço, bem como aos Web services, abordando os padrões fundamentais utilizados no desenvolvimento de serviços.

No próximo capítulo serão abordadas as principais técnicas de segurança em redes de computadores, tais como criptografia e seus algoritmos de chave simétrica e chave pública, assinatura digital e função de hash, além de certificados digitais, tendo em vista a necessidade de segurança em Web services. 


\section{Segurança em Redes de Computadores}

Com o surgimento e a evolução da Internet, os computadores estão a todo o momento realizando comunicação entre si, facilitando assim o acesso à informação e a realização de negócios, tais como compra e venda de produtos em um comércio eletrônico. Porém, à medida que ocorre esta evolução, deve-se aumentar a atenção para a segurança, pois a mesma tornou-se um requisito indispensável aos sistemas computacionais, garantindo que o acesso e o compartilhamento de informações ocorram sem danificar o funcionamento dos sistemas e que estas informações não fiquem expostas a usuários mal intencionados.

Desta forma, no decorrer deste capítulo são apresentados os conceitos fundamentais da segurança, assim como a criptografia, tanto a de chave simétrica quanto a de chave pública, a assinatura digital e, por fim, o gerenciamento de chaves públicas.

\subsection{Conceitos Básicos}

A segurança pode ser compreendida como uma qualidade de serviço que visa assegurar o fornecimento do serviço e evitar a ocorrência de violações nos sistemas. As propriedades que a segurança deve garantir são (Bishop, 2002) (Landwehr, 2001):

- Confidencialidade: garante que a informação será revelada apenas para entidades autorizadas.

- Integridade: garante que a informação não poderá ser modificada, de forma acidental ou intencional, por entidades que não possuam este direito. 
- Autenticidade: garante que as entidades que se comunicam são realmente quem afirmam ser.

- Não-repúdio: garante que uma entidade não poderá negar a sua participação na ocorrência de uma transação ou de um evento atribuído a ela.

- Disponibilidade: garante que entidades legítimas terão acesso às informações e aos recursos, não podendo este acesso ser restringido de forma maliciosa.

A exploração de vulnerabilidades que podem estar presentes nos sistemas geralmente resulta em violações de segurança. Tais vulnerabilidades podem ser causadas por erros de programação, erros de configuração ou até mesmo erros de operação, permitindo que usuários não autorizados tenham acesso ao sistema ou que usuários autênticos realizem ações não autorizadas, comprometendo assim o correto funcionamento do sistema (Tanenbaum, 2003).

Uma ameaça representa uma possível ação que, caso seja efetivada, poderá comprometer o sistema, enquanto que um ataque é definido como a efetivação desta ameaça, realizado por um intruso malicioso por meio da exploração de vulnerabilidades. Os ataques podem ser classificados em ataques passivos e ataques ativos (Stallings, 2005).

Os ataques passivos caracterizam-se por monitorar as transmissões, visando obter informações que estejam sendo transmitidas e assim comprometer a confidencialidade. Ataques deste tipo são difíceis de serem detectados, pois nos mesmos não há modificação de dados. Desta forma, estes ataques, geralmente, não são percebidos pelo emissor e receptor das mensagens e a melhor forma de evitá-los é por meio da prevenção, por exemplo, com criptografia. Estes ataques dividem-se em dois tipos:

- Revelação do conteúdo da mensagem: visa descobrir por meio de um software sniffer o conteúdo de transmissões que podem conter informações importantes ou confidenciais, sejam elas mensagem de $e$-mail ou arquivos transferidos.

- Análise de tráfego: tem como propósito conhecer quais tipos de dados e a quantidade de informações transportada pela rede, sendo útil para descobrir o perfil de comunicação em um link específico. Estas informações podem ser utilizadas para ataques de negação de serviço.

Já os ataques ativos envolvem modificar o fluxo de dados ou gerar um fluxo falso. Estes tipos de ataques são difíceis de impedir devido a grande variedade de potenciais vulnerabilidades tanto físicas quanto de software e de rede. Portanto, a defesa contra estes ataques é focada na detecção dos mesmos e na recuperação de eventuais interrupções ou atrasos causados (Stallings, 2005). Estes ataques dividem-se em quatro tipos:

- Disfarce ou personificação: ocorre quando uma entidade utiliza a identidade de outra, visando enviar ou receber mensagens aparentando ser esta entidade, sem a permissão da mesma. 
- Repetição: possui o objetivo de capturar mensagens passivamente e, posteriormente, retransmiti-las para conseguir um efeito não autorizado.

- Modificação de mensagem: ocorre quando há a interceptação e modificação de alguma parte de uma mensagem legítima, antes que a mesma chegue ao seu destino.

- Negação de serviço (Denial of Service - DoS): caracteriza-se por impedir ou restringir a utilização ou o gerenciamento normal das instalações de comunicação. Geralmente este ataque é provocado pela inundação de um canal de comunicação ou recurso com mensagens, sobrecarregando-os com o propósito de diminuir o desempenho e negar acesso a outros.

As ameaças em sistemas computacionais são frequentes e evitar os ataques não é trivial, pois é necessária a identificação e a correção das vulnerabilidades que possam existir nos sistemas. À medida que a complexidade dos sistemas aumenta, maiores serão suas vulnerabilidades de segurança e prejuízos financeiros causados caso os mesmos sejam comprometidos.

\subsection{Criptografia}

A palavra criptografia é o resultado da junção de duas palavras de origem grega e significa "escrita secreta". Em suma, a criptografia pode ser entendida como um conjunto de métodos e técnicas para criptografar (cifrar ou codificar) informações legíveis por meio de um algoritmo de criptografia parametrizado por uma chave, convertendo um texto original, denominado texto aberto (texto claro ou texto simples), em um texto ilegível, denominado texto cifrado (cifra ou texto código). Posteriormente, é possível para o receptor decriptar este texto cifrado, ou seja, efetuar o processo inverso e recuperar as informações originais (Tanenbaum, 2003) (Moreno et al., 2005). Na Figura 3.1 é ilustrado o processo descrito.

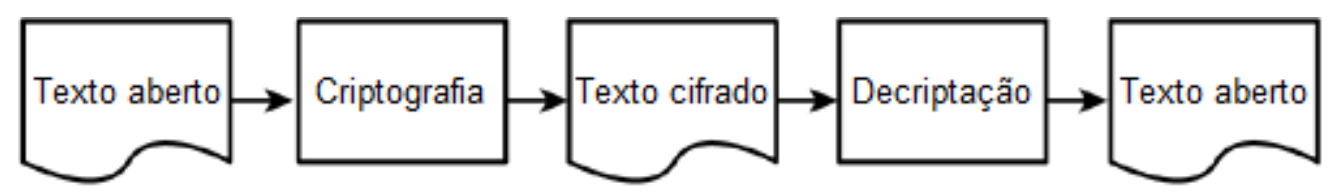

Figura 3.1: Esquema geral da criptografia - Adaptado de (Rosenberg e Remy, 2004).

Um algoritmo de criptografia é uma sequência de procedimentos envolvendo matemática que torna possível criptografar e decriptar dados importantes e sigilosos. Porém, para realizar estas operações o algoritmo deve ter como parâmetro a chave correta, a qual é formada por um conjunto de bits que determinam o tamanho da mesma.

O esforço necessário para criar, testar e instalar um novo algoritmo toda vez que o antigo for comprometido torna impraticável manter o mesmo em segredo, sendo assim, o princípio de Kerckhoff diz que todos os algoritmos devem ser públicos e somente as chaves devem ser secretas. 
Desta forma, os algoritmos são divulgados à comunidade e o sigilo das informações é assegurado pela chave, ganhando importância o tamanho da mesma, uma vez que quanto maior o seu comprimento, mais segura torna-se a criptografia para um mesmo algoritmo (Tanenbaum, 2003). Além disso, com base no tipo de chave a criptografia pode ser classificada em criptografia de chave simétrica ou criptografia de chave pública.

\subsubsection{Criptografia de Chave Simétrica}

A criptografia de chave simétrica, também conhecida como criptografia de chave privada, possui este nome porque os processos de criptografia e decriptação são realizados com a utilização de uma única chave, isto é, tanto o emissor quanto o receptor compartilham a mesma chave. Assim, para garantir a segurança é essencial que esta chave seja mantida em segredo. Como ilustrado na Figura 3.2, o texto aberto é criptografado em texto cifrado pelo emissor utilizando a chave secreta compartilhada. Após ser transmitida, a mensagem cifrada é então decriptada pelo receptor utilizando novamente a mesma chave secreta.

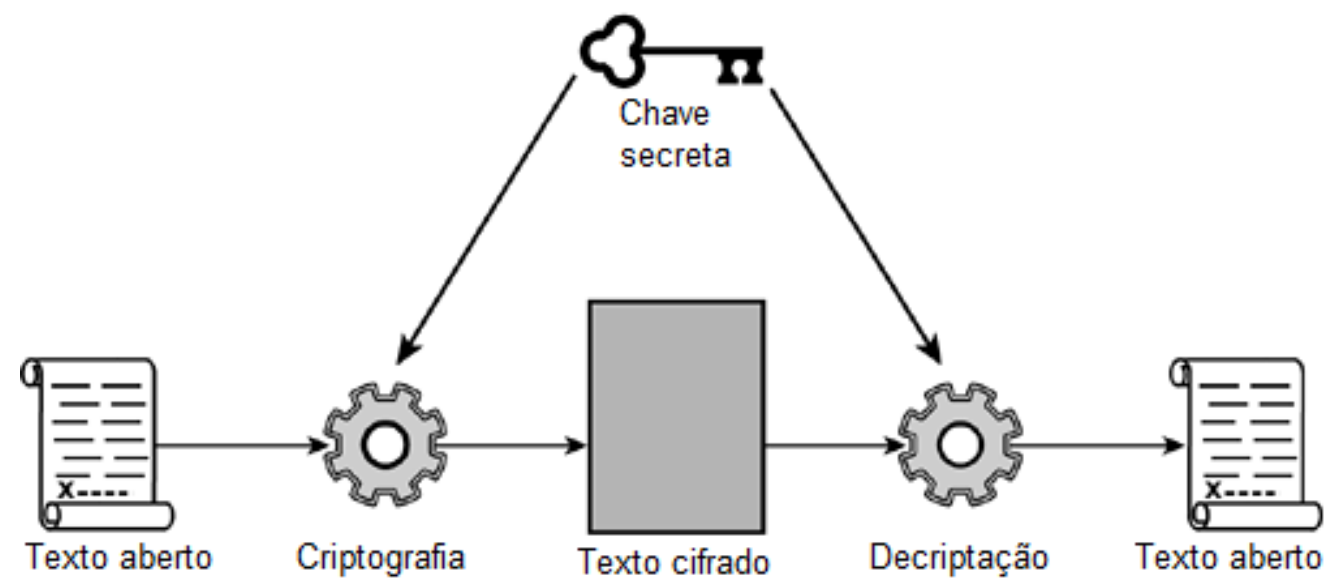

Figura 3.2: Criptografia de chave simétrica - Adaptado de (Rosenberg e Remy, 2004).

A vantagem da criptografia de chave simétrica é que os algoritmos desta categoria são rápidos e podem operar em tamanhos arbitrários de mensagens (Rosenberg e Remy, 2004). A desvantagem deste tipo de criptografia é a dificuldade para gerenciar uma chave compartilhada, a qual deve ser enviada para todos os usuários autorizados antes que as mensagens possam ser trocadas e ainda deve ser mantida em segredo para usuários não autorizados (Moreno et al., 2005).

Dentre os algoritmos de chave simétrica, destacam-se o DES (Data Encryption Standard), o 3DES (Triple Data Encryption Standard) e o AES (Advanced Encryption Standard), ambos explicados a seguir.

Desenvolvido pela IBM em 1977, o DES foi adotado pelo governo norte-americano como seu padrão oficial para informações não confidenciais, sendo bastante utilizado também em aplicações comerciais. O DES possui como parâmetro uma chave de 64 bits e criptografa texto aberto em blocos de 64 bits, gerando 64 bits de texto cifrado (Tanenbaum, 2003). Na verdade, 8 bits desta chave 
são bits de paridade ímpar, ou seja, a chave do DES possui efetivamente 56 bits (Kurose e Ross, 2009). Diante do poder computacional disponível atualmente, tais chaves são consideradas fáceis de serem descobertas, tornando o DES inseguro e não recomendado (Kanneganti e Chodavarapu, 2008).

Como o DES foi considerado inseguro, o governo dos Estados Unidos propôs o 3DES, o qual executa três vezes seguidas o algoritmo DES de 64 bits, aumentando assim o comprimento da chave para 192 bits. Desta forma, o 3DES executa primeiro o algoritmo DES no modo de criptografia sobre os dados utilizando uma chave de 64 bits. Em seguida, executa o algoritmo DES no modo de decriptação sobre a saída da primeira rodada de criptografia utilizando uma segunda chave. E, por fim, executa novamente o algoritmo DES no modo de criptografia sobre a saída da segunda rodada utilizando uma terceira chave (Kurose e Ross, 2009). Devido a todo este procedimento, o 3DES é considerado bastante lento quando comparado a outros algoritmos de criptografia simétrica, como o AES.

Mesmo com o 3DES, o DES começou a se aproximar do fim de sua vida útil, sendo necessário um novo padrão criptográfico. Assim, por meio de um concurso de criptografia patrocinado pelo NIST (National Institute of Standards and Technology) em 2001, o algoritmo Rijndael (Daemen e Rijmen, 2000) foi eleito o sucessor do DES e passou a ser denominado AES. A especificação do mesmo determina que o tamanho do bloco seja de 128 bits e o comprimento da chave seja de 128 , 192 ou 256 bits (Feldhofer et al., 2004). O NIST julga que uma máquina que conseguisse quebrar o DES de 64 bits em 1 segundo precisaria de aproximadamente 149 milhões de anos para quebrar o AES de 128 bits (Kurose e Ross, 2009).

\subsubsection{Criptografia de Chave Pública}

A questão da distribuição de chaves sempre foi o grande problema da criptografia de chave simétrica, pois as partes que desejam se comunicar devem concordar com a chave compartilhada, mas para isto é necessária uma comunicação prévia e supostamente segura. Assim, dois pesquisadores da Universidade de Stanford, Whitfield Diffie e Martin Hellman, propuseram em 1976 o algoritmo Diffie-Hellman Key Exchange (Diffie e Hellman, 1976). Neste algoritmo, as chaves de criptografia e decriptação eram distintas e a chave de decriptação não podia ser derivada da chave de criptografia (Tanenbaum, 2003).

Desta forma, a criptografia de chave pública, também conhecida como criptografia de chave assimétrica, utiliza um par de chaves denominadas chave privada e chave pública. Qualquer uma das chaves pode ser utilizada para criptografar os dados, porém a mesma não pode ser utilizada para decriptá-los, ou seja, se a criptografia foi realizada com a chave pública, somente a respectiva chave privada poderá realizar a decriptação. Para que este tipo de criptografia obtenha sucesso é fundamental que a chave privada seja mantida em segredo, enquanto a chave pública deve ser divulgada a outros usuários que desejam se comunicar (Rosenberg e Remy, 2004). 
Na Figura 3.3 é ilustrado o funcionamento da criptografia de chave pública, onde o emissor da mensagem utiliza a chave pública do receptor para criptografar o texto aberto em texto cifrado. Após o recebimento do texto cifrado resultante, o receptor utiliza sua chave privada para decriptar o texto cifrado em texto aberto.

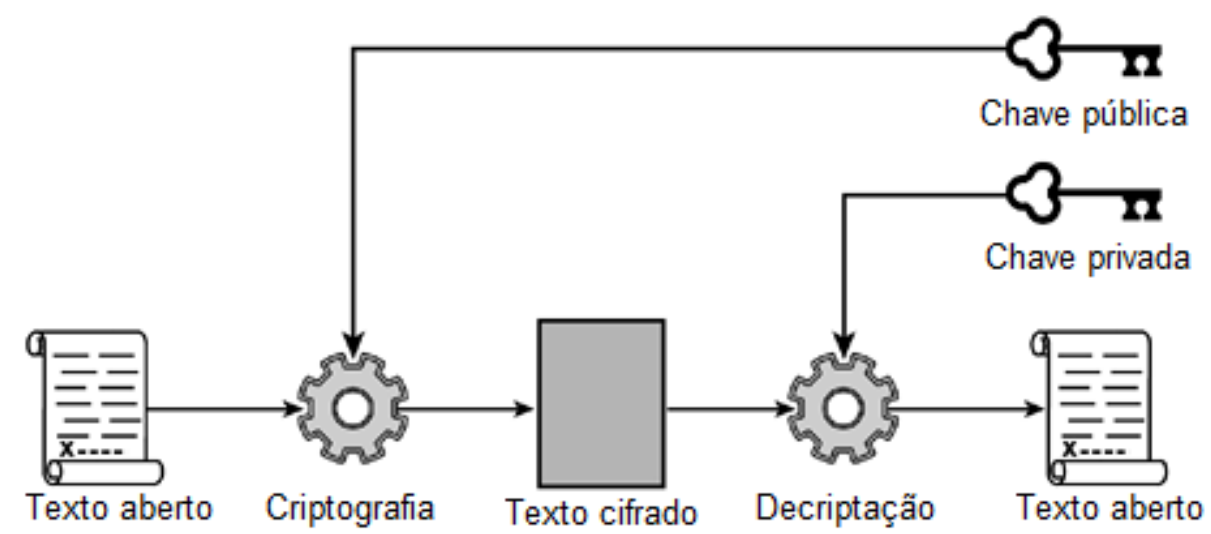

Figura 3.3: Criptografia de chave pública - Adaptado de (Rosenberg e Remy, 2004).

Embora existam muitos algoritmos que tratam desta abordagem, o algoritmo RSA (Rivest, Shamir, Adleman) tornou-se praticamente um sinônimo de criptografia de chave pública (Kurose e Ross, 2009). O RSA é considerado um algoritmo forte, porém sua principal desvantagem deve-se à exigência de chaves de pelo menos 1024 bits para que haja um nível satisfatório de segurança (semelhante ao nível de segurança dos algoritmos de chave simétrica de 128 bits), tornando-o assim bastante lento (Tanenbaum, 2003).

Devido a essa lentidão, o RSA torna-se pouco viável para criptografar uma grande quantidade de dados, porém o mesmo pode ser muito útil para a distribuição de chaves. Assim, na prática a maioria dos sistemas utiliza um algoritmo de chave pública, como o RSA, para criptografar e distribuir chaves únicas de sessão (chaves secretas compartilhadas), as quais serão utilizadas juntamente com algum algoritmo de chave simétrica, como o 3DES ou o AES, para criptografar os dados propriamente ditos (Kocher et al., 2004).

\subsection{Assinatura Digital}

A autenticidade de documentos legais, financeiros e outros é definida por meio da presença de uma assinatura autorizada. Semelhante ao que ocorre com as assinaturas por escrito, a assinatura digital necessariamente deve ser verificável, não falsificável e incontestável (Kurose e Ross, 2009). Ou seja, deve ser possível provar que um documento assinado por uma pessoa foi realmente assinado por ela (verificável) e que apenas aquela pessoa poderia ter assinado este documento (não falsificável), portanto a mesma não pode posteriormente repudiar o documento e negar que o tenha assinado (incontestável). 
Todos estes requisitos podem ser cumpridos por meio da utilização das técnicas de criptografia de chave pública, como o algoritmo RSA. Assim, além da operação normal de criptografar com a chave pública e decriptar com a chave privada, existe a possibilidade de criptografar com a chave privada e decriptar com a chave pública. É evidente que neste caso não é garantida a confidencialidade da mensagem, visto que qualquer um que tenha posse da chave pública pode decriptá-la. Porém, esta forma de utilização é muito útil para se verificar a autenticidade, pois se o emissor criptografa uma mensagem com sua chave privada e a envia para o receptor, o mesmo irá utilizar a chave pública do emissor para ter certeza, ou até mesmo provar, que a mensagem somente poderia ter vindo deste emissor (Sosnoski, 2009). Para tanto, é de fundamental importância que a chave privada seja sempre mantida em segredo.

Na prática, devido à lentidão dos algoritmos de chave pública, os métodos para assinatura digital assinam não o documento que pretendem autenticar, mas sim um sumário de mensagem (message digest), também conhecido como resumo de mensagem, obtido por meio do processamento da mensagem em uma função de hash (Moreno et al., 2005). A função de hash será explicada na Seção 3.3.1, contudo, resumidamente, ela é uma função que extrai um trecho qualquer do texto aberto e a partir dele computa uma cadeia de bits que será a saída gerada.

O processo de geração da assinatura digital é realizado utilizando a combinação da criptografia de chave pública com a função de hash, conforme ilustrado na Figura 3.4. As etapas para esta geração de assinatura são:

1. No documento contendo texto aberto aplica-se a função de hash, como por exemplo, o SHA1 (Secure Hash Algorithm 1), criando um sumário de mensagem de tamanho fixo.

2. Ocorre a criptografia do sumário de mensagem com a chave privada do emissor.

3. Finalmente, o documento original e o sumário de mensagem criptografado com a chave privada do emissor são enviados para o receptor.

O receptor deste documento realiza um processo de verificação de assinatura digital, para determinar a identidade do emissor e determinar se o documento chegou sem alterações, conforme ilustrado na Figura 3.5. As etapas para esta verificação de assinatura são:

1. O receptor recebe o documento contendo texto aberto e o sumário de mensagem criptografado.

2. Ao mesmo tempo ou separadamente, o receptor obtém a chave pública do emissor.

3. O documento original em texto aberto é submetido à mesma função de hash utilizada pelo emissor, neste caso o SHA-1. Este algoritmo é idêntico em todas as plataformas, assim o receptor possui a confiança de que se o mesmo resultado ocorrer, então o documento não foi alterado. 


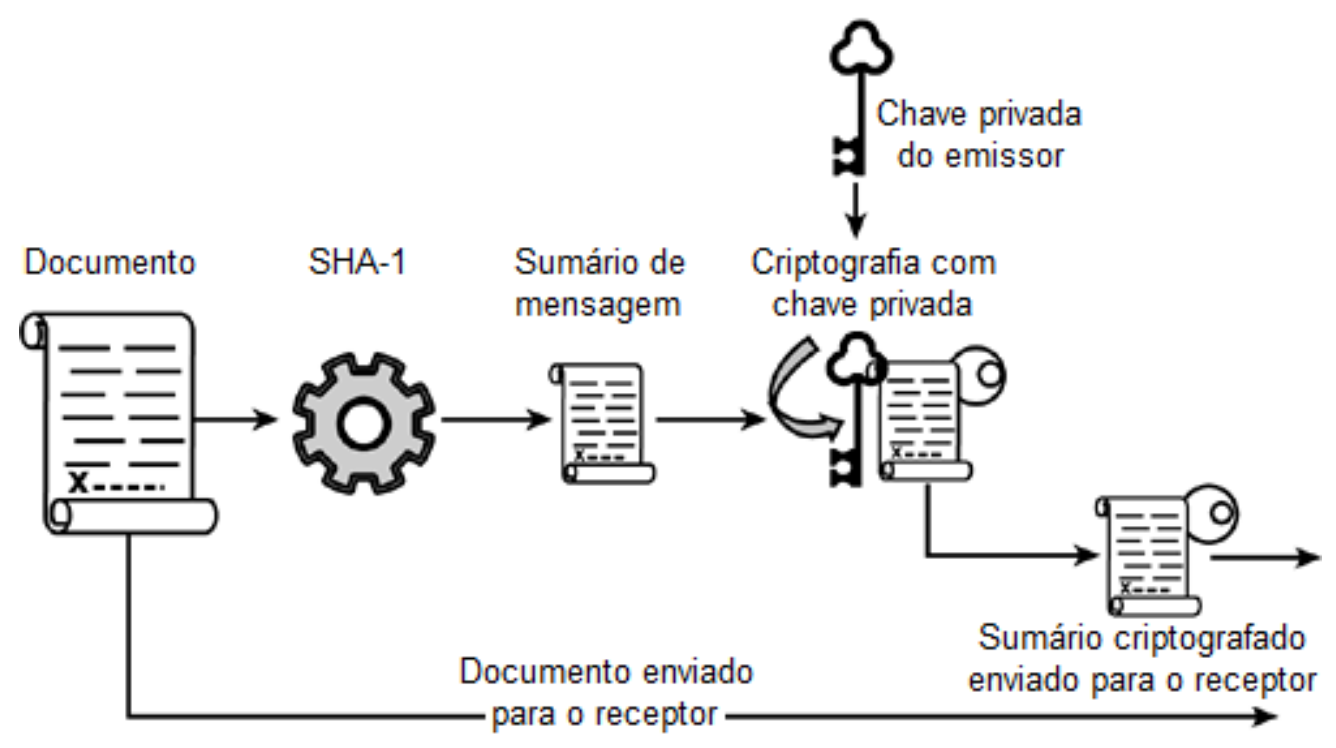

Figura 3.4: Geração de assinatura digital - Adaptado de (Rosenberg e Remy, 2004).

4. O receptor utiliza a chave pública do emissor para decriptar o sumário de mensagem. Se a decriptação ocorrer com sucesso e o receptor confiar na validade da chave pública do emissor, então o receptor terá a certeza de que o envio do documento foi realizado realmente por aquele emissor.

5. Por fim, ocorre uma comparação bit a bit entre o sumário de mensagem computado localmente a partir do documento original e o sumário de mensagem recebido e já decriptado. Caso eles sejam exatamente iguais, a assinatura é considerada válida.

\subsubsection{Função de Hash}

Como visto anteriormente, a assinatura digital envolve o uso de uma função matemática denominada função de hash seguida pela criptografia de chave pública. O conceito fundamental consiste em utilizar uma função de hash para gerar um sumário de mensagem (representação da mensagem completa) de tamanho fixo e então criptografá-la com a chave privada do emissor da mensagem (Ravi et al., 2004). Este processo é útil devido à limitação da criptografia de chave pública no que diz respeito à quantidade de dados e o longo tempo necessário para criptografá-los.

Para ter esta utilidade, a função de hash deve possuir as seguintes características (Burnett e Paine, 2001):

- Deve ser eficiente e rápida para computar o sumário de mensagem.

- Deve ser impraticável determinar a entrada da função (ou seja, a mensagem original) a partir do sumário de mensagem. 


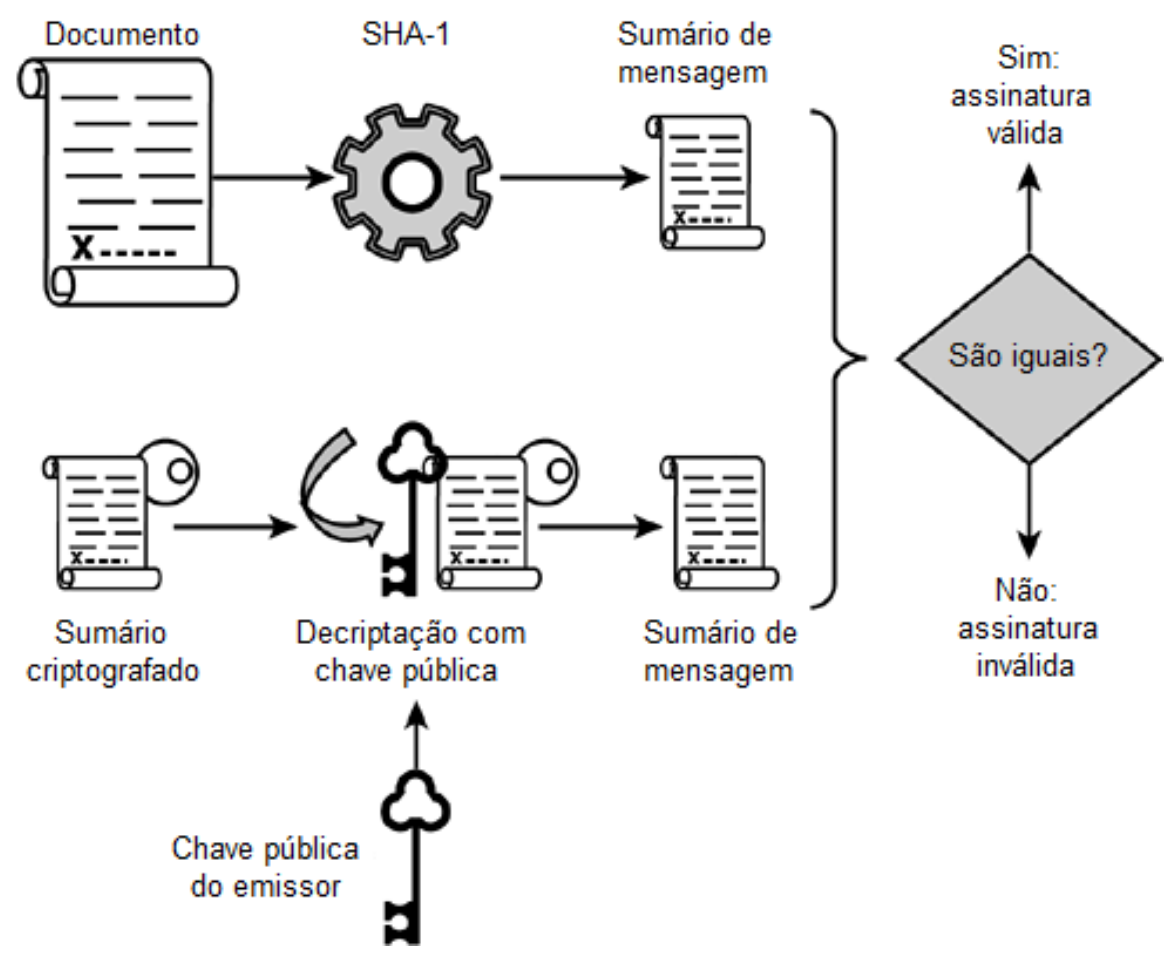

Figura 3.5: Verificação de assinatura digital - Adaptado de (Rosenberg e Remy, 2004).

- Deve ser impraticável determinar duas entradas distintas (ou seja, mensagens diferentes) que resultem em um sumário de mensagem idêntico.

Os algoritmos de função hash mais conhecidos da comunidade acadêmica são o MD5 (MessageDigest Algorithm 5) e o SHA-1 (Secure Hash Algorithm 1), ambos descritos a seguir.

O MD5 é o quinto de uma série de algoritmos desenvolvidos por Ronald Rivest. Este algoritmo computa um sumário de mensagem de 128 bits por meio de um processo de quatro etapas, composto pela etapa de enchimento (adição de um " 1 " seguido de vários " 0 " até que o comprimento da mensagem satisfaça dadas condições), etapa de anexação (anexação de uma representação de 64 bits do comprimento da mensagem antes do enchimento), etapa de inicialização de um acumulador e, finalmente, a etapa iterativa, na qual os blocos de 16 palavras de mensagem são misturados em quatro rodadas de processamento (Kurose e Ross, 2009). O MD5 já foi muito utilizado, porém foram encontradas vulnerabilidades em seu algoritmo (Ng et al., 2004).

O algoritmo em utilização atualmente é o SHA-1, proposto pelo NIST e que possui os mesmos princípios do MD5, exceto por gerar um sumário de mensagem de 160 bits, o que o torna mais confiável. Atualmente foi proposto o SHA-2, uma versão melhorada do SHA-1, com sumários de mensagem de 256, 384 e 512 bits (Sugita et al., 2009). 


\subsection{Gerenciamento de Chaves Públicas}

A desvantagem da criptografia de chave simétrica é a obrigação que as partes que desejam se comunicar possuem de concordar previamente com uma chave secreta. Já com a criptografia de chave pública este acordo torna-se desnecessário, porém ainda existe um problema, pois as partes que pretendem se comunicar precisam ter certeza de que obtiveram a chave pública verdadeira da outra parte da comunicação. Para ambos os problemas, da criptografia de chave simétrica e da criptografia de chave pública, a solução pode ser obtida por meio de um intermediário de confiança (Kurose e Ross, 2009).

Este intermediário de confiança, na criptografia de chave simétrica, é conhecido como central de distribuição de chaves (Key Distribution Center - KDC), a qual é uma entidade de rede única e de confiança com a qual o usuário estabelece uma chave secreta compartilhada. Assim, por meio da KDC é possível obter as chaves compartilhadas necessárias para se realizar a comunicação.

Já na criptografia de chave pública o intermediário de confiança é conhecido como autoridade certificadora (Certification Authority - CA), a qual possui o objetivo de certificar que uma determinada chave pública pertence a uma entidade (pessoa, roteador ou rede). Se a chave pública for certificada e se a autoridade certificadora que a certificou for confiável, então há a certeza em relação a quem esta chave pública pertence (Kurose e Ross, 2009). Para ser confiável, uma autoridade certificadora não precisa ser uma agência do governo, podendo até mesmo ser uma organização comercial, como a VeriSign. Após a certificação da chave pública, a mesma pode ser distribuída em um servidor de chave pública, em uma página Web, em uma mídia removível, dentre outros.

A tarefa de uma autoridade certificadora é validar identidades e emitir certificados (explicados na Seção 3.4.1). Para tanto, a mesma segue duas etapas (Kurose e Ross, 2009):

1. Verificar se uma entidade é realmente quem diz ser. Para tal verificação não há procedimentos obrigatórios, devendo-se confiar que a autoridade certificadora efetuou uma verificação de identidade rigorosa.

2. Assim que for verificada a identidade da entidade, a autoridade certificadora gera um certificado que vincula esta identidade à chave pública da entidade. Este certificado é assinado pela autoridade certificadora e nele contém a chave pública e a informação que identifica de forma única o proprietário da mesma.

A abordagem da autoridade certificadora apresenta algumas dificuldades, pois a mesma entraria em colapso caso fosse única e tivesse que emitir os certificados do mundo todo. Além disso, seria difícil eleger uma autoridade que fosse aceita no mundo inteiro como legítima e confiável. Por estes motivos foi desenvolvida a ICP (Infraestrutura de Chave Pública), também conhecida como PKI (Public Key Infrastructure) (Tanenbaum, 2003). Basicamente, esta infraestrutura é constituída por vários componentes, como usuários, autoridades certificadoras, certificados e diretórios, e tem 
como objetivo fornecer uma maneira de estruturá-los e definir padrões para os vários documentos e protocolos para assim criar, gerenciar, armazenar, distribuir e revogar certificados digitais (Stallings, 2005).

\subsubsection{Certificados}

Um certificado digital é uma estrutura de dados que contém informações de identidade juntamente com a chave pública de uma entidade. Ao assinar o certificado, a autoridade certificadora atesta a identidade da entidade descrita no mesmo. Desta forma, as partes que desejam se comunicar podem confiar na veracidade da chave pública contida no certificado (Rosenberg e Remy, 2004).

Devido à dificuldade de se administrar todos os formatos diferentes de certificados, a ITU (International Telecommunication Union) aprovou um padrão conhecido como X.509. Desta forma, o X.509 representa um padrão de estrutura para se descrever certificados com seu formato geral incluindo os seguintes campos (Tanenbaum, 2003):

- Version: representa a versão do X.509.

- Serial number: este número de série identifica o certificado de forma exclusiva.

- Signature algorithm: refere-se ao algoritmo utilizado para assinar o certificado.

- Issuer: o nome da organização que emitiu este certificado.

- Validity period: representa as datas inicial e final do certificado, ou seja, quando teve início a validade do certificado e quando a mesma irá expirar.

- Subject name: o nome da entidade cuja chave pública está contida neste certificado.

- Public key: refere-se à chave publica da entidade do certificado.

- Issuer ID: representa um campo opcional utilizado para identificar de forma exclusiva o emissor do certificado.

- Subject ID: campo opcional que identifica de forma exclusiva a entidade do certificado.

- Extensions: um conjunto de um ou mais campos de extensões.

- Signature: refere-se à assinatura do certificado, ou seja, o sumário de mensagem de todos os outros campos, criptografados com a chave privada da autoridade certificadora. 


\subsection{SSL e TLS}

A camada de transporte possui tecnologias de segurança específicas, as quais são muito úteis para garantir a segurança da comunicação em camadas abaixo da camada de aplicação (O'Neill, 2003). O exemplo mais utilizado destas tecnologias é o SSL (Secure Sockets Layer) (Freier et al., 1996), o qual foi desenvolvido pela Netscape para garantir confidencialidade e autenticação em interações HTTP, de forma que os algoritmos utilizados nestes processos sejam negociados entre os dois parceiros da comunicação. Já o protocolo TLS (Transport Layer Security) (Dierks e Allen, 1999) é uma versão estendida do SSL, adotado como padrão da Internet e muito utilizado na maioria dos navegadores Web e no comércio eletrônico. Nesta seção, os protocolos SSL e TLS serão referenciados apenas como SSL já que os mesmos operam basicamente do mesmo modo.

O SSL é composto por duas camadas principais, conforme ilustrado na Figura 3.6. A primeira camada é o Protocolo de Registro SSL, a qual implementa um canal seguro, criptografando e autenticando as mensagens transmitidas por qualquer protocolo orientado a conexão. A segunda camada é constituída por Protocolo de Handshake SSL, Protocolo de Mudança de Especificação de Cifra SSL e Protocolo de Alerta SSL, os quais estabelecem e mantém uma sessão SSL, ou seja, um canal seguro entre um cliente e um servidor (Coulouris et al., 2005).

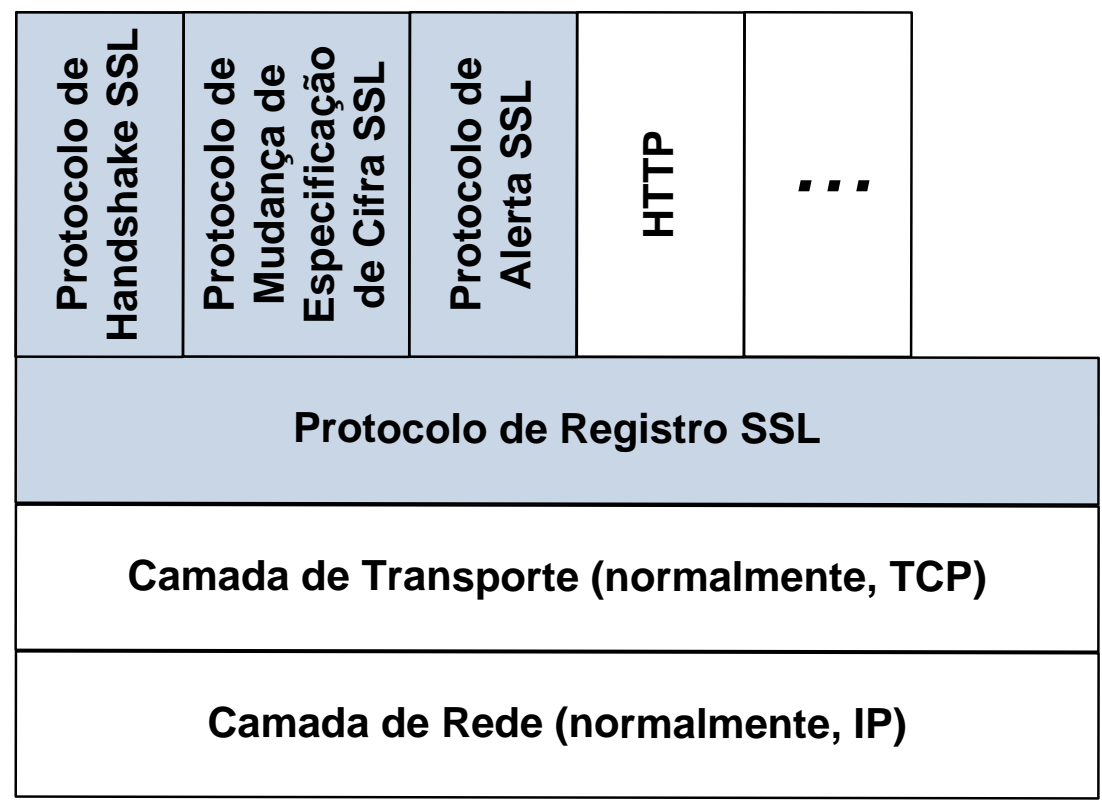

\section{Protocolos SSL}

\section{Outros protocolos}

Figura 3.6: Pilha de protocolos SSL - Adaptado de (Stallings, 2005).

O Protocolo de Registro SSL é uma camada em nível de sessão que visa o transporte de dados em nível de aplicativo de forma transparente entre dois processos, garantindo confidencialidade, autenticidade e integridade aos mesmos. 
O Protocolo de Handshake SSL visa estabelecer uma sessão SSL, iniciando uma troca de mensagens em texto aberto, informando opções e parâmetros necessários para efetuar o processo de criptografia e autenticação, permitindo que um cliente e um servidor possam autenticar-se um ao outro e negociem os diferentes parâmetros necessários para uma sessão segura, isto é, o conjunto comum de algoritmos de criptografia (cipher suite) que serão utilizados para autenticação, troca de chaves de sessão, hashing e criptografia de dados. Portanto, o canal seguro pode ser completamente configurado, possibilitando que a comunicação em ambas as direções seja criptografada e autenticada. Mas não obrigatoriamente, para que assim não haja desperdício de recursos computacionais, como, por exemplo, em execuções de processos de criptografia onde a mesma não seja necessária (Coulouris et al., 2005). Resumidamente, o funcionamento do handshake ocorre primeiramente com uma comunicação não criptografada para as trocas iniciais, seguida da utilização de criptografia de chave pública e, por último, após o estabelecimento de uma chave secreta compartilhada, há a troca para a criptografia de chave simétrica. Cada uma destas trocas é opcional e deve ser antecedida por uma negociação.

E por fim, o Protocolo de Mudança de Especificação de Cifra SSL possibilita atualizações dinâmicas do conjunto de cifras utilizado em uma conexão, enquanto o Protocolo de Alerta SSL visa enviar mensagens de alerta a um parceiro da comunicação (Ravi et al., 2004).

Como discutido anteriormente, tecnologias como o SSL visam prover segurança ponto-aponto, onde a cada etapa a mensagem é decriptada e uma nova conexão SSL é criada, não garantindo assim a segurança fim-a-fim, a qual é estritamente necessária em Web services (Mashood e Wikramanayake, 2007).

\subsection{Considerações Finais}

Este capítulo apresentou os conceitos relacionados à segurança em redes de computadores, assim como as técnicas utilizadas para garantir a segurança, tais como a criptografia de chave simétrica e de chave pública que garantem a confidencialidade e a assinatura digital que garante a integridade e autenticidade das informações transmitidas.

No próximo capítulo serão abordadas algumas das especificações de segurança para XML e para Web services, sendo de grande importância para o desenvolvimento deste projeto de pesquisa. 



$\frac{7}{4}$

\section{Especificações de Segurança em Web Services}

Para que os Web services sejam amplamente adotados é essencial que sua utilização seja segura, visto que nenhuma empresa deseja se arriscar expondo suas aplicações e fluxos de negócios sem antes assegurar-se de que não terá prejuízos. Por esta razão, órgãos como a W3C, OASIS e WS-I estão propondo especificações com o objetivo de tornar estes serviços mais seguros. Tais especificações, juntamente com as especificações de segurança para XML, permitem que requisitos de segurança indicados anteriormente sejam garantidos em Web services.

Desta forma, neste capítulo são apresentadas algumas das especificações de segurança para XML e para Web services, tendo em vista a importância e utilização das mesmas para o desenvolvimento deste projeto de pesquisa.

\subsection{XML Encryption}

Padronizado pela W3C, o XML Encryption (W3C, 2002) define um modo para criptografar dados e representar de forma estruturada o resultado em um documento XML, garantindo o requisito de confidencialidade no mesmo. O XML Encryption tem a finalidade de prover segurança fim-a-fim para aplicações que necessitam trocar dados em formato XML de forma segura, sem a preocupação de que os mesmos possam ter seu conteúdo revelado e utilizado indevidamente por terceiros (Siddiqui, 2002).

O XML Encryption visa prover um conjunto de recursos que não é fornecido pelo SSL/TLS. Assim, o XML Encryption permite a criptografia de dados em níveis de granularidades diferen- 
tes, isto é, possibilita selecionar as partes de dados que se deseja criptografar. Tal recurso é útil quando se deseja optar por criptografar somente um elemento específico de um documento XML, permitindo que o restante do mesmo permaneça com seu conteúdo original.

Diferentemente do SSL, o qual criptografa grupos inteiros de dados para transportá-los, o $X M L$ Encryption realiza criptografia apenas nos dados que realmente necessitam de segurança. Isto é vantajoso, visto que a criptografia consome além de muito tempo, recursos computacionais e, portanto, a mesma deve ser utilizada de forma criteriosa (Nagappan et al., 2003).

Outra vantagem do XML Encryption é que o mesmo permite o estabelecimento de sessões seguras com mais de uma aplicação, o que não ocorre com o SSL. E, além de dados XML, o XML Encryption pode ser utilizado para criptografar outros tipos de dados que não sejam XML.

Na Figura 4.1 é ilustrada uma estrutura básica utilizada pelo XML Encryption para representar os dados criptografados sobre um único elemento. Na linha 1 pode-se observar o elemento raiz EncriptedData, o qual possui três elementos filhos, que armazena informações como o namespace (linha 2) e indica que o processo de criptografia está sendo aplicado apenas sobre um elemento (linha 3). Na linha 4 encontra-se o elemento EncryptionMethod, primeiro filho de EncriptedData, que identifica o algoritmo utilizado para a criptografia, que neste caso é o 3DES (linha 5). Já na linha 6 está o segundo filho, Key In fo, o qual armazena informações sobre a chave. E, finalmente, na linha 9 está o terceiro e último filho, Ci pherData, o qual contém o valor resultante da criptografia sobre o elemento, armazenando o mesmo no elemento CipherValue (linha 10).

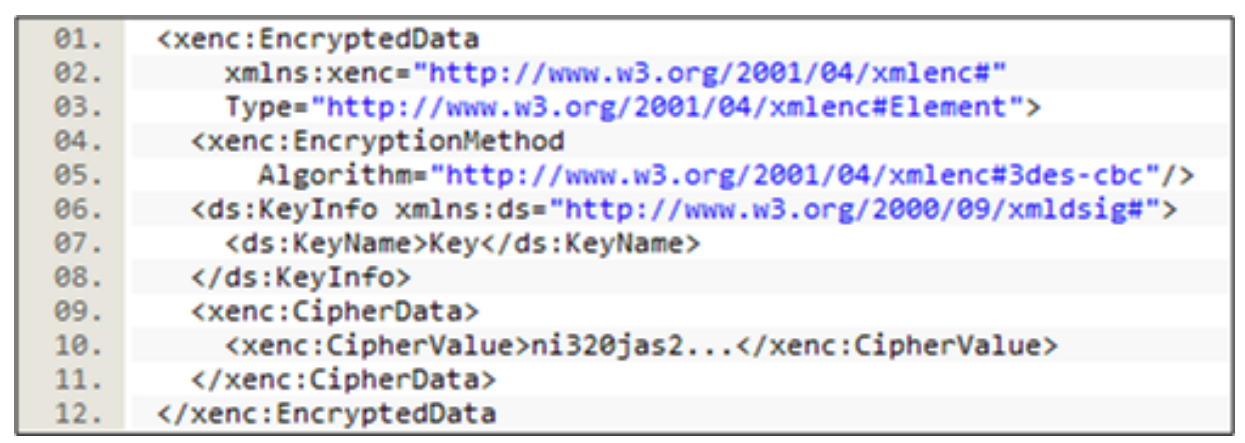

Figura 4.1: Estrutura do XML Encryption.

O processo de decriptação é realizado obtendo o texto cifrado contido no elemento Ci pherValue (linha 10) e verificando o algoritmo utilizado (linha 5) contido no elemento Encrypt i onMethod, as informações sobre a chave no elemento Key Info (linha 6) e qual elemento foi cifrado (linha 3). Com a reunião destas informações, pode-se então realizar a decriptação.

\subsection{XML Signature}

O XML Signature é um padrão da W3C (W3C, 2008b) que especifica um processo para a geração e validação de assinaturas digitais expressas em XML, garantindo a integridade e auten- 
ticidade não apenas em documentos XML, mas também em qualquer outro tipo de documento digital (Mogollon, 2008).

Uma propriedade importante do XML Signature é a possibilidade de assinar apenas partes específicas do documento XML (Yue-Sheng et al., 2009). Esta propriedade é útil, pois permite que um documento XML tenha adições ou alterações de informações em outras partes do mesmo no decorrer do seu tempo de vida, sem que isto invalide a parte assinada. Neste caso, se a assinatura fosse realizada sobre todo o documento XML, qualquer modificação dos dados invalidaria a mesma.

O XML Signature provê três tipos de assinaturas, conforme ilustrado na Figura 4.2. As assinaturas do tipo Enveloped e Enveloping acompanham o documento XML que as mesmas referenciam, sendo o primeiro tipo utilizado em Web services. Já o tipo Detached caracteriza-se pela separação da assinatura dos dados assinados, somente mantendo uma referência do documento na estrutura XML da assinatura (Nagappan et al., 2003).
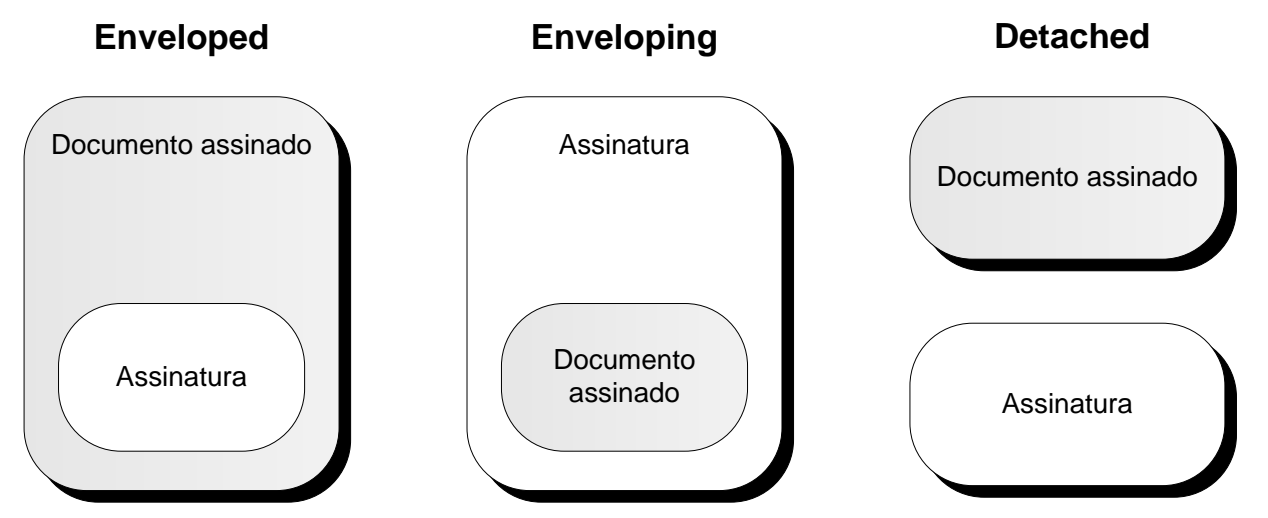

Figura 4.2: Tipos de assinaturas do XML Signature - Adaptado de (Nordbotten, 2009).

A Figura 4.3 exibe a estrutura da especificação XML Signature, onde a linha 1 indica o elemento raiz denominado Signature, o qual possui três filhos: SignedInfo, SignatureValue e KeyInfo. O SignedInfo na linha 2 caracteriza os detalhes do processo de assinatura, representados pelos elementos CanonicalizationMethod na linha 3, o qual indica o algoritmo utilizado na normalização do documento (linha 4) e SignatureMethod na linha 5, que informa o algoritmo utilizado na assinatura, sendo neste caso a combinação do algoritmo de criptografia de chave pública RSA com a função de hash SHA-1 (linha 6). O elemento Reference na linha 7 contém, por sua vez, uma referência aos dados que foram assinados e outras informações, tais como o algoritmo utilizado para gerar o sumário de mensagem, neste caso o SHA-1 (linha 10), e o seu valor resultante (linha 11). O elemento SignatureValue na linha 14 representa o valor da assinatura e, finalmente, o elemento Key Info na linha 15 fornece informações sobre a chave utilizada na verificação da assinatura.

A verificação de integridade do documento XML é realizada com o receptor calculando localmente o sumário de mensagem e o comparando com o sumário de mensagem contido na men- 


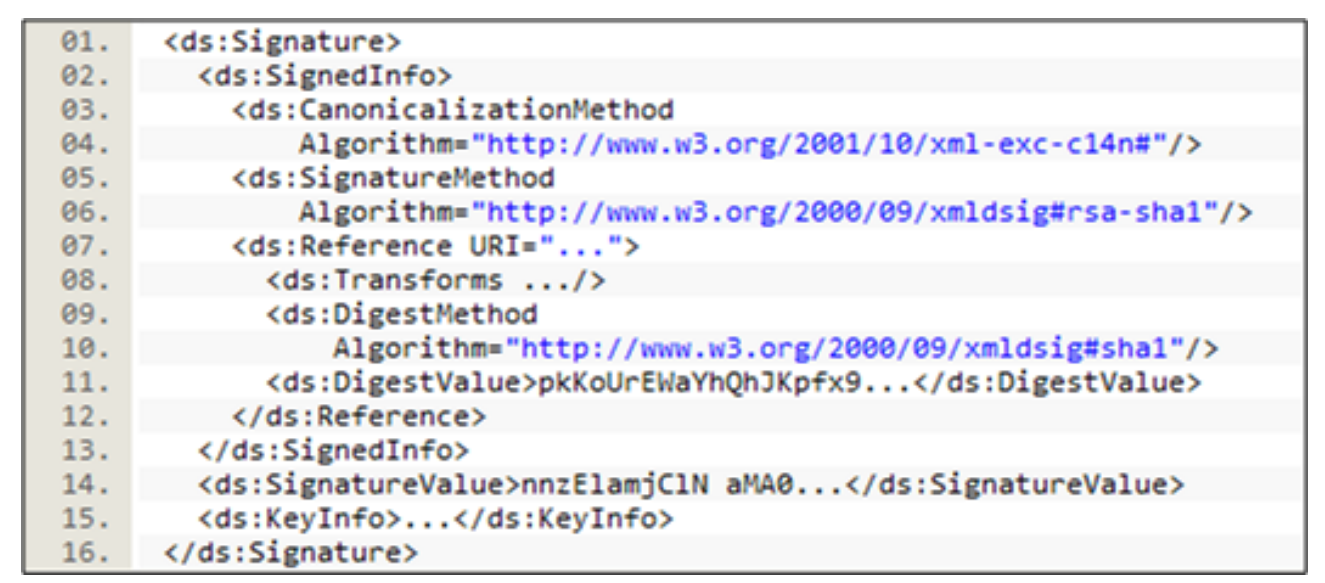

Figura 4.3: Estrutura do XML Signature.

sagem. Caso os dois sejam iguais, então a assinatura é considerada válida, garantindo assim a integridade do documento.

\subsection{XKMS}

Geralmente o gerenciamento de chaves está associado com a geração, distribuição, negociação, troca e revogação de certificados digitais. Desta forma, o XKMS (XML Key Management Specification) foi padronizado pela W3C (W3C, 2005) visando definir protocolos para a distribuição e registro de chaves públicas. Estes protocolos são adequados para serem utilizados em conjunto com as especificações XML Encryption e XML Signature, auxiliando na resolução de questões relacionadas à infraestrutura de chaves públicas.

O XKMS possui o objetivo de simplificar para o desenvolvedor a utilização de uma funcionalidade sofisticada de gerenciamento de chaves públicas, desta forma o mesmo não precisa ter preocupação com detalhes de infraestrutura necessários para o suporte de tal gerenciamento. Além disso, o XKMS visa prover este suporte ao gerenciamento de chaves públicas para aplicações que utilizam XML (Rosenberg e Remy, 2004). Para cumprir tais objetivos, o XKMS disponibiliza dois serviços, o X-KISS (XML Key Information Service Specification) e o X-KRSS (XML Key Registration Service Specification), ambos explicados nas seções seguintes.

\subsubsection{X-KISS}

Com a utilização do XML Signature, os signatários de mensagens podem incluir informações sobre sua chave pública dentro do elemento Key Info para que a mesma possa ser enviada e verificada pelo receptor da mensagem. Porém, o elemento Key In fo pode não conter informações relacionadas à localização ou validação da chave pública. Assim, o X-KISS oferece duas operações para que tais informações sejam obtidas e validadas (Mogollon, 2008): 
- Localizar (locate): permite localizar informações relacionadas ao elemento Key Info, sendo que as mesmas podem ser obtidas localmente em uma base de dados ou por meio de uma requisição a outros servidores. Em uma situação onde apenas o e-mail do signatário esteja contido no elemento Key Info, o X-KISS utiliza esta informação para localizar a chave que esteja associada a este $e$-mail.

- Validar (validate): além de oferecer as mesmas funcionalidades da operação localizar, permite também a validação das informações relacionadas à chave pública.

\subsubsection{X-KRSS}

O X-KRSS oferece operações que visam o registro e gerenciamento das informações relacionadas à chave pública. Deste modo, uma aplicação cliente pode solicitar ao serviço X-KRSS o registro de uma chave pública, associando informações relacionadas no registro da mesma, tais como um nome ou outro identificador. Além do registro, é preciso que estas informações sejam gerenciadas (O’Neill, 2003). Assim, são definidas quatro operações:

- Registrar (register): esta operação registra um par de chaves e as informações associadas às mesmas. Antes de realizar o registro, o serviço confere a autenticidade das informações e verifica se o requisitante tem a posse da chave privada informada.

- Recuperar (recover): esta operação recupera uma chave privada previamente registrada, ou seja, quando um cliente perde sua chave privada, ele pode solicitar ao serviço uma cópia. Tal recuperação é possível apenas se a chave privada foi gerada pelo próprio serviço X-KRSS, caso contrário ele não possuirá uma cópia da mesma.

- Reemitir (reissue): esta operação permite a reemissão de informações associadas a uma chave previamente registrada, sendo esta operação útil no caso de um certificado expirar.

- Revogar (revoke): esta operação realiza a revogação de uma chave previamente registrada, isto significa que a chave não é mais considerada confiável e por este motivo não deve mais ser utilizada.

\subsection{WS-Security}

A especificação WS-Security foi inicialmente proposta pela IBM e Microsoft, sendo atualmente padronizada pela OASIS (OASIS, 2006a), com a finalidade de propor um conjunto de extensões às mensagens SOAP visando à implementação de Web services seguros. Desta forma, o WS-Security define métodos para incorporar a segurança em mensagens SOAP, como, por exemplo, troca de credenciais, confidencialidade e integridade da mensagem (Jensen et al., 2007). 
A especificação WS-Security possui o propósito de garantir segurança fim-a-fim no nível de mensagem no que diz respeito a três pontos principais (Chou e Yurov, 2005):

- Confidencialidade da mensagem: a mensagem SOAP pode ser criptografada total ou parcialmente com a utilização da especificação XML Encryption, sendo que a mesma deve conter as informações relacionadas à criptografia realizada.

- Integridade da mensagem: a mensagem SOAP pode ser assinada com a utilização do $X M L$ Signature e a mesma deve conter as informações relacionadas à sua assinatura.

- Credenciais de segurança: credenciais de segurança com informações de autenticação podem ser incluídas na mensagem SOAP. Estas credenciais são conhecidas também como autenticação de acesso, identificação ou tokens de segurança.

Credenciais de segurança são definidas no WS-Security como mecanismos de acesso e métodos utilizados para autenticação e autorização. As senhas, por exemplo, são um tipo de credenciais de segurança não assinadas, enquanto um certificado X.509 é um exemplo de credencial de segurança assinado digitalmente por uma autoridade específica. As principais credenciais de segurança são (Mogollon, 2008):

- UsernameToken: define como as informações de nome de usuário e senha estão incluídas na mensagem SOAP.

- BinarySecurityToken: credenciais de segurança binárias, tais como certificados X.509, ou credenciais de outros formatos que não sejam XML requerem um formato especial de codificação para inclusão na mensagem SOAP.

- XML Tokens: conjunto de credenciais que definem como as credenciais de segurança XML podem ser incorporadas ao cabeçalho da mensagem SOAP.

$\mathrm{Na}$ Figura 4.4 é ilustrada uma mensagem SOAP com WS-Security e credencial de segurança UsernameToken, onde o elemento de segurança do cabeçalho é denominado Security (linha 3) e o mesmo é utilizado para transportar informações relacionadas à segurança. Dentro deste elemento está o elemento UsernameToken (linha 4), o qual carrega uma identidade por meio dos elementos Username (linha 5) e Password (linha 8), ambos criptografados para garantir a confidencialidade dos mesmos.

\subsection{WS-Policy}

A especificação WS-Policy é um padrão da W3C (W3C, 2007c) que provê um modelo de propósito geral para a descrição de políticas por meio de uma gramática flexível e extensível que 


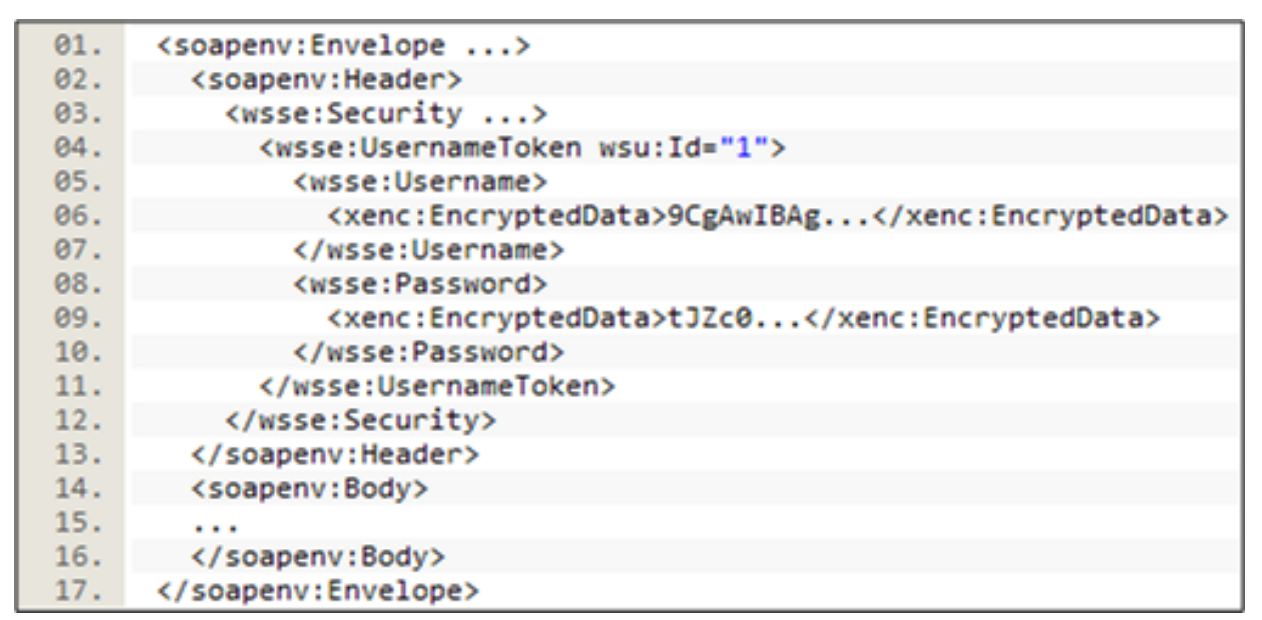

Figura 4.4: Estrutura do WS-Security com UsernameToken.

permite especificar uma variedade de requisitos e habilidades para o ambiente dos Web services. Assim, o WS-Policy permite que as entidades envolvidas nas interações definam suas escolhas para a comunicação por meio de uma representação da política do serviço (Sidharth e Liu, 2008).

Na especificação WS-Policy uma política é definida como um conjunto de alternativas de política, sendo que cada alternativa, por sua vez, é um conjunto de asserções de política. Algumas destas asserções de política definidas pela especificação representam requisitos e capacidades tradicionais, tais como seleção de protocolo e método de autenticação.

O WS-Policy descreve uma forma para representar uma política com o propósito de tornar as asserções de política interoperáveis, permitindo assim que as entidades no ambiente dos Web services processem as políticas de forma padronizada. Assim, o elemento raiz da forma normal é denominado Policy, o elemento Exact lyone define um conjunto de alternativas de políticas e o elemento All descreve a alternativa de política (Mihindukulasooriya, 2008).

Na Figura 4.5 é ilustrada a estrutura de uma política definida com o WS-Policy, onde a descrição da mesma se inicia no elemento Policy (linha 1). Logo após, o elemento Exact lyone (linha 2) indica que pelo menos uma das duas alternativas de política apresentadas deve ser satisfeita. E finalmente, cada elemento All (linhas 3 e 8) define uma alternativa de política, composta por diversas asserções de política.

Um provedor de Web services expõe sua política visando determinar as condições que precisam ser satisfeitas para que o mesmo forneça seu serviço a um cliente. Assim, um cliente em potencial, após a análise da política, tem condições de decidir se deseja ou não acessar o serviço.

\subsection{WS-SecurityPolicy}

A especificação WS-SecurityPolicy é um padrão da OASIS (OASIS, 2007a) com o propósito de fornecer asserções de política relacionadas à segurança que podem ser utilizadas com o WS-Policy e em conjunto com o WS-Security, WS-SecureConversation e WS-Trust. Por meio destas asserções 


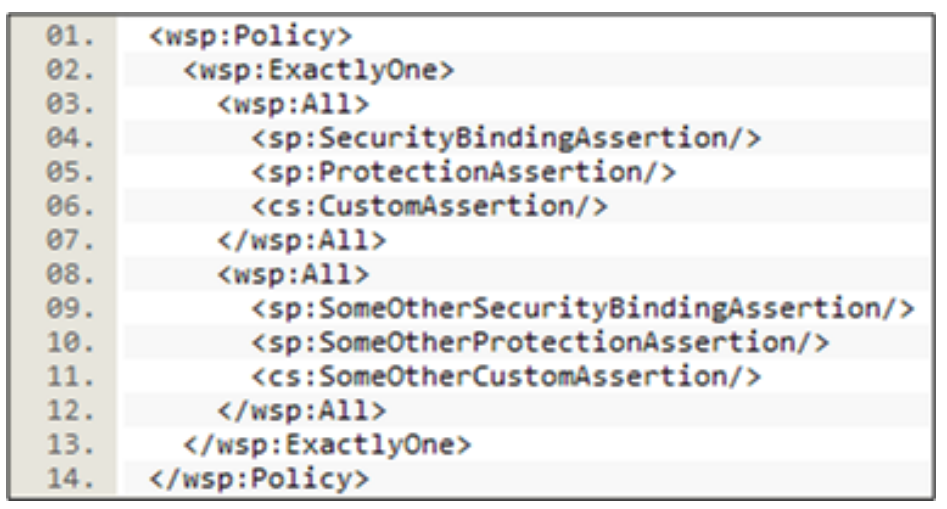

Figura 4.5: Política definida com WS-Policy.

podem ser especificadas as exigências, as capacidades e limitações de uma implementação de Web services seguros (Merrill e Grimshaw, 2009).

Na Figura 4.6 é ilustrada a estrutura de uma política com WS-SecurityPolicy, onde nota-se o formato padronizado do WS-Policy juntamente com elementos relacionados à segurança, tais como os elementos AsymetricBinding, AlgorithmSuite e EncryptedParts. O elemento AsymetricBinding (linha 4) define a utilização da tecnologia de chave pública. O elemento AlgorithmSuite (linha 6) indica uma asserção para um conjunto de algoritmos utilizados, como, por exemplo, o TripleDesRsa15 (linha 8), que engloba o algoritmo RSA para criptografia de uma chave de sessão, o algoritmo 3DES para criptografia de blocos de dados, a função de hash SHA-1 para assinatura digital, dentre outros. Finalmente, o elemento EncryptedParts (linha 13) especifica as partes da mensagem que exigem criptografia, como, por exemplo, o corpo inteiro da mensagem (linha 14).

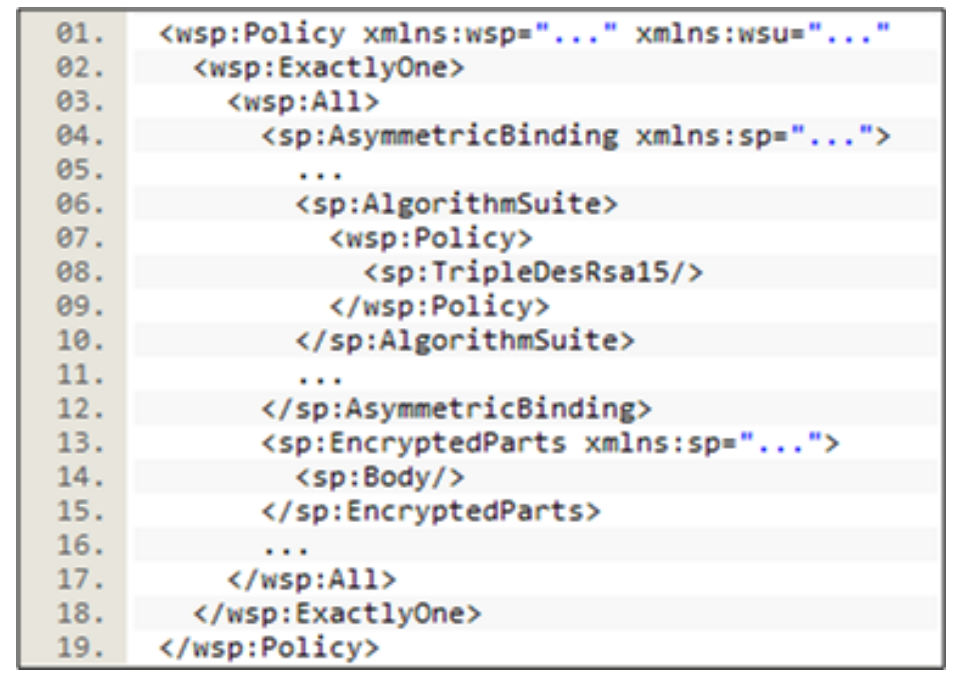

Figura 4.6: Política definida com WS-SecurityPolicy. 


\subsection{Outras Especificações de Segurança para Web Ser- vices}

Na realidade o WS-Security foi a primeira especificação de segurança para Web services a ser lançada pela IBM e Microsoft (Microsoft, 2002), conforme ilustrado na Figura 4.7.

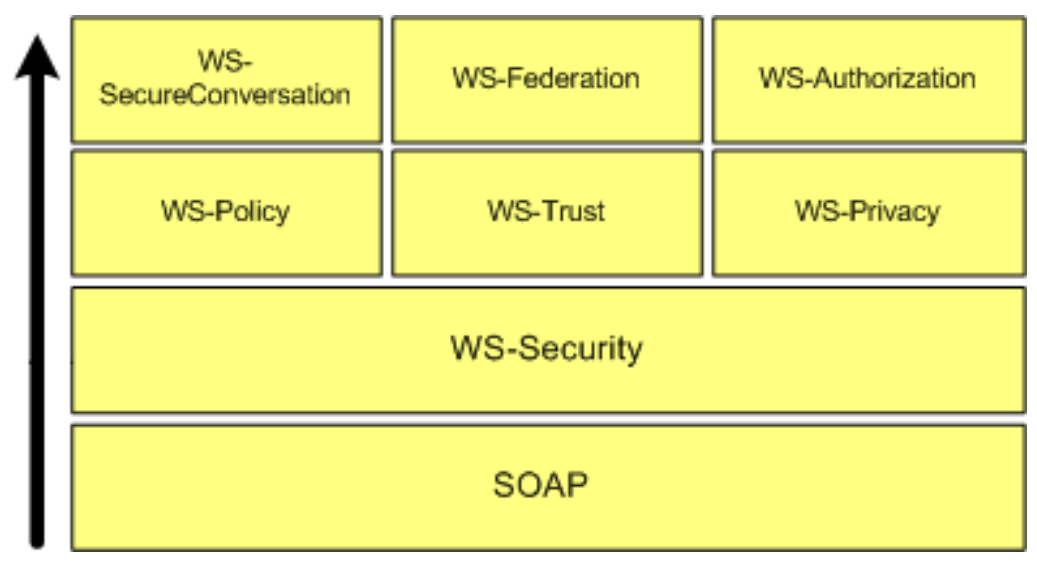

Figura 4.7: Pilha de especificações de segurança para Web services - Adaptado de (Tang et al., 2006).

Ainda na Figura 4.7, pode-se perceber que as especificações estão sendo desenvolvidas de baixo para cima. O SOAP está na base da pilha por ser um protocolo independente de transporte. Já o WS-Security está acima do SOAP, pois o mesmo provê meios de criptografia e assinatura digital em uma mensagem SOAP utilizando XML Encryption e XML Signature, além de incluir credenciais de segurança na mesma. Desta forma, visualizando esta pilha de especificações de cima para baixo, nota-se que cada especificação depende de suas antecessoras, construindo assim um contexto de segurança completa para Web services. A seguir é dada uma breve explicação sobre cada uma destas especificações (Microsoft, 2002):

- WS-Policy: padrão da W3C (W3C, 2007c) que permite que as organizações que estão expondo seus Web services especifiquem os seus requisitos por meio de políticas (explicado anteriormente na Seção 4.5). Mais especificamente, uma extensão do WS-Policy denominada WS-SecurityPolicy (OASIS, 2007a) define as políticas de segurança para os Web services, tais como os algoritmos de criptografia e assinatura digital suportadas (abordado anteriormente na Seção 4.6).

- WS-Trust: padrão da OASIS (OASIS, 2007c) que define como relações de confiança são estabelecidas, permitindo aos Web services interoperar com segurança.

- WS-Privacy: proposta ainda não padronizada que visa comunicar as políticas de privacidade indicadas pelas organizações que estão implantando Web services (Nordbotten, 2009). 
- WS-SecureConversation: padrão da OASIS (OASIS, 2007d) que fornece mecanismos para o estabelecimento e identificação de um contexto de segurança, ou seja, permite a criação de sessões onde diversas mensagens SOAP podem ser trocadas sem a necessidade de avaliar a autenticação e autorização de cada uma delas (Holgersson e Söderstrom, 2005).

-WS-Federation: proposta com padronização em andamento pela OASIS (OASIS, 2008b) que visa descrever como gerenciar e intermediar o relacionamento de confiança em um ambiente heterogêneo federado, incluindo suporte para identidades federadas. Federação, neste caso, envolve a intermediação entre especificações de segurança diferentes (O’Neill, 2003).

-WS-Authorization: proposta ainda não padronizada que visa descrever como as políticas de acesso para um Web service são especificadas e gerenciadas (Nordbotten, 2009).

\subsection{Considerações Finais}

Este capítulo apresentou as principais especificações de segurança para Web services identificando suas características e levando em consideração sua utilidade para o projeto a ser desenvolvido. Desta forma, algumas destas especificações serão utilizadas no desenvolvimento e implantação da arquitetura de segurança proposta para Web services, a qual será apresentada no próximo capítulo. 


\section{Arquitetura de Segurança Proposta para Web Services}

Este capítulo descreve os componentes e o funcionamento da arquitetura de segurança proposta para os Web services. Primeiramente, na Seção 5.1 são informados os trabalhos relacionados. Por fim, nas Seções 5.2 e 5.3 são explicados, respectivamente, o desenvolvimento e o funcionamento desta arquitetura.

\subsection{Trabalhos Correlatos}

Toda comunicação em Web services é realizada por meio de mensagens SOAP em formato XML, conforme já mencionado e exemplificado no Capítulo 2. A troca de mensagens é realizada via texto puro, sem nenhuma preocupação com a segurança. O protocolo SOAP não implementa segurança, tanto por questões de manutenção quanto por questões como simplicidade e portabilidade. Desta forma, a segurança na comunicação deve ser implementada tanto em nível de sistema (nas camadas de rede e de transporte) quanto em nível de aplicação por meio de configurações personalizadas e aplicações de padrões de segurança em XML (Scribner e Stiver, 2001).

No trabalho de (Yau et al., 2009) os autores propõem um modelo de troca adaptativa em sistemas baseados em serviços para melhorar o desempenho e segurança de sistemas com recursos limitados. Este modelo pode ajustar as configurações de segurança dos serviços para assim prover, simultaneamente, proteção suficiente e satisfazer os requisitos de desempenho para sistemas baseados em SOA. Foram desenvolvidas métricas de desempenho e segurança, e a combinação delas em uma função objetivo com troca de dois fatores de ponderação representa as preferências sobre 
o desempenho e segurança. Desta forma, pode-se alcançar a segurança máxima, o desempenho máximo, ou o equilíbrio entre segurança e desempenho com o ajuste destes fatores de ponderação. Este tipo de trabalho evidencia a necessidade de avaliação não apenas dos parâmetros de segurança, mas também dos parâmetros de desempenho em Web services.

Em (Knap e Mlýnková, 2009) é apresentada uma proposta de formalização de abordagens de processamento para a verificação da integridade de Web services de modo a mostrar a vulnerabilidade diante de diversos tipos de ataques. Estas vulnerabilidades destacadas permitiram averiguar qual tipo de segurança se faz necessária no contexto de Web services, além de motivar a observação e o levantamento das contramedidas a serem utilizadas, o que conduziu ao uso dos mecanismos abordados, avaliados e adaptados nesta dissertação.

Outro trabalho relacionado com a proposta deste projeto de mestrado é discutido em (Chen et al., 2007), em que é destacada uma avaliação de desempenho para Web services considerando aspectos de segurança. Os autores se concentram principalmente na variabilidade dos tamanhos de mensagens e na aplicação de algumas políticas de segurança, tais como políticas de criptografia, assinatura digital e criptografia de uma mensagem assinada, utilizando para tanto uma infraestrutura de chaves simétricas e assimétricas. Porém, eles não consideram as principais especificações de segurança para Web services, tampouco comparam os diversos algoritmos de criptografia existentes. Além disso, limitam a avaliação de desempenho a um ambiente com a participação de apenas algumas entidades de uma arquitetura SOA. A necessidade de se avaliar as especificações de segurança, frente aos principais tipos de ataques proferidos a este tipo de plataforma, e também a necessidade da utilização destas especificações como principais contramedidas a estes ataques, faz com que estudos mais específicos devam ser realizados.

Em (Engelen e Zhang, 2008a), os autores identificaram oportunidades para otimizar o WSSecurity analisando mais detalhadamente a sobrecarga causada por suas operações. Já em (Engelen e Zhang, 2008b), os mesmos autores examinam novamente a sobrecarga da especificação WS-Security, com o objetivo de avaliar técnicas de otimização do desempenho da assinatura digital nesta especificação. Eles comparam várias técnicas de otimização presentes na literatura, além de introduzir um novo sumário de mensagem baseado em caching com o propósito de melhorar o desempenho do WS-Security. Foi realizada uma avaliação de desempenho considerando o impacto destas otimizações em diferentes tamanhos de mensagens SOAP. Os resultados desta avaliação indicam que algumas combinações específicas das técnicas de otimização aumentaram em até quatro vezes a velocidade dos algoritmos utilizados na assinatura digital. Entretanto, com os resultados pode-se concluir também que o SSL permanece mais eficiente mesmo quando comparado à melhor otimização do WS-Security. Trabalhos como estes demonstram a necessidade e o estudo atual de técnicas de segurança em arquiteturas orientadas a serviços. Principalmente no que diz respeito à melhor forma de utilização do WS-Security, devido à sobrecarga no desempenho causada por este.

O trabalho de (Liu et al., 2005) é focado no desempenho das operações de segurança. Desta forma, os resultados foram obtidos em uma computação local, com o provedor de serviços e o cliente na mesma máquina, não se importando com questionamentos sobre quanto tempo a men- 
sagem, adicionada dos elementos relacionados à segurança, gastou durante o seu tráfego na rede. Ou seja, o intuito foi averiguar o desempenho das operações de criptografia, do processamento do SOAP/XML e das implementações do WS-Security e do WS-SecureConversation. A partir destes resultados pode-se observar que o tamanho da mensagem SOAP é um fator importante no tempo gasto em seu processamento, assim como a complexidade da estrutura da mensagem também deve ser considerada como relevante. Assim, quando se realiza criptografia e assinatura em uma mensagem SOAP, há um aumento tanto nas operações realizadas quanto na complexidade da mensagem devido à adição de elementos relacionados à segurança. No trabalho realizado nesta dissertação de mestrado características relacionadas ao tempo gasto na rede foram levadas em consideração, demonstrando assim a utilização em um ambiente mais próximo do real do que o observado no trabalho de (Liu et al., 2005).

Em (Alrouh e Ghinea, 2009), os autores comparam o desempenho de diversos mecanismos de segurança WSIT (Web Services Interoperability Technologies). O WSIT foi desenvolvido em um esforço conjunto entre a Sun e a Microsoft com o objetivo de permitir a interoperabilidade entre serviços Java e .Net e melhorar a qualidade de serviço. Estes mecanismos são aplicados em um Web service simples com a finalidade de testá-los com diferentes tamanhos de mensagens SOAP, de 1 byte a 1 Mbyte. Os resultados destes experimentos mostraram que mecanismos de segurança da camada de transporte, como o SSL, são consideravelmente mais velozes do que os mecanismos de segurança em nível de mensagem. Além disso, diferentemente dos mecanismos de segurança da camada de transporte, os protocolos de segurança em nível de mensagem possuem o problema de escalabilidade quando mensagens grandes são trocadas. Entretanto, apesar deste fato desmotivar o uso de segurança em nível de mensagem, já foi explicado neste trabalho a necessidade de se fazer uso destes mecanismos. Devido a esta necessidade, de garantia de segurança fim-a-fim, é que este trabalho apresenta estudos neste sentido.

No trabalho de (Gruschka et al., 2011) é introduzido um sistema de processamento de WSSecurity baseado em fluxo. Desta forma, este artigo mostra como uma mensagem SOAP segura com WS-Security pode ser completamente processada por fluxo, incluindo seus elementos de segurança. Esta abordagem melhora o desempenho do processamento de documentos XML quando comparado às abordagens tradicionais e aumenta a eficiência no que diz respeito ao consumo de recursos, aumentando assim a robustez contra diversos tipos de ataque DoS (Denial of Service). Com base nas conclusões obtidas no trabalho apresentado por (Gruschka et al., 2011) é que se pode inferir que uma vez melhorada a qualidade dos padrões, como o WS-Security, pode favorecer ainda mais o aumento da robustez das contramedidas.

Em (Juric et al., 2006) é realizada uma avaliação de desempenho comparando Web services e RMI (Remote Method Invocation), incluindo ainda suas variantes seguras, respectivamente, WSSecurity e RMI-SSL. Esta avaliação é realizada em dois diferentes sistemas operacionais: Windows e Linux. Com os resultados obtidos, pode-se observar que Web services e WS-Security possuem um desempenho inferior quando comparados ao RMI e RMI-SSL, devido principalmente ao tamanho das mensagens trocadas e à sobrecarga causada pelo processamento das mesmas. Entretanto, cabe 
ressaltar que o crescimento do número de serviços é notório, e que a necessidade de se melhorar e avaliar a relação segurança/desempenho do WS-Security, entre outros padrões de Web services, se torna cada vez mais evidente.

Os autores do trabalho (Viega e Epstein, 2006) argumentam sobre a importância de projetar e garantir segurança para os Web services, mas que tal garantia não significa apenas utilizar os padrões de segurança. Eles complementam afirmando que é necessário que os desenvolvedores compreendam as limitações e desvantagens destes padrões, para assim garantir a segurança plena de seus Web services. Desta forma, os autores identificam os perigos mais comuns e que devem ser evitados:

- Padrões de segurança podem não ser seguros: em sua utilização normal, o padrão pode apresentar falhas de segurança não intencionais.

- Utilização do padrão de segurança inadequado: o desenvolvedor de Web services pode aplicar o padrão de segurança de forma incorreta. E assim a expectativa em relação ao nível de segurança não será satisfeita.

- Desconhecer o que o padrão de segurança não garante: o desenvolvedor pode desprezar riscos de segurança que os padrões não abrangem.

Nesse sentido, a necessidade da avaliação dos padrões de segurança se faz necessária, não somente para o real conhecimento destes, mas também para permitir que se verifique a possível combinação entre eles para que se possa aumentar o nível de segurança. Estas observações somente serão possíveis caso se tenha um conhecimento mais detalhado e uma avaliação de desempenho mais apurada de cada padrão.

Outro trabalho que margeia o trabalho aqui proposto é o apresentado em (Jensen et al., 2007). Nele são apresentados alguns tipos de ataques mais frequentes aos Web services. Fazendo uma análise desse trabalho torna-se evidente que os Web services estão expostos não somente aos ataques conhecidos dos protocolos da Internet, mas também a ataques específicos como:

- Coercive Parsing, SOAPAction Spoofing, Attack Obfuscation, BPEL State Deviation e Instantiation Flooding, ambos causando sobrecarga de CPU (Central Processing Unit).

- DoS, Oversized Cryptography, Indirect Flooding e Workflow Engine Hijacking, ambos causando sobrecarga de CPU e memória.

- XML Injection e WSDL Scanning, ambos permitindo acesso a conteúdo sigiloso.

- Metadata Spoofing, permitindo escuta ou modificação de dados.

É apresentada também uma análise do impacto da segurança no desempenho das aplicações, e também pode ser evidenciado que isto ocorre devido à não existência de um padrão de fato 
para a segurança em Web services. É possível averiguar também que tanto a falta quanto o uso indevido das especificações de segurança podem ocasionar a degradação de uma arquitetura SOA, tanto em termos de segurança quanto de desempenho. Desta forma, torna-se ainda mais evidente a necessidade do estudo proposto por este projeto de mestrado.

Além da segurança, outro tópico importante para este trabalho é o desempenho em Web services. E neste tópico existe um item em particular que é fundamental para a sobrecarga no desempenho dos mesmos: o processamento de mensagens SOAP no formato XML. Desta forma, no trabalho de (Andresen et al., 2004) entende-se que o maior custo da codificação e decodificação do XML não está nos dados que a mensagem carrega, mas sim na complexidade estrutural dos elementos. Os autores evidenciam que grande parte do tempo gasto pelo provedor de serviços é aplicada na codificação da mensagem XML. Este processo, conhecido como marshalling, transforma a representação em memória de um objeto em um formato de dados apropriado para armazenamento ou transmissão. Além disso, os autores do trabalho indicam uma série de considerações necessárias, especialmente se o desenvolvimento ou a integração dos sistemas possui limitações no que diz respeito ao desempenho. Estas considerações relacionadas ao processamento de mensagens SOAP são apresentadas a seguir:

- Mensagens SOAP acarretam grande sobrecarga, devido à necessidade de um tempo de execução considerável para o processamento do XML.

- Em média, 50\% do tempo total gasto na execução é aplicado na codificação dos dados em XML e na criação de uma conexão HTTP.

- Codificação de dados binários para o formato XML gera uma sobrecarga no processamento.

- Não há otimização dos dados no formato XML.

- Inexistência de balanceamento entre a velocidade de execução e a interoperabilidade.

- SOAP, devido à sua dependência com o XML, é ineficiente quando comparado ao RMI e CORBA (Common Object Request Broker Architecture) em computação distribuída.

Existem ainda outros fatores que podem causar a sobrecarga no processamento de mensagens SOAP, destacando-se dentre eles:

- Velocidade de codificação e decodificação: um dos principais custos relacionados ao processamento de dados em XML é a conversão de dados binários para o padrão ASCII (American Standard Code for Information Interchange) e vice-versa. Este alto custo ocorre principalmente para valores de ponto flutuante e matrizes de grandes dimensões (Ying et al., 2005). 
- Tamanho da mensagem: o tamanho da representação de dados na mensagem SOAP é, normalmente, cerca de dez vezes maior que sua representação binária correspondente. Tal fato deve-se principalmente a fatores relacionados à codificação e decodificação de valores de ponto flutuante.

- Alto custo da rede de transmissão: para realizar transferência de dados binários via mensagens SOAP são utilizados algoritmos de codificação binária como o base64, o qual define meios de representar dados binários no padrão ASCII. Esta codificação ocasiona maior tempo de utilização da CPU e uso intensivo da memória, podendo degradar o desempenho do sistema. E como visto anteriormente, os dados no padrão ASCII resultantes da conversão são maiores que os dados binários originais, necessitando de maior largura de banda para a transmissão dos dados (Zhang et al., 2007). Há um estudo apresentado em (Estrella et al., 2009) que identifica, por meio de uma avaliação de desempenho, os principais aspectos pertinentes à transmissão de dados binários em mensagens SOAP, utilizando para tanto três técnicas diferentes: binário puro, a qual converte os dados binários para o padrão ASCII; SwA (SOAP with Attachments) e MTOM (Message Transmission Optimization Mechanism), as quais anexam os dados binários fora da mensagem SOAP, referenciando-os por meio de uma URI contida na mensagem.

\subsection{Desenvolvimento e Implementação da Arquitetura}

Como visto anteriormente, Web services proveem uma tecnologia independente de plataforma e de linguagem de programação que visa a interoperabilidade entre máquinas em uma rede. Para tanto, os Web services utilizam uma interface descrita em XML (WSDL) e os clientes interagem com os Web services por meio de um sistema de mensagens em XML padronizadas (SOAP), geralmente transmitidas utilizando o protocolo HTTP juntamente com uma serialização XML e outros padrões Web relacionados (W3C, 2004).

No entanto, a concepção de aplicações de diferentes domínios se comunicando causa preocupação em relação às ameaças à segurança. Desta forma, a troca de mensagens seguras torna-se uma questão importante no ambiente de Web services. A mensagem entregue deve ser confidencial, ou seja, apenas entidades autorizadas podem ter acesso ao seu conteúdo. O receptor da mensagem deve ser capaz de verificar a sua integridade para ter a certeza de que a mesma não foi modificada em trânsito e deve conhecer a identidade do emissor para assim garantir a autenticidade da mensagem (Mi et al., 2005). O desafio em prover segurança em um ambiente de Web services consiste em analisar e compreender os riscos de tornar seguro um serviço baseado na Web de acordo com as técnicas de segurança existentes, com o objetivo de preencher esta lacuna.

Para tanto, neste trabalho é proposta uma arquitetura de segurança para Web services, a qual provê confidencialidade, autenticidade e integridade às aplicações deste tipo por meio de técnicas como criptografia e assinatura digital. Tal segurança é alcançada utilizando-se os padrões WS- 
Security, XML Encryption, XML Signature, WS-SecurityPolicy, dentre outros. Na Figura 5.1 é apresentado um modelo desta arquitetura e os seus componentes são:

- Serviço: um processo de negócio implementado em software e disponibilizado em um provedor de serviços.

- Cliente: uma aplicação que consome o serviço, ou seja, realiza requisições ao serviço.

- Rampart: desenvolvido pela Apache, o Rampart (Apache, 2011a) é o módulo de segurança do Axis2 (Apache, 2010). Este módulo implementa as especificações WS-Security, WSSecureConversation, WS-SecurityPolicy e WS-Trust (ambas já explicadas detalhadamente no Capítulo 4), provendo segurança aos Web services de acordo com as normas das mesmas. Um detalhe importante a se notar diz respeito à diferença de posição do módulo Rampart em relação ao cliente e ao serviço, conforme ilustrado na Figura 5.1. Isto ocorre devido à obrigatoriedade deste módulo estar presente em um repositório de módulos da aplicação cliente, enquanto no lado do provedor o mesmo não ocorre, ou seja, o módulo deve estar presente em um repositório de módulos do provedor de serviços e não no serviço propriamente dito. Em ambos os casos, tanto no cliente quanto no serviço, ocorrem as interações de segurança, já que por meio delas é que o módulo Rampart realiza as operações de segurança na mensagem, tais como a criptografia e a assinatura digital.

- Política de segurança: um documento no formato XML que descreve a política de segurança por meio de asserções que definem parâmetros como: se a mensagem SOAP será apenas criptografada, apenas assinada ou ambas as operações serão executadas; os algoritmos de criptografia e assinatura empregados na segurança desta mensagem; dentre outros. A descrição destas políticas de segurança deve seguir as normas das especificações WS-Policy e WS-SecurityPolicy (abordadas previamente no Capítulo 4). A política utilizada pode ser combinada entre os participantes da comunicação em uma negociação prévia, entretanto, o cliente conseguirá acessar o serviço se, e somente se, esta política for satisfeita.

- Keystore: uma base de dados (repositório) que armazena a chave privada da entidade à qual o keystore pertence e certificados no padrão X.509 (vide Seção 3.4.1). Estes certificados podem ser da entidade proprietária do keystore, de outras entidades que pretendem se comunicar com a mesma de forma segura e da autoridade certificadora que assinou estes certificados. Devido à natureza acadêmica deste trabalho e ao custo relativamente alto para submeter chaves públicas para certificação em uma autoridade certificadora real como a VeriSign ${ }^{1}$ e a Certisign $^{2}$, foi implementada uma autoridade certificadora utilizando a ferramenta OpenSSL (OpenSSL, 2011) para a realização de experimentos nesta arquitetura. O OpenSSL é um projeto colaborativo que visa desenvolver um conjunto robusto de ferramentas de código

\footnotetext{
${ }^{1}$ http: //www.verisign.com.br/

${ }^{2}$ http: //www. certisign.com.br/
} 
aberto que implementam os protocolos SSL e TLS, bem como uma biblioteca completa de criptografia para uso geral. Já os keystores foram implementados utilizando uma ferramenta denominada Keytool (Keytool, 2010), a qual faz parte do Java Development Kit (JDK). O Keytool permite a criação e o gerenciamento dos keystores, bem como das chaves e certificados contidos neles. Os certificados, contendo suas respectivas chaves públicas, gerados a partir do Keytool são assinados pela autoridade certificadora implementada, utilizando para isso uma chave privada RSA de 1024 bits. Vale ressaltar ainda que para obter acesso aos certificados das chaves públicas basta possuir a senha do keystore. Contudo, além da senha do keystore, o acesso à chave privada é restringido por meio de uma senha específica associada a ela. Estas senhas podem ser recuperadas programaticamente (por exemplo, uma classe Java) empregando um banco de dados, um servidor LDAP (Lightweight Directory Access Protocol), ou outras formas de armazenamento.

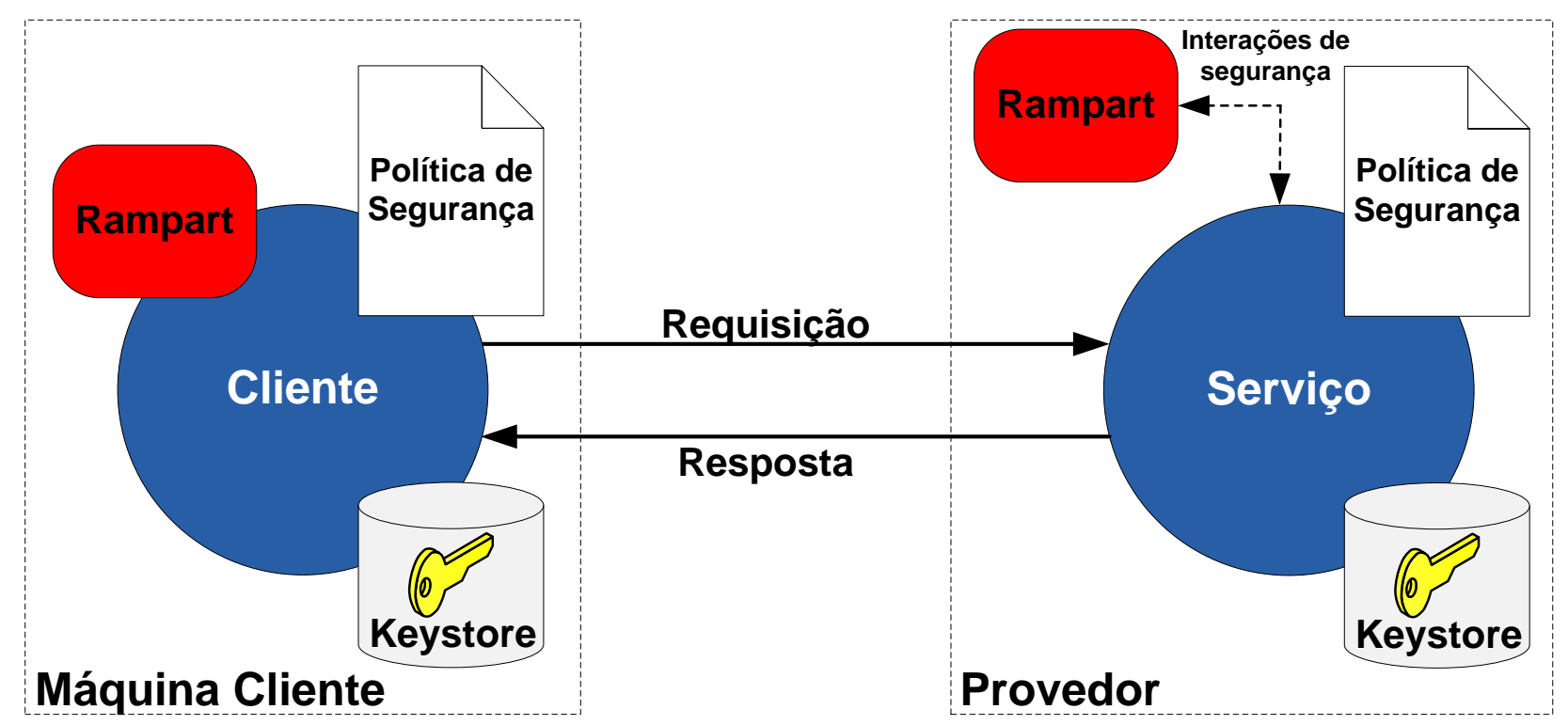

Figura 5.1: Arquitetura de segurança para Web services.

\subsection{Funcionamento da Arquitetura}

Após a apresentação da arquitetura de segurança para Web services e de seus componentes, pode-se agora compreender o seu funcionamento. Primeiramente, parte-se do pressuposto de que um contrato prévio foi realizado, onde provedor de serviços e cliente trocaram suas chaves públicas certificadas por uma autoridade certificadora confiável de forma segura. Sendo assim, o certificado contendo a chave pública do serviço já está armazenado no keystore do cliente, assim como o certificado contendo a chave pública do cliente já está armazenado no keystore do serviço, conforme ilustrado na Figura 5.2. 


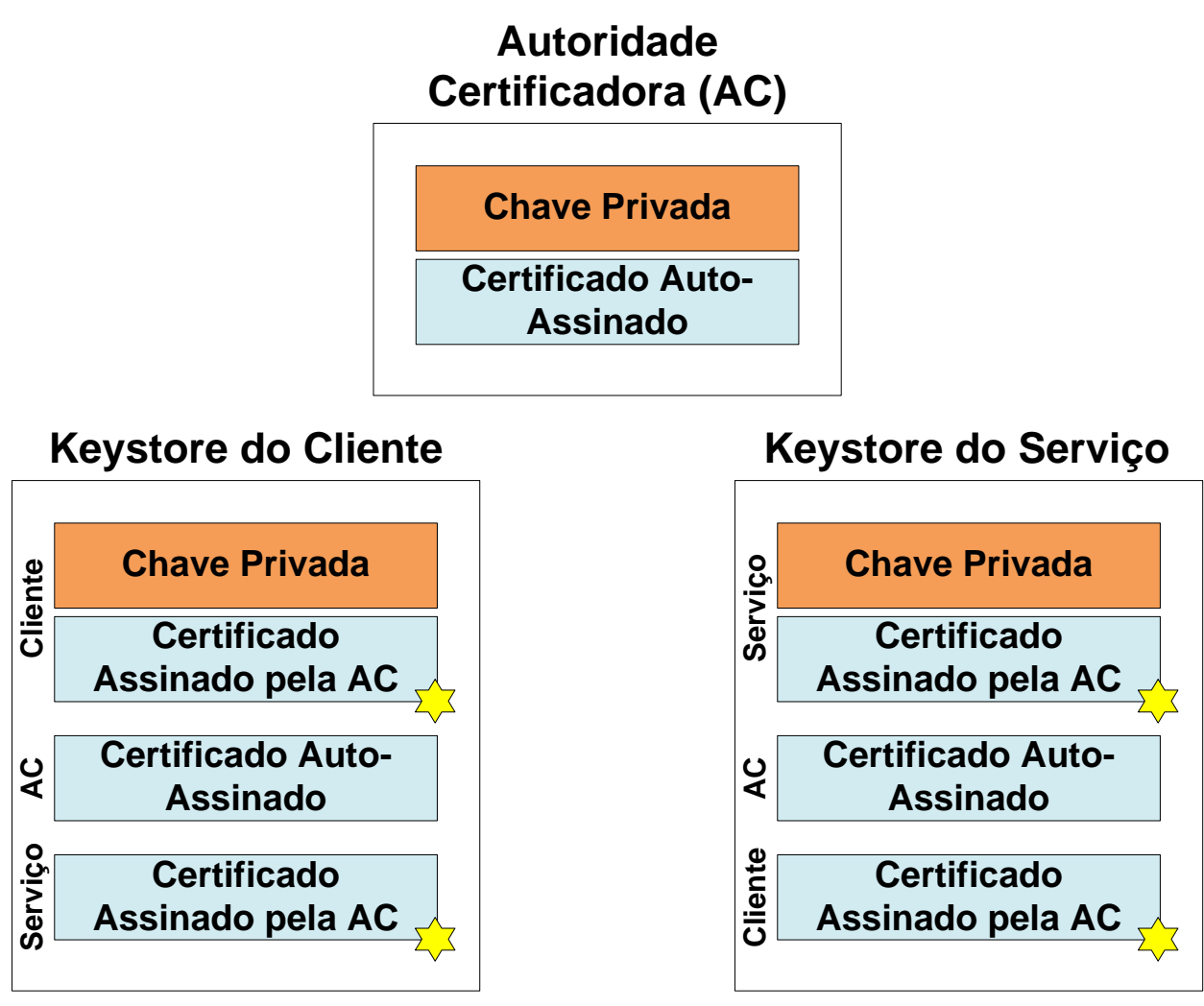

Figura 5.2: Autoridade certificadora e os keystores do cliente e do serviço - Adaptado de (Fernando, 2006).

Desta forma, são necessárias as seguintes etapas para a realização de uma requisição segura do cliente para o serviço, onde a mensagem SOAP é assinada e depois criptografada:

1. O cliente carrega a política de segurança, a qual contém as exigências de segurança que ele deve cumprir para realizar a requisição, tais como os algoritmos e tamanhos de chaves utilizados na criptografia e quais operações de segurança devem ser aplicadas na mensagem. Esta política será consultada pelo cliente durante todo este processo.

2. Neste exemplo, a política de segurança exige que seja realizada assinatura digital seguida de criptografia na mensagem SOAP. Então o cliente acessa seu keystore e recupera a sua chave privada para efetuar a assinatura de acordo com os algoritmos descritos na política.

3. Logo depois, o cliente acessa novamente seu keystore e recupera a chave pública do serviço. Esta chave pública será utilizada juntamente com um algoritmo de chave pública (especificado na política, por exemplo, o RSA) para criptografar uma chave única de sessão (chave secreta compartilhada) recém-gerada. Esta chave secreta em conjunto com um algoritmo de chave simétrica (também especificado na política, por exemplo, o 3DES ou o AES) são os responsáveis por criptografar os dados propriamente ditos que serão inseridos no corpo da mensagem SOAP. Após realizar a criptografia dos dados e ser criptografada com a chave pública do serviço, a chave secreta é então anexada ao cabeçalho da mensagem. A Figura 5.3 
ilustra todo este procedimento de criptografia, o qual é necessário para aumentar o desempenho quando se deseja transmitir uma grande quantidade de dados. Pois se fosse utilizada apenas criptografia de chave pública, tal transmissão seria muito lenta.

4. Finalmente, ocorre o envio da requisição segura, ou seja, uma mensagem SOAP protegida.

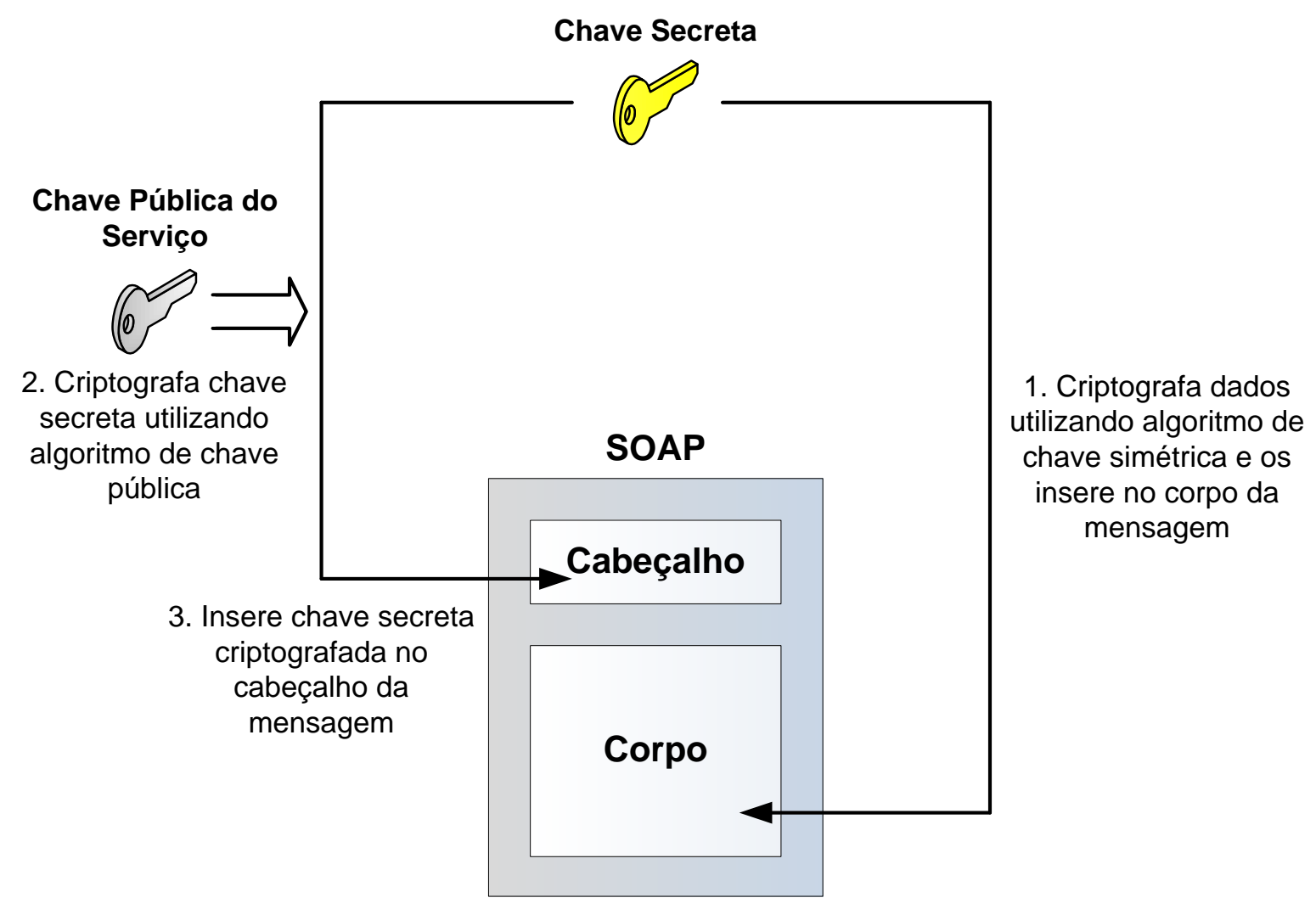

Figura 5.3: Procedimento de criptografia.

Posteriormente ao envio, para que o serviço seja capaz de processar a requisição devem ocorrer as seguintes etapas:

1. Logo após o recebimento, o serviço verifica se os requisitos existentes na política de segurança contida em sua WSDL foram satisfeitos, além de obter outras informações úteis durante todo este processo.

2. Se os requisitos de segurança foram satisfeitos, o serviço acessa o seu keystore e recupera sua chave privada. Esta é então empregada juntamente com um algoritmo de chave pública para decriptar a chave secreta contida no cabeçalho da mensagem SOAP. Em posse da chave secreta decriptada, pode-se agora utilizá-la em conjunto com um algoritmo de chave simétrica para decriptar os dados propriamente ditos que estão contidos no corpo da mensagem. A Figura 5.4 ilustra todo este procedimento. 
3. Em seguida, o serviço acessa novamente seu keystore e recupera a chave pública do cliente. Esta chave pública é então utilizada para verificar a autenticidade do cliente e, consequentemente, a integridade da mensagem. Ambas são providas pela assinatura digital e foram previamente elucidadas com detalhes na Seção 3.3.

4. Após a confirmação da autenticidade e da integridade, o serviço é capaz de processar a requisição.

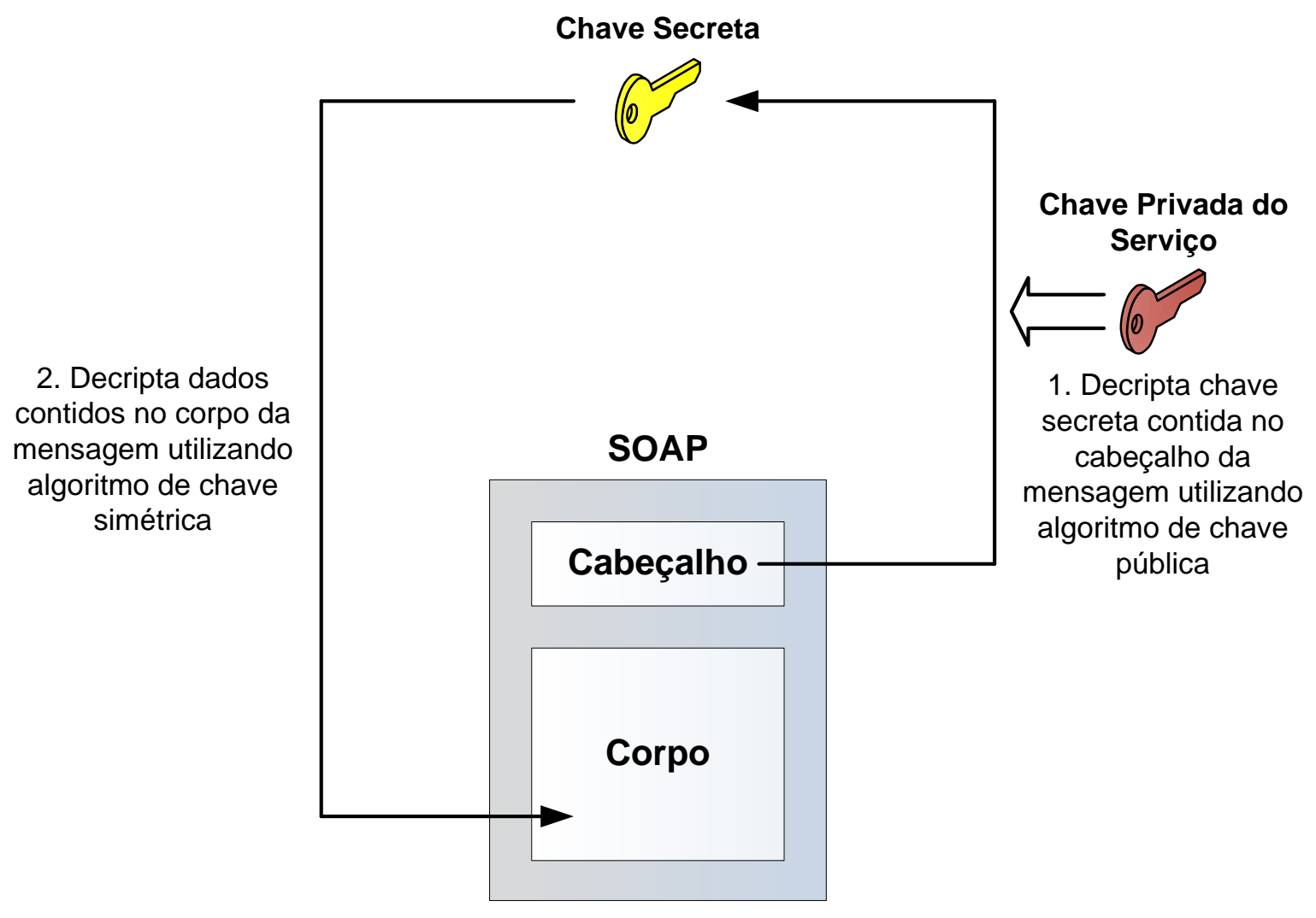

Figura 5.4: Procedimento de decriptação.

Para a emissão da resposta, o serviço deve refazer as etapas descritas para o cliente, substituindo o keystore do cliente por seu próprio keystore. Da mesma forma, o cliente deve refazer os passos descritos para o serviço para poder processar a resposta, substituindo o keystore do serviço pelo seu keystore.

A especificação desta arquitetura, bem como o uso da mesma, permitiu que os experimentos necessários para avaliar o desempenho dos mecanismos de segurança utilizados pudessem ser realizados de maneira mais próxima à efetuada em um sistema real. 


\subsection{Considerações Finais}

Neste capítulo, além dos trabalhos relacionados a este projeto, foram apresentados os componentes da arquitetura de segurança implantada para Web services. Logo após, foi explicado detalhadamente o funcionamento da mesma.

No próximo capítulo, são apresentados os resultados obtidos a partir da execução de Web services nesta arquitetura, a qual foi útil na realização da avaliação de desempenho proposta neste trabalho de mestrado. 


\section{Avaliação de Desempenho de Web Services Seguros}

A arquitetura de segurança para Web services desenvolvida e explicada anteriormente no Capítulo 5 permitiu a realização de experimentações em um ambiente mais próximo do real.

Assim, este capítulo apresenta a avaliação de desempenho realizada, a qual pode ser dividida em dois estudos de caso (Seções 6.1 e 6.2). No estudo de caso 1 foi realizada uma avaliação de desempenho de técnicas de segurança, como assinatura e criptografia. Enquanto no estudo de caso 2 foi realizada uma avaliação de desempenho mais complexa, envolvendo a variação de algoritmos criptográficos e dos tamanhos das chaves utilizadas. Em ambos os estudos de caso a segurança foi provida em nível de mensagem por meio de padrões de segurança para Web services (discutidos anteriormente no Capítulo 4), principalmente o WS-Security.

\subsection{Estudo de Caso 1}

Esta seção tem como objetivo apresentar a metodologia utilizada nos experimentos realizados ainda na fase inicial deste trabalho, bem como os resultados obtidos e suas análises. É importante ressaltar que os resultados descritos neste estudo de caso deram origem à publicação de dois artigos: (Rodrigues et al., 2010) e (Rodrigues et al., 2011). 


\subsubsection{Domínio da Aplicação}

No início deste trabalho desenvolveu-se um Web service que fornece a operação Add, a qual realiza a soma de dois números inteiros e retorna o resultado. Desta forma, o cliente envia ao Web service uma requisição contendo dois números inteiros, e este último efetua a soma e envia uma resposta com o valor obtido.

Tal aplicação foi escolhida devido à sua simplicidade, evitando o gasto de tempo com processamento não relacionado à avaliação de desempenho, tais como lógica de negócio e acesso ao banco de dados. Assim, torna-se mais fácil identificar a sobrecarga no desempenho causada pela troca de mensagens seguras utilizando WS-Security.

\subsubsection{Configuração do Ambiente de Testes}

Para que uma avaliação de desempenho de um sistema computacional seja considerada adequada, é indispensável detalhar todos os elementos de hardware e software utilizados e apurar como estes elementos podem influenciar no desempenho do sistema.

A infraestrutura computacional utilizada nestes experimentos está listada na Tabela 6.1. É possível observar que o ambiente de experimentos é constituído de duas máquinas distintas, porém com configurações de hardware idênticas. Em uma delas são hospedados e executados os Web services e na outra são executados os vários clientes. $\mathrm{O}$ ambiente físico para a execução dos experimentos é apresentado na Figura 6.1.

Tabela 6.1: Elementos de hardware.

\begin{tabular}{|c|c|c|}
\hline Componente & Quantidade & Características \\
\hline Provedor de serviços & 1 & $\begin{array}{r}\text { Processador Intel Core 2 Quad Q6600 2,4 GHz, 2 GB } \\
\text { de memória RAM, 120 GB de HD. }\end{array}$ \\
\hline Clientes & 1 & $\begin{array}{r}\text { Processador Intel Core 2 Quad Q6600 2,4 GHz, 2 GB } \\
\text { de memória RAM, 120 GB de HD. }\end{array}$ \\
\hline Switch & 1 & Gigabit 3Com Baseline 2916 \\
\hline
\end{tabular}

Os clientes e os serviços foram implementados utilizando a linguagem de programação Java. Adicionalmente, foram utilizados o motor de processamento SOAP Apache Axis2 1.4.1 (Apache, 2010), o servidor de aplicações Apache Tomcat 6.0.18 (Apache, 2011b) e o módulo de segurança Rampart 1.4 (Apache, 2011a) (explicado anteriormente na Seção 5.2).

\subsubsection{Planejamento dos Experimentos}

O planejamento de experimentos constitui uma etapa fundamental da avaliação de desempenho de sistemas computacionais. Nesta etapa são definidos os fatores ou as características que serão 


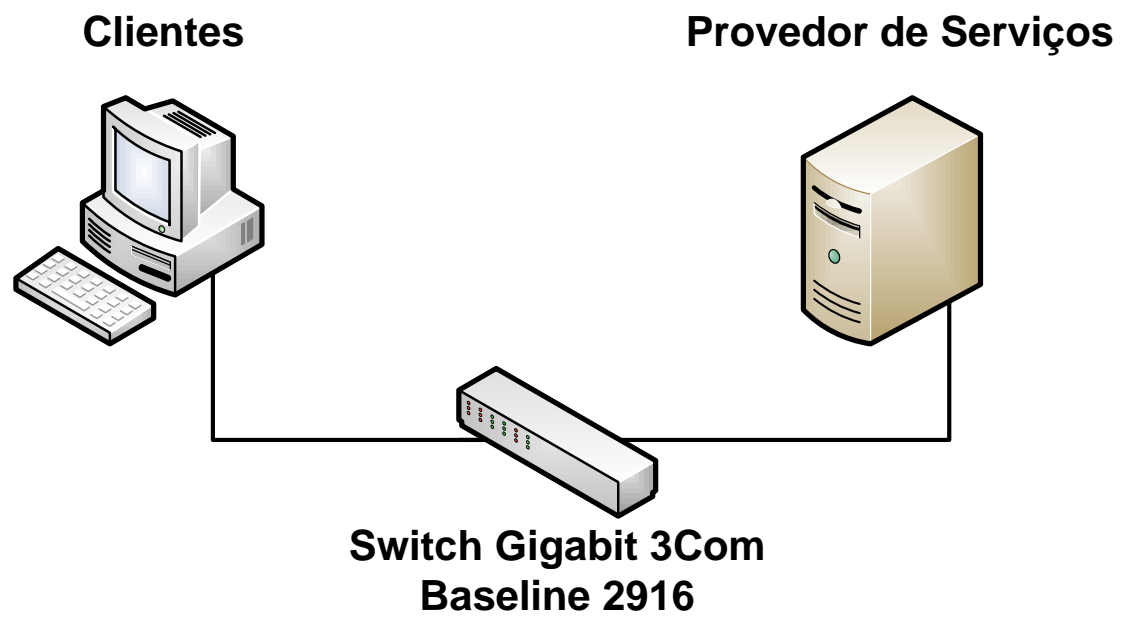

Figura 6.1: Ambiente para execução de experimentos.

avaliadas, examinando quais delas podem influenciar no desempenho de um determinado sistema computacional (Jain, 1991).

Além disso, é necessário determinar a quantidade de dados coletados, a quantidade de replicações dos experimentos e a interação entre os fatores. A definição da quantidade de replicações é imprescindível para obter validação estatística dos resultados. Existe uma variedade de termos empregados durante a etapa de projeto e análise de experimentos, dentre os quais se destacam (Jain, 1991):

- Variável de resposta: representa o resultado (saída) de um experimento. Normalmente, a variável de resposta é a medida de desempenho do sistema.

- Fatores: são as variáveis que afetam a variável de resposta do sistema.

- Níveis: são os valores que um determinado fator pode assumir.

- Interação: indica a dependência entre os fatores avaliados.

O planejamento de experimentos deve ser projetado para obter o máximo de dados coletados com uma quantidade mínima de experimentos. Existem diversas maneiras de realizar este planejamento e as mais utilizadas são (Jain, 1991):

- Planejamento simples: neste tipo de planejamento deve-se determinar uma configuração inicial, fixando cada um dos fatores e variando os demais. Desta forma, é possível averiguar a influência de cada fator no desempenho do sistema. O planejamento simples é muito utilizado e possui a vantagem de ser facilmente implementado, porém não permite analisar a interação entre os fatores.

- Planejamento fatorial completo: neste tipo de planejamento são utilizadas todas as combinações considerando todos os fatores e níveis. Assim, é possível avaliar todos os fatores, 
determinar o efeito de cada fator nos experimentos e verificar as interações entre eles. A principal desvantagem do fatorial completo é a grande quantidade de experimentos que devem ser realizados.

- Planejamento fatorial parcial: este tipo de planejamento consiste em aproveitar apenas uma fração dos experimentos definidos no planejamento fatorial completo. Desta maneira, considera-se apenas uma parte de todos os experimentos.

A avaliação de desempenho apresentada neste estudo de caso utiliza a abordagem do planejamento fatorial completo. Este planejamento foi escolhido devido à utilização de poucos fatores (três) com dois níveis cada.

Na Tabela 6.2 são apresentados os fatores e níveis considerados nestes experimentos. O primeiro fator diz respeito à criptografia e possui dois níveis que representam se a mensagem foi ou não criptografada. O segundo fator refere-se à assinatura digital e também possui dois níveis que indicam se a mensagem foi ou não assinada. E o terceiro fator definido foi a quantidade de clientes, o qual possui dois níveis (5 e 10). Na Tabela 6.3 estão sumarizados os experimentos realizados, de acordo com os fatores e níveis definidos.

Tabela 6.2: Fatores e níveis dos experimentos.

\begin{tabular}{|c|c|}
\hline Fatores & Níveis \\
\hline Criptografia & Sim \\
& Não \\
\hline Assinatura digital & Sim \\
& Não \\
\hline Clientes & 5 \\
& 10 \\
\hline
\end{tabular}

Tabela 6.3: Experimentos realizados.

\begin{tabular}{|c|c|c|}
\hline Exp. & Tipo & Clientes \\
\hline 1 & Sem segurança (criptografia: não; assinatura: não) & 5 \\
\hline 2 & Criptografia (criptografia: sim; assinatura: não) & 5 \\
\hline 3 & Assinatura (criptografia: não; assinatura: sim) & 5 \\
\hline 4 & Assinatura e criptografia (criptografia: sim; assinatura: sim) & 5 \\
\hline 5 & Sem segurança (criptografia: não; assinatura: não) & 10 \\
\hline 6 & Criptografia (criptografia: sim; assinatura: não) & 10 \\
\hline 7 & Assinatura (criptografia: não; assinatura: sim) & 10 \\
\hline 8 & Assinatura e criptografia (criptografia: sim; assinatura: sim) & 10 \\
\hline
\end{tabular}

Quando necessária, a criptografia é realizada utilizando o algoritmo RSA versão 1.5 (Kaliski, 1998) de 1024 bits para criptografia da chave secreta, juntamente com o algoritmo 3DES para 
criptografia do corpo da mensagem SOAP (conforme visto anteriormente na Seção 5.3). Da mesma forma, a assinatura digital é realizada utilizando o algoritmo RSA/SHA-1 (Weis, 2006) e ainda inclui um timestamp, isto é, um registro de data e hora na mensagem (útil para prevenir ataques do tipo repetição em um servidor).

Neste estudo de caso a variável de resposta escolhida foi o RTT (Round Trip Time), ou seja, o tempo gasto desde a requisição do cliente até o recebimento da resposta. O RTT é bastante utilizado quando se pretende avaliar Web services, como em (Juric et al., 2006) e (Alrouh e Ghinea, 2009). Também se optou por replicar 30 vezes cada experimento a fim de garantir uma validação estatística. Esta quantidade de replicações foi suficiente para obter intervalos de confiança relativamente baixos, permitindo assim uma comparação adequada dos resultados (Jain, 1991).

\subsubsection{Análise dos Resultados}

A análise dos resultados consistiu na observação das médias dos RTTs obtidos na execução dos experimentos. Para que houvesse uma validação estatística, foram calculados os desvios padrão e os intervalos de confiança de 95\% (Jain, 1991). Cabe ainda ressaltar que todos os gráficos de colunas apresentados nesta seção indicam valores em milissegundos no eixo Y.

Na Tabela 6.4 e no gráfico da Figura 6.2 são apresentados os resultados obtidos para 5 clientes. No gráfico é possível observar que os Web services sem mecanismos de segurança apresentam o melhor desempenho. Em relação aos Web services sem segurança, há um aumento nos RTTs de pouco mais de 10 vezes para os Web services que trocam mensagens criptografadas, de aproximadamente 5,5 vezes para os Web services que assinam as mensagens e de quase 11 vezes para os Web services que assinam e criptografam as mensagens. Como era esperado, os Web services que trocam mensagens assinadas e criptografadas exibem o pior desempenho. O fato dos Web services que assinam as mensagens serem mais rápidos do que os Web services que as criptografam confirma o que foi comentado anteriormente na Seção 3.3.1, onde é explicado que o processo de assinatura digital não assina o documento que deseja autenticar, mas sim um resumo da mensagem. Portanto, devido a menor quantidade de dados, é necessário um tempo menor para sua realização. Ainda em relação à Figura 6.2, pode-se notar que os intervalos de confiança do gráfico não se sobrepõem. Isto significa que se pode afirmar que os resultados obtidos são estatisticamente diferentes.

Tabela 6.4: RTT - 5 clientes.

\begin{tabular}{|c|c|c|c|}
\hline Tipo & RTT & Desv. Padrão & Int. Confiança \\
\hline Sem segurança & 283,68 & 38,02 & 13,61 \\
\hline Criptografia & 2861,31 & 78,00 & 27,91 \\
\hline Assinatura & 1547,76 & 62,13 & 22,23 \\
\hline Assinatura e criptografia & 3094,20 & 73,43 & 26,28 \\
\hline
\end{tabular}




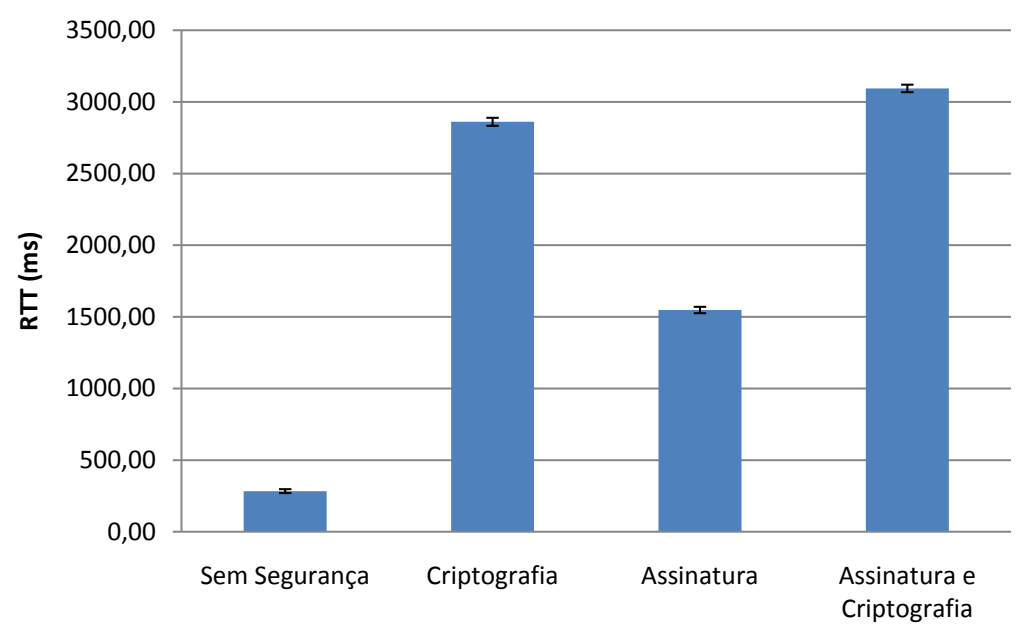

Figura 6.2: RTT - 5 clientes.

Os valores obtidos para 10 clientes são exibidos na Tabela 6.5 e no gráfico da Figura 6.3. Podese observar que os Web services com maior eficiência são aqueles desprovidos de qualquer tipo de segurança. Quando comparados com estes Web services, há uma degradação no desempenho de quase 6,5 vezes para os Web services que realizam assinatura digital, de cerca de 12 vezes para os Web services que realizam criptografia e de aproximadamente 12,5 vezes para Web services que realizam os dois procedimentos de segurança, sendo estes últimos os mais ineficientes. Com 10 clientes, novamente é apontado o melhor desempenho dos Web services que proveem assinatura em relação aos que proveem criptografia, justificando este comportamento da mesma forma que na análise anterior com 5 clientes. Da mesma forma, esta análise mostra que novamente não ocorre sobreposição dos intervalos de confiança, ou seja, os resultados obtidos são estatisticamente diferentes.

Tabela 6.5: RTT - 10 clientes.

\begin{tabular}{|c|c|c|c|}
\hline Tipo & RTT & Desv. Padrão & Int. Confiança \\
\hline Sem segurança & 482,59 & 36,05 & 12,90 \\
\hline Criptografia & 5877,78 & 138,38 & 49,52 \\
\hline Assinatura & 3100,42 & 90,63 & 32,43 \\
\hline Assinatura e criptografia & 6038,10 & 129,20 & 46,23 \\
\hline
\end{tabular}

Nos dois casos (5 e 10 clientes), a queda no desempenho dos Web services seguros ocorre devido à utilização do padrão WS-Security. Este padrão introduz uma sobrecarga significativa nas mensagens SOAP, devido ao aumento do tamanho da mensagem e do custo inerente das operações de criptografia e assinatura digital em mensagens XML.

Cabe ressaltar que não somente a inclusão de segurança com WS-Security, mas também o número de clientes implica no aumento dos RTTs e, consequentemente, na degradação do desempenho do sistema. Outra observação importante é o fato de que o aumento da quantidade de clientes 


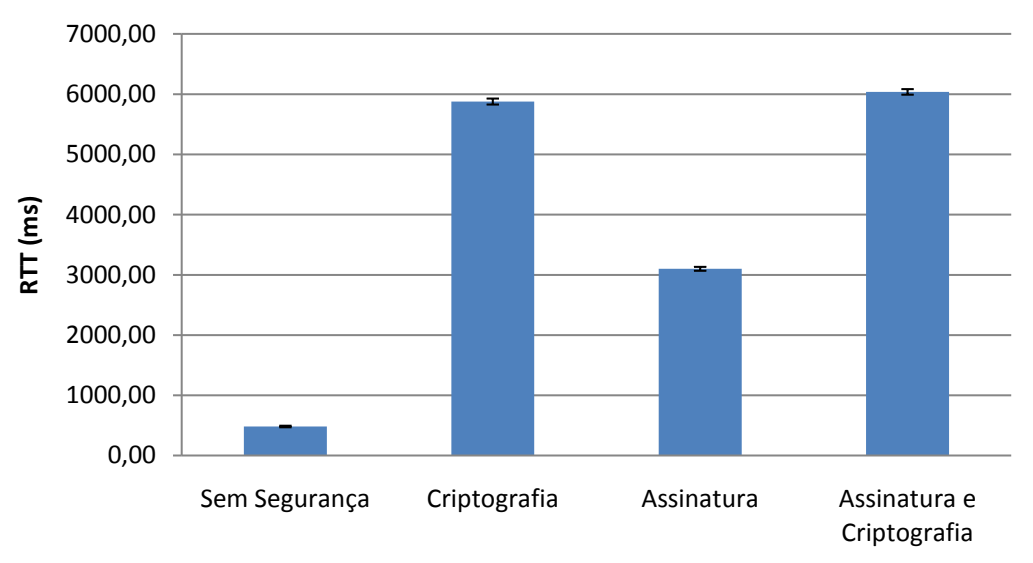

Figura 6.3: RTT - 10 clientes.

causa maior degradação no desempenho quando há algum mecanismo de segurança aplicado aos Web services.

Os resultados exibidos mostram a existência de uma considerável redução no desempenho quando se utiliza o WS-Security para prover segurança aos Web services. Portanto, é necessário decidir cuidadosamente quais medidas de segurança devem ser adotadas neste tipo de sistema. Para aplicações que exigem um equilíbrio entre desempenho e segurança, é recomendado que as mensagem trocadas sejam as menores possíveis. Outra alternativa para diminuir a sobrecarga é criptografar/assinar apenas as partes mais sensíveis da mensagem, ou seja, aquelas partes que realmente importam.

\section{Análise da Influência dos Fatores}

O objetivo desta seção é apresentar uma análise utilizando modelos de regressão que possibilitam quantificar a influência de cada fator na execução dos experimentos. A análise de regressão permite estimar ou predizer uma variável aleatória em função de outras variáveis. Neste tipo de análise, a variável estimada é denominada variável de resposta, enquanto as variáveis utilizadas para estimá-la são denominadas de fatores (Jain, 1991). Resumidamente, esta etapa é responsável por determinar os fatores que mais influenciaram estes resultados, além de averiguar se a interação entre os fatores causou alguma influência significante.

O gráfico ilustrado na Figura 6.4 apresenta a porcentagem de influência de cada fator, onde os fatores são representados pelas letras A, B e C, e as interações entre os fatores são representadas pelas combinações destas letras. É possível notar no gráfico que o fator criptografia (A) possui a maior influência, sendo esta de 58\%. O segundo fator mais influente é a quantidade de clientes (C) com $22 \%$, seguido pelo fator assinatura (B) com $7 \%$ de influência. A interação entre os fatores criptografia e clientes (AC) representa uma influência de 7\%, enquanto a interação entre criptografia e assinatura $(A B)$ possui $4 \%$ de influência. Finalmente, as interações entre os fatores assinatura e clientes (BC) e criptografia, assinatura e clientes (ABC) não apresentam influência significativa, permanecendo na faixa de $1 \%$. 


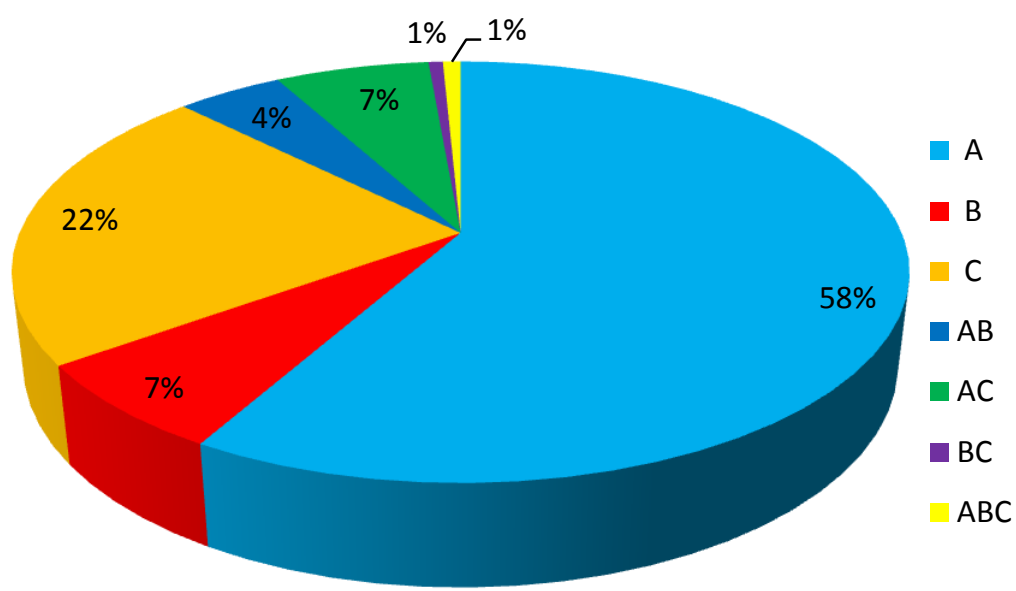

A: criptografia B: assinatura C: clientes

Figura 6.4: Influência dos fatores.

Mais uma vez pode ser observado que o fator de maior influência é a criptografia. Desta forma, torna-se evidente a importância de avaliar o impacto e a influência causada por outros algoritmos de criptografia distintos com tamanhos de chaves diferentes. É bem conhecido que o tamanho da chave determina, levando-se em conta também o algoritmo criptográfico em questão, o nível de segurança da criptografia, ou seja, a dificuldade em se descobrir a chave. Isto significa que um estudo mais detalhado do tipo de algoritmo e da chave associada pode possibilitar uma escolha consciente de um ou de outro algoritmo, bem como a escolha do tamanho da chave, dependendo do grau de segurança esperado combinado ao desempenho desejado. Esta avaliação compõe um segundo estudo de caso que será descrito posteriormente na Seção 6.2.

\section{Comparação WS-Security vs. SSL}

Para efeito comparativo, foram realizados testes para coleta de dados com Web services que utilizam SSL para garantir segurança na camada de transporte. É importante ressaltar que o SSL é uma das técnicas mais utilizadas para prover segurança. E apesar de possuir um desempenho relativamente melhor quando comparado aos mecanismos de segurança do WS-Security, conforme exibido na Tabela 6.6 e na Figura 6.5, o SSL não garante segurança fim-a-fim, apenas ponto-aponto (como explicado anteriormente na Seção 1.1). Portanto, tal técnica é pouco recomendada para Web services.

Tabela 6.6: RTT - Web services que utilizam SSL.

\begin{tabular}{|c|c|c|c|}
\hline Clientes & RTT & Desv. Padrão & Int. Confiança \\
\hline 5 & 2777,17 & 56,15 & 20,09 \\
\hline 10 & 5723,85 & 131,00 & 46,88 \\
\hline
\end{tabular}




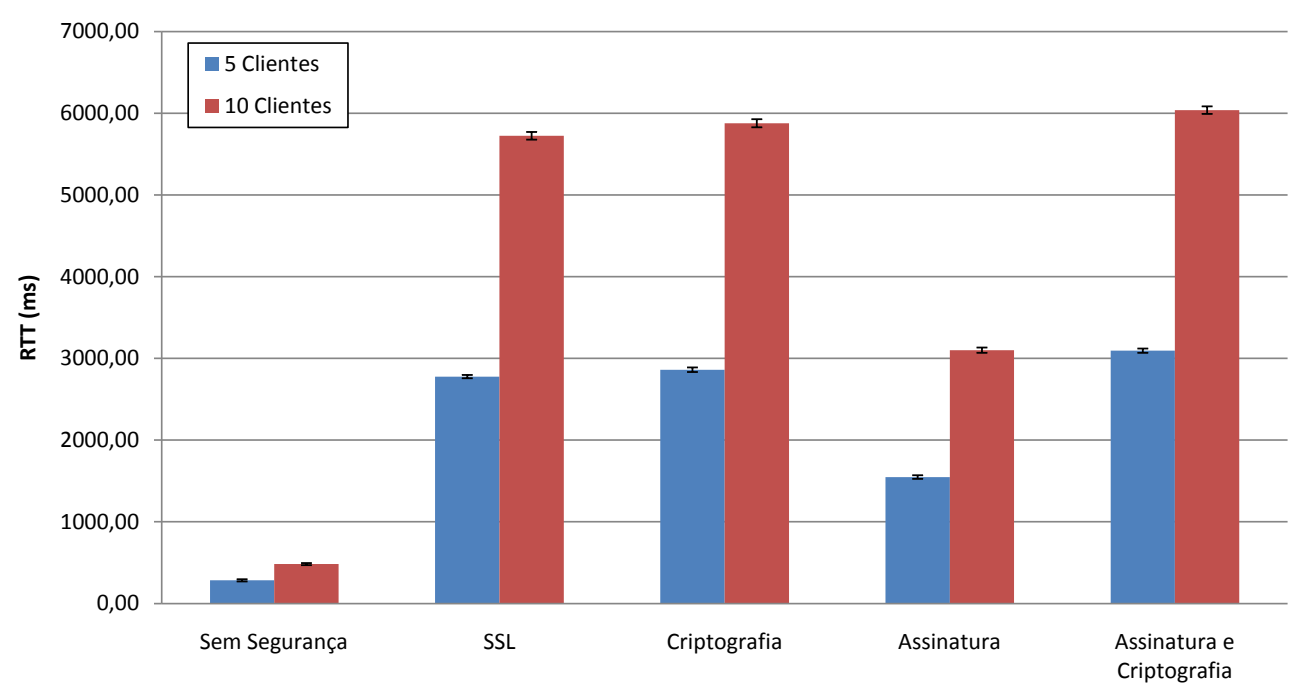

Figura 6.5: WS-Security vs. SSL.

\subsection{Estudo de Caso 2}

Os resultados obtidos na Seção 6.1 caracterizaram-se como um estudo inicial do impacto de cada um dos fatores no desempenho do sistema como um todo, demonstrando que segurança e desempenho são fatores relevantes para aplicações SOA e que a inclusão de um deles leva à degradação do outro.

Sendo assim, o estudo de caso contido nesta seção possui a finalidade de avaliar o desempenho da criptografia e assinatura digital em mensagens SOAP, realizando a variação dos algoritmos criptográficos, assim como o comprimento de suas chaves.

\subsubsection{Domínio da Aplicação}

Para a realização dos experimentos finais, optou-se por desenvolver um Web service que tivesse a funcionalidade de uma aplicação real, possibilitando assim averiguar a sobrecarga causada pelos diferentes algoritmos criptográficos neste tipo de aplicação.

Deste modo, em um evento relacionado à área de segurança, houve um primeiro contato com um funcionário do Ministério da Justiça, o qual apresentou uma aplicação real para um problema real. Este problema consistia justamente na necessidade de transmissão segura de informações via Web services entre diversos órgãos federais. Após o contato inicial, foram obtidas maiores informações acerca do assunto. Resumidamente, foi criado um grupo de trabalho, o GT Interoperabilidade, visando realizar provas de conceito empregando Web services, com o objetivo de desenvolver uma infraestrutura que possibilitasse a troca segura de dados entre os órgãos federais, tais como Ministério da Justiça, Controladoria Geral da União, Procuradoria Geral da República, Câmara dos Deputados, Senado Federal, dentre outros.

Neste contexto, e de maneira independente do grupo de trabalho citado, foram estudadas as características do protótipo desenvolvido na prova de conceito. Assim, para a realização desta ava- 
liação de desempenho decidiu-se implementar um Web service que realizasse transmissão segura de documentos com tamanho médio de 1,7 MB. Isto é, o cliente envia uma requisição contendo um documento e recebe outro documento de mesmo tamanho. Tanto a requisição quanto a resposta são criptografadas e assinadas digitalmente.

\subsubsection{Configuração do Ambiente de Testes}

Similarmente à Seção 6.1.2, esta seção visa especificar os elementos de hardware e software empregados na avaliação de desempenho.

Na Tabela 6.7 está listada a infraestrutura computacional utilizada nos experimentos executados. Neste caso o ambiente físico para execução dos experimentos é composto por quatro máquinas distintas, mas que possuem configurações idênticas. Uma destas máquinas é utilizada como provedor de serviços e as demais são utilizadas como clientes, conforme ilustrado na Figura 6.6.

Tabela 6.7: Elementos de hardware.

\begin{tabular}{|c|c|c|}
\hline Componente & Quantidade & Características \\
\hline Provedor de serviços & 1 & $\begin{array}{r}\text { Processador Intel Core 2 Quad Q6600 2,4 GHz, 2 GB } \\
\text { de memória RAM, 120 GB de HD. }\end{array}$ \\
\hline Clientes & 3 & $\begin{array}{r}\text { Processador Intel Core 2 Quad Q6600 2,4 GHz, 2 GB } \\
\text { de memória RAM, 120 GB de HD. }\end{array}$ \\
\hline Switch & 1 & Gigabit 3Com Baseline 2916 \\
\hline
\end{tabular}

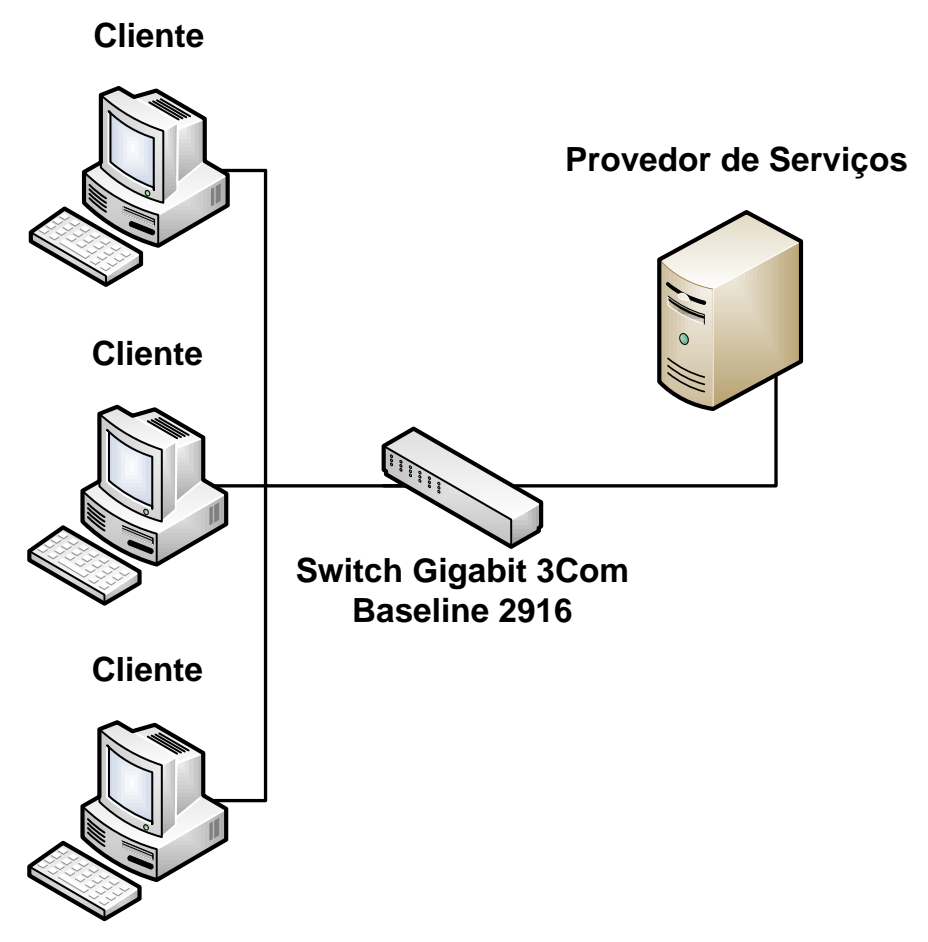

Figura 6.6: Ambiente para execução de experimentos. 
A implementação dos serviços e dos clientes foi realizada utilizando a linguagem de programação Java. Além disso, utilizou-se o servidor de aplicações Apache Tomcat 7.0.6 (Apache, 2011b), o motor de processamento SOAP Apache Axis2 1.5.4 (Apache, 2010) e o módulo de segurança Rampart 1.5.1 (Apache, 2011a) (comentado previamente na Seção 5.2).

\subsubsection{Planejamento dos Experimentos}

De modo análogo à Seção 6.1.3 do estudo de caso anterior, a avaliação de desempenho apresentada neste estudo de caso também emprega a abordagem do fatorial completo, pois são definidos apenas três fatores com no máximo três níveis cada. Os fatores e níveis utilizados são exibidos na Tabela 6.8. O primeiro fator considerado é o algoritmo de chave simétrica, utilizado para criptografar os dados da mensagem, e possui três níveis: AES 192, AES 256 e 3DES. O segundo fator refere-se ao algoritmo de chave pública, empregado na criptografia da chave secreta (chave de sessão) (explicado anteriormente na Seção 5.3), o qual possui dois níveis: RSA-OAEP (Housley, 2003) e RSA 1.5 (Kaliski, 1998), ambos com chaves de 1024 bits. E por fim, o terceiro fator é definido como a quantidade de clientes, novamente com dois níveis: 1 e 3. Estas quantidades de clientes foram escolhidas com base nas características definidas pelo GT Interoperabilidade, o qual estima, durante a etapa de protótipo, esta faixa de clientes por dia. Os experimentos realizados foram elaborados de acordo com a especificação dos fatores e níveis, e são apresentados na Tabela 6.9.

Tabela 6.8: Fatores e níveis dos experimentos.

\begin{tabular}{|c|c|}
\hline Fatores & Níveis \\
\hline Algoritmo de chave simétrica & AES 192 \\
& AES 256 \\
& 3DES \\
\hline Algoritmo de chave pública & RSA-OAEP \\
& RSA 1.5 \\
\hline Clientes & 1 \\
& 3 \\
\hline
\end{tabular}

Neste ponto é necessário um esclarecimento sobre os algoritmos RSA 1.5 e RSA-OAEP. Enquanto o primeiro é uma implementação do algoritmo RSA, o segundo requer uma melhor explicação. Basicamente, o RSA é vulnerável ao ataque de texto cifrado escolhido. Neste tipo de ataque, o criptoanalista possui uma grande quantidade de mensagens e seus equivalentes criptografados e, além disso, pode produzir uma mensagem criptografada específica para ser decriptada e obter o resultado gerado, com a finalidade de deduzir as chaves utilizadas. Visando impedir este tipo de ataque, a RSA Security Inc., um fornecedor de RSA e antigo mantenedor da sua patente, aconselha modificar o texto aberto por meio de um procedimento denominado preenchimento ideal de criptografia assimétrica (Optimal Asymmetric Encryption Padding - OAEP) (Liu e Li, 2008) (Boldyreva 
Tabela 6.9: Experimentos realizados.

\begin{tabular}{|c|c|c|}
\hline Exp. & Tipo & Clientes \\
\hline 1 & AES192 - RSA-OAEP & 1 \\
\hline 2 & AES256 - RSA-OAEP & 1 \\
\hline 3 & 3DES - RSA-OAEP & 1 \\
\hline 4 & AES192 - RSA1.5 & 1 \\
\hline 5 & AES256 - RSA1.5 & 1 \\
\hline 6 & 3DES - RSA1.5 & 1 \\
\hline 7 & AES192 - RSA-OAEP & 3 \\
\hline 8 & AES256 - RSA-OAEP & 3 \\
\hline 9 & 3DES - RSA-OAEP & 3 \\
\hline 10 & AES192 - RSA1.5 & 3 \\
\hline 11 & AES256 - RSA1.5 & 3 \\
\hline 12 & 3DES - RSA1.5 & 3 \\
\hline
\end{tabular}

et al., 2010). Uma explicação completa sobre o ataque citado e o OAEP pode ser encontrada em (Bellare e Rogaway, 1995) e (Pointcheval, 2002).

É importante destacar ainda a inclusão de um timestamp na mensagem e a utilização do algoritmo RSA/SHA-1 em todos os experimentos para a realização da assinatura digital. Inicialmente, pretendia-se que a função de hash também fosse considerada um fator nesta avaliação de desempenho. Assim, os níveis deste fator seriam os algoritmos SHA-1 e SHA-256. Contudo, durante a pesquisa descobriu-se que a implementação do SHA-256 no módulo de segurança Rampart não funciona corretamente, conforme pode ser visto em (Apache, 2009). A própria Apache considera este um defeito com alta prioridade, mas que desde 2009 está sem resolução, o que impediu a avaliação deste fator neste trabalho.

Retornando ao planejamento de experimentos, a variável de resposta utilizada neste estudo de caso foi novamente o RTT. Além disso, cada experimento foi replicado 30 vezes visando assegurar uma validação estatística. Os intervalos de confiança mantiveram-se baixos com a quantidade de replicações realizadas, possibilitando que os resultados fossem comparados adequadamente (Jain, 1991).

\subsubsection{Análise dos Resultados}

Para a realização da análise dos resultados contida nesta seção, foram observadas as médias dos RTTs coletados na execução dos experimentos. Foram calculados os desvios padrão e os intervalos de confiança com nível de 95\% para possibilitar uma avaliação estatística apropriada (Jain, 1991). Além disso, todos os gráficos de colunas apresentados a seguir indicam valores em milissegundos no eixo Y. 


\section{Comparação entre Algoritmos de Chave Simétrica}

Esta seção apresenta algumas análises sob o ponto de vista dos algoritmos de chave simétrica avaliados. Na Tabela 6.10 e no gráfico da Figura 6.7 são ilustrados os resultados coletados com apenas 1 cliente, comparando os algoritmos de chave simétrica combinados com o algoritmo de chave pública RSA-OAEP. Enquanto na Tabela 6.11 e no gráfico da Figura 6.8 são apresentados os resultados para comparação entre os algoritmos de chave simétrica em combinação com o algoritmo de chave pública RSA 1.5, também com 1 cliente. Nos dois casos, é possível notar que o Web service utilizando o algoritmo AES 192 obtém o melhor desempenho em termos de tempo, com uma ligeira vantagem em relação ao AES 256. Neste contexto, o pior desempenho pertence ao algoritmo 3DES. No caso do RSA-OAEP, o 3DES tem um acréscimo no RTT de 10,76\% quando comparado ao AES 192, enquanto no caso do RSA 1.5 este acréscimo em relação ao AES 192 é de 10,92\%. Os intervalos de confiança exibidos para os algoritmos AES 192 e AES 256 estão sobrepostos em ambos os casos, indicando que não há diferença estatística entre eles. Portanto, estes resultados levam a concluir que em termos de segurança e rapidez, a melhor escolha neste contexto é o AES 256.

Tabela 6.10: Algoritmos de chave simétrica com RSA-OAEP (1 cliente).

\begin{tabular}{|c|c|c|c|}
\hline Tipo & RTT & Desv. Padrão & Int. Confiança \\
\hline AES192 - RSA-OAEP & 4986,67 & 117,87 & 42,18 \\
\hline AES256 - RSA-OAEP & 5015,70 & 163,33 & 58,45 \\
\hline 3DES - RSA-OAEP & 5523,23 & 129,10 & 46,20 \\
\hline
\end{tabular}

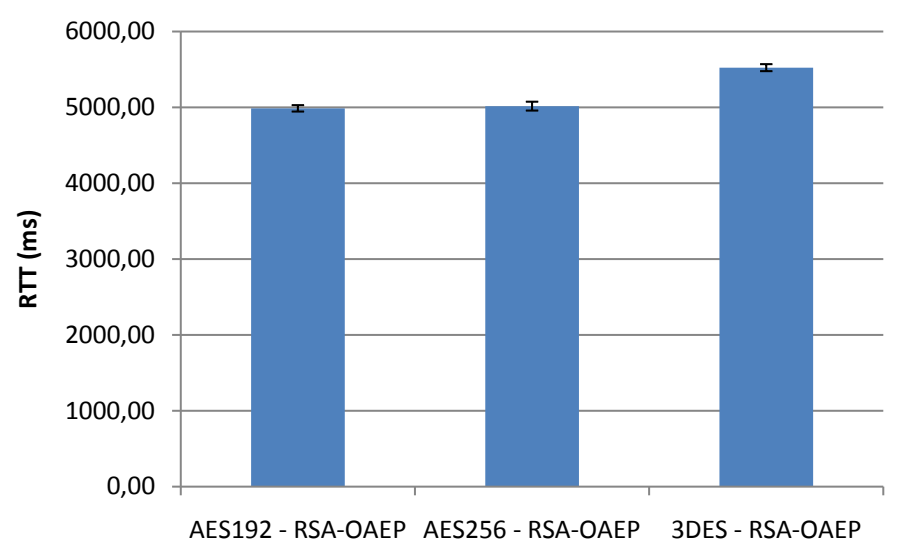

Figura 6.7: Algoritmos de chave simétrica com RSA-OAEP (1 cliente).

Com relação aos resultados obtidos com 3 clientes, na Tabela 6.12 e no gráfico da Figura 6.9 são exibidos os valores para comparação entre os algoritmos de chave simétrica em conjunto com o algoritmo RSA-OAEP e na Tabela 6.13 e no gráfico da Figura 6.10 são apresentados os valores comparando os algoritmos de chave simétrica combinados com o algoritmo RSA 1.5. Em ambos os casos, os resultados evidenciam que o menor RTT pertence ao Web service que emprega o 
Tabela 6.11: Algoritmos de chave simétrica com RSA 1.5 (1 cliente).

\begin{tabular}{|c|c|c|c|}
\hline Tipo & RTT & Desv. Padrão & Int. Confiança \\
\hline AES192 - RSA1.5 & 4998,93 & 147,43 & 52,76 \\
\hline AES256 - RSA1.5 & 5025,37 & 131,79 & 47,16 \\
\hline 3DES - RSA1.5 & 5545,13 & 105,63 & 37,80 \\
\hline
\end{tabular}

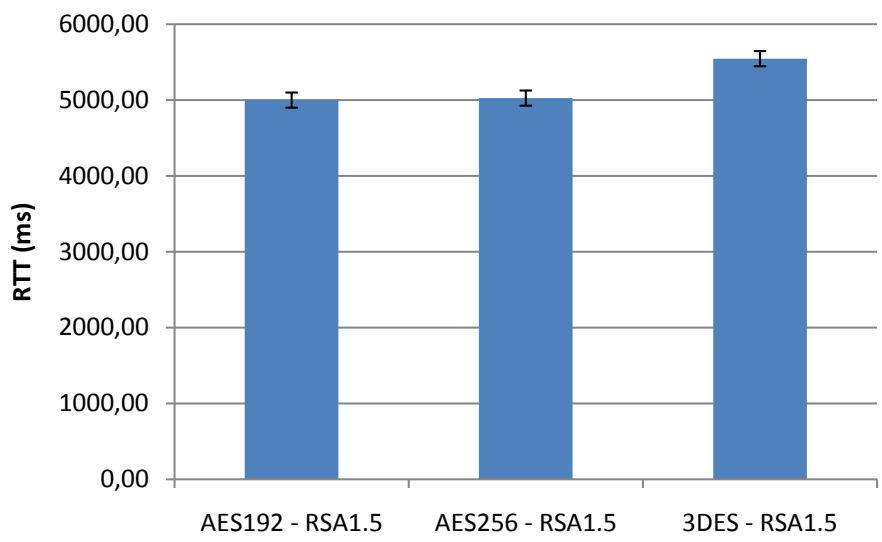

Figura 6.8: Algoritmos de chave simétrica com RSA 1.5 (1 cliente).

algoritmo AES 192. O AES 256 apresenta o segundo menor RTT, com um aumento em relação ao AES 192 de 4,47\% no caso do RSA-OAEP e de 4,26\% no caso do RSA 1.5. O pior desempenho em ambos os casos está relacionado ao 3DES. Quando comparado ao AES 192, há uma piora no RTT de $14,59 \%$ e de $15,12 \%$ nos casos do RSA-OAEP e do RSA 1.5, respectivamente. Observa-se ainda nos gráficos de ambos os casos que os intervalos de confiança não se encontram sobrepostos, significando que os resultados são estatisticamente diferentes.

Tabela 6.12: Algoritmos de chave simétrica com RSA-OAEP (3 clientes).

\begin{tabular}{|c|c|c|c|}
\hline Tipo & RTT & Desv. Padrão & Int. Confiança \\
\hline AES192 - RSA-OAEP & 5072,09 & 54,05 & 19,34 \\
\hline AES256 - RSA-OAEP & 5298,91 & 95,16 & 34,05 \\
\hline 3DES - RSA-OAEP & 5811,87 & 179,98 & 64,40 \\
\hline
\end{tabular}

Tabela 6.13: Algoritmos de chave simétrica com RSA 1.5 (3 clientes).

\begin{tabular}{|c|c|c|c|}
\hline Tipo & RTT & Desv. Padrão & Int. Confiança \\
\hline AES192 - RSA1.5 & 5109,30 & 108,20 & 38,72 \\
\hline AES256 - RSA1.5 & 5326,71 & 124,12 & 44,42 \\
\hline 3DES - RSA1.5 & 5881,92 & 186,28 & 66,66 \\
\hline
\end{tabular}

É possível notar alguns comportamentos similares nos casos apresentados. O 3DES sempre se apresenta como o algoritmo de chave simétrica mais ineficiente em todos os casos analisados. Tal 


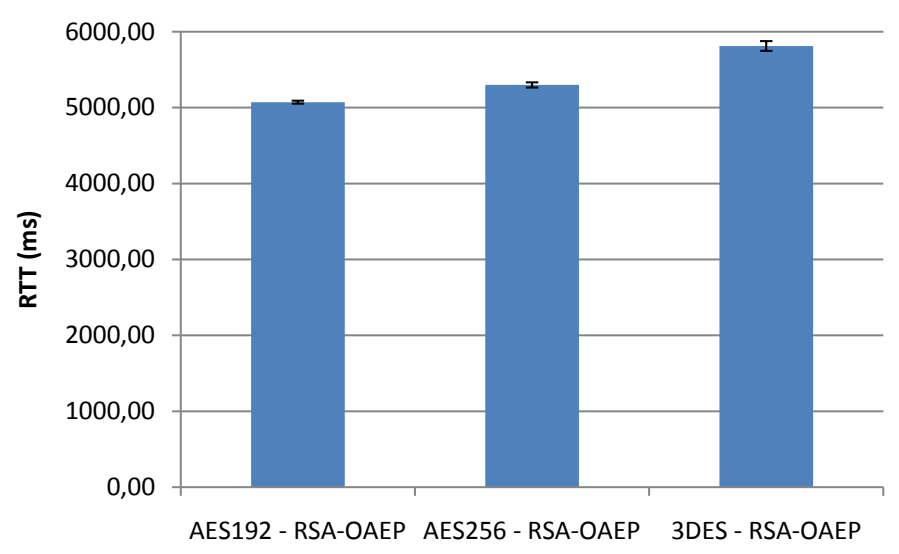

Figura 6.9: Algoritmos de chave simétrica com RSA-OAEP (3 clientes).

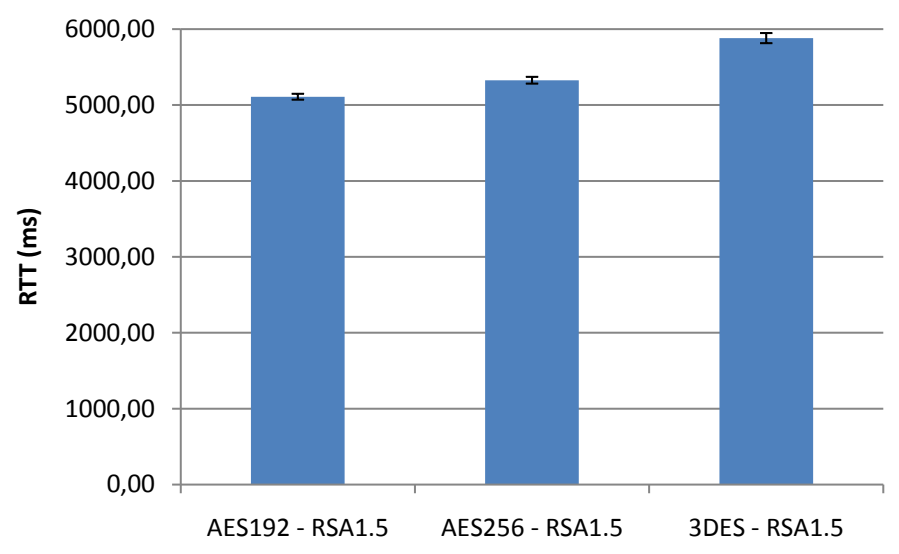

Figura 6.10: Algoritmos de chave simétrica com RSA 1.5 (3 clientes).

ineficiência justifica-se pelo fato da execução do algoritmo DES por três vezes consecutivas (conforme explicado anteriormente na Seção 3.2.1), tornando-o lento em relação a outros algoritmos de chave simétrica.

\section{Comparação entre Algoritmos de Chave Pública}

A análise contida nesta seção apresenta os resultados sob o ponto de vista dos algoritmos de chave pública. Com apenas 1 cliente, na Tabela 6.14 e no gráfico da Figura 6.11 podem ser vistos os resultados obtidos comparando os algoritmos de chave pública em conjunto com o AES 192, na Tabela 6.15 e no gráfico da Figura 6.12 estão os resultados comparando os algoritmos de chave pública combinados com o AES 256 e finalmente na Tabela 6.16 e no gráfico da Figura 6.13 encontram-se os valores obtidos para a comparação dos algoritmos de chave pública em conjunto com o 3DES. Nestes três casos é possível notar um comportamento semelhante, onde a utilização do RSA-OAEP exibe o melhor desempenho, porém com pequena diferença em relação ao RSA 1.5. Com relação aos intervalos de confiança, pode-se observar a sobreposição dos mesmos, apontando que não existe diferença estatística entre eles.

Os valores obtidos nos experimentos com 3 clientes estão representados nas tabelas e figuras que seguem. Na Tabela 6.17 e no gráfico da Figura 6.14 são apresentados os resultados para com- 
Tabela 6.14: Algoritmos de chave pública com AES 192 (1 cliente).

\begin{tabular}{|c|c|c|c|}
\hline Tipo & RTT & Desv. Padrão & Int. Confiança \\
\hline AES192 - RSA-OAEP & 4986,67 & 117,87 & 42,18 \\
\hline AES192 - RSA1.5 & 4998,93 & 147,43 & 52,76 \\
\hline
\end{tabular}

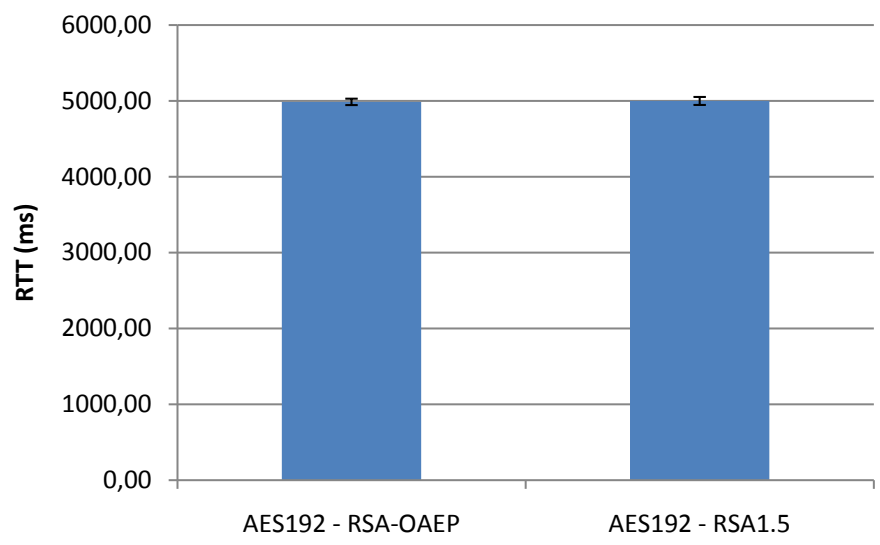

Figura 6.11: Algoritmos de chave pública com AES 192 (1 cliente).

Tabela 6.15: Algoritmos de chave pública com AES 256 (1 cliente).

\begin{tabular}{|c|c|c|c|}
\hline Tipo & RTT & Desv. Padrão & Int. Confiança \\
\hline AES256 - RSA-OAEP & 5015,70 & 163,33 & 58,45 \\
\hline AES256 - RSA1.5 & 5025,37 & 131,79 & 47,16 \\
\hline
\end{tabular}

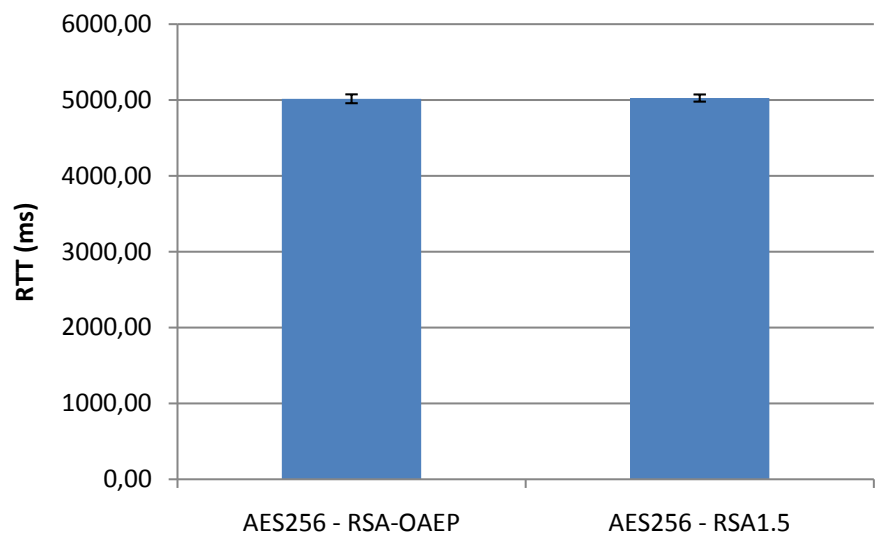

Figura 6.12: Algoritmos de chave pública com AES 256 (1 cliente).

Tabela 6.16: Algoritmos de chave pública com 3DES (1 cliente).

\begin{tabular}{|c|c|c|c|}
\hline Tipo & RTT & Desv. Padrão & Int. Confiança \\
\hline 3DES - RSA-OAEP & 5523,23 & 129,10 & 46,20 \\
\hline 3DES - RSA1.5 & 5545,13 & 105,63 & 37,80 \\
\hline
\end{tabular}

paração dos algoritmos de chave pública juntamente com o AES 192, na Tabela 6.18 e no gráfico da Figura 6.15 são apresentados os resultados comparando os algoritmos de chave pública com o AES 


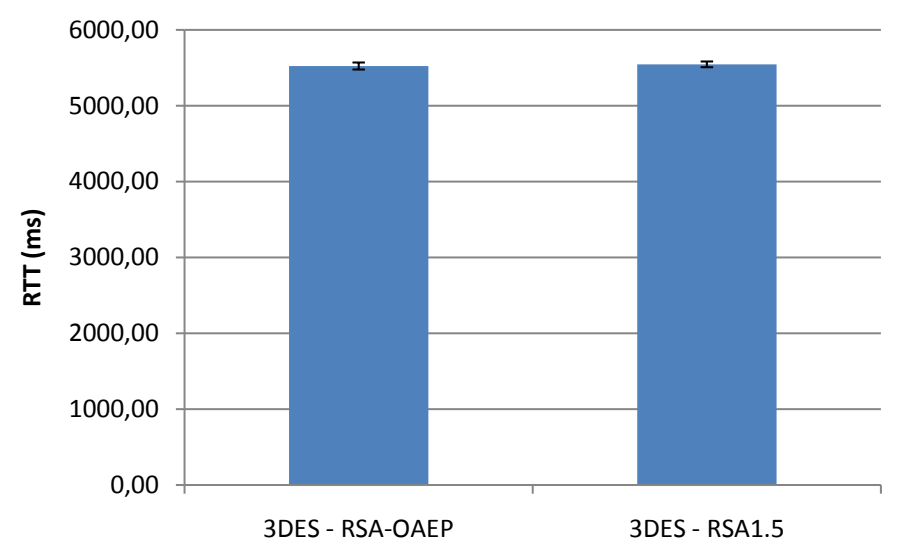

Figura 6.13: Algoritmos de chave pública com 3DES (1 cliente).

256 e, por fim, na Tabela 6.19 e no gráfico da Figura 6.16 estão os valores para comparação dos algoritmos de chave pública combinados com o 3DES. Novamente é possível encontrar um padrão no comportamento destes casos, onde o algoritmo RSA-OAEP possui o menor RTT. No entanto, com 3 clientes a diferença entre o RSA-OAEP e o RSA 1.5 aumenta em relação aos experimentos com 1 cliente. Pode-se observar pelas tabelas que os intervalos de confiança se sobrepõem apenas na comparação entre o RSA-OAEP e o RSA 1.5 combinados com o AES 256.

Tabela 6.17: Algoritmos de chave pública com AES 192 (3 clientes).

\begin{tabular}{|c|c|c|c|}
\hline Tipo & RTT & Desv. Padrão & Int. Confiança \\
\hline AES192 - RSA-OAEP & 5072,09 & 54,05 & 19,34 \\
\hline AES192 - RSA1.5 & 5109,30 & 108,20 & 38,72 \\
\hline
\end{tabular}

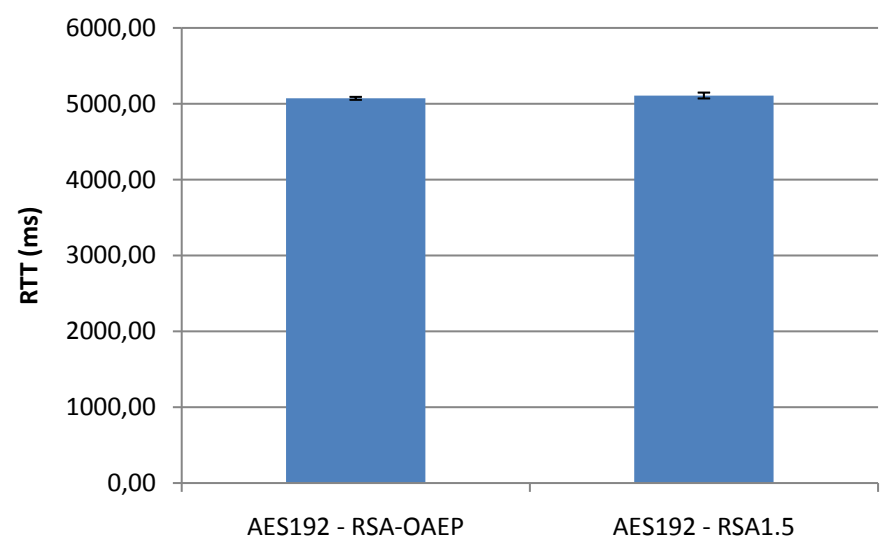

Figura 6.14: Algoritmos de chave pública com AES 192 (3 clientes).

É importante destacar que em todos os casos apresentados nesta seção o algoritmo RSA-OAEP mostrou-se melhor em termos de desempenho, além de evitar o ataque de texto cifrado escolhido, conforme descrito previamente na Seção 6.2.3. Portanto, é possível concluir que o RSA-OAEP torna-se a melhor opção neste contexto. 
Tabela 6.18: Algoritmos de chave pública com AES 256 (3 clientes).

\begin{tabular}{|c|c|c|c|}
\hline Tipo & RTT & Desv. Padrão & Int. Confiança \\
\hline AES256 - RSA-OAEP & 5298,91 & 95,16 & 34,05 \\
\hline AES256 - RSA1.5 & 5326,71 & 124,12 & 44,42 \\
\hline
\end{tabular}

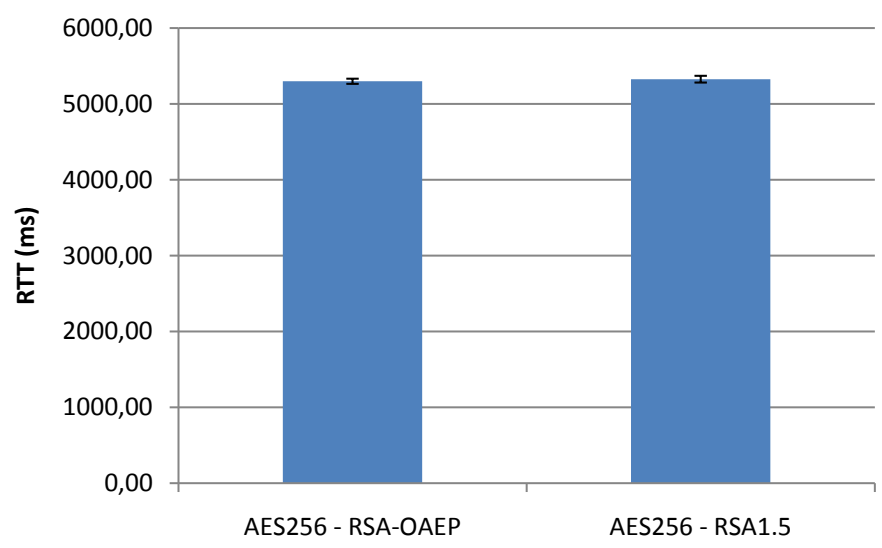

Figura 6.15: Algoritmos de chave pública com AES 256 (3 clientes).

Tabela 6.19: Algoritmos de chave pública com 3DES (3 clientes).

\begin{tabular}{|c|c|c|c|}
\hline Tipo & RTT & Desv. Padrão & Int. Confiança \\
\hline 3DES - RSA-OAEP & 5811,87 & 179,98 & 64,40 \\
\hline 3DES - RSA1.5 & 5881,92 & 186,28 & 66,66 \\
\hline
\end{tabular}

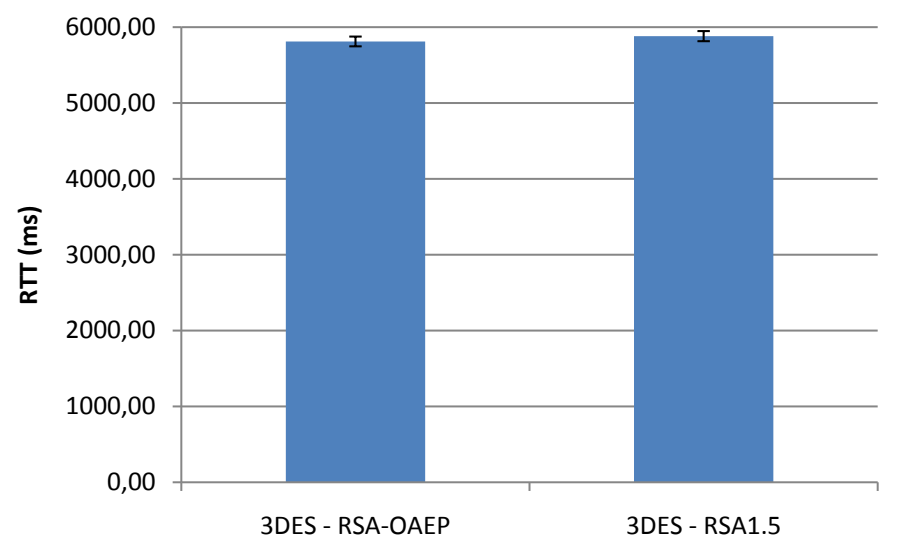

Figura 6.16: Algoritmos de chave pública com 3DES (3 clientes).

\section{Comparação entre Quantidade de Clientes}

Nesta seção é realizada uma análise com foco na quantidade de clientes, ou seja, os resultados dos algoritmos avaliados são comparados com 1 e 3 clientes. Na Tabela 6.20 e no gráfico da Figura 6.17 são exibidos os resultados do AES 192 com RSA-OAEP. Na Tabela 6.21 e no gráfico da Figura 6.18 são comparados os resultados do AES 256 com RSA-OAEP. E, finalmente, na Tabela 6.22 e no gráfico da Figura 6.19 são apresentados os resultados do 3DES com RSA-OAEP. É possível 
perceber que o aumento do número de clientes acarreta degradação no desempenho de 1,71\% para o AES 192 com RSA-OAEP. Para o AES 256 com RSA-OAEP esta queda no desempenho é de $5,65 \%$. Enquanto para o 3DES com RSA-OAEP esta redução é de 5,23\%. Em nenhuma destas comparações os intervalos de confiança se sobrepuseram, garantindo assim que os resultados são estatisticamente diferentes.

Tabela 6.20: RTT - AES192 - RSA-OAEP.

\begin{tabular}{|c|c|c|c|}
\hline Qtde. Clientes & RTT & Desv. Padrão & Int. Confiança \\
\hline 1 & 4986,67 & 117,87 & 42,18 \\
\hline 3 & 5072,09 & 54,05 & 19,34 \\
\hline
\end{tabular}

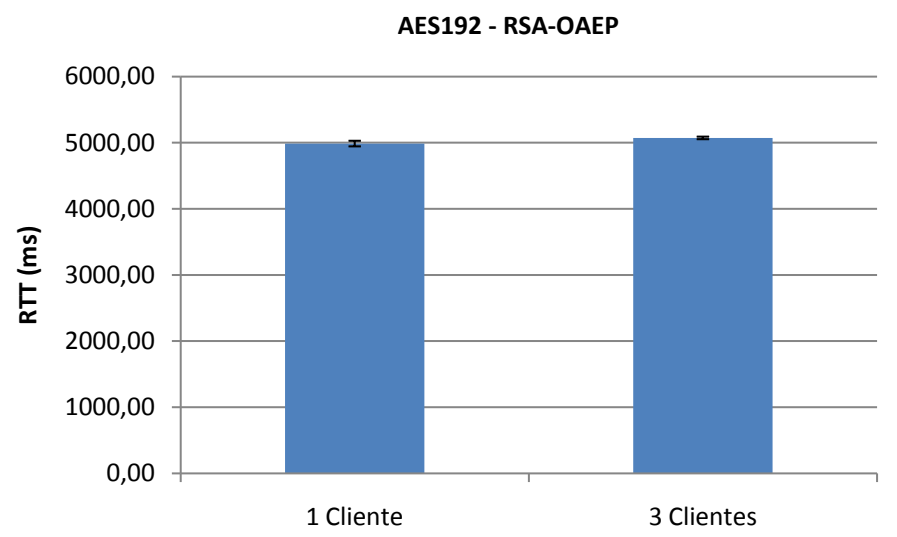

Figura 6.17: RTT - AES192 - RSA-OAEP.

Tabela 6.21: RTT - AES256 - RSA-OAEP.

\begin{tabular}{|c|c|c|c|}
\hline Qtde. Clientes & RTT & Desv. Padrão & Int. Confiança \\
\hline 1 & 5015,70 & 163,33 & 58,45 \\
\hline 3 & 5298,91 & 95,16 & 34,05 \\
\hline
\end{tabular}

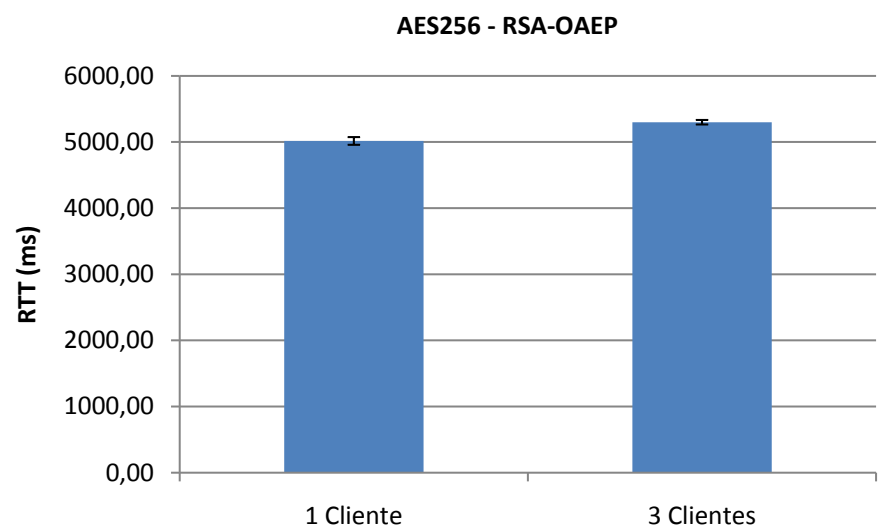

Figura 6.18: RTT - AES256 - RSA-OAEP. 
Tabela 6.22: RTT - 3DES - RSA-OAEP.

\begin{tabular}{|c|c|c|c|}
\hline Qtde. Clientes & RTT & Desv. Padrão & Int. Confiança \\
\hline 1 & 5523,23 & 129,10 & 46,20 \\
\hline 3 & 5811,87 & 179,98 & 64,40 \\
\hline
\end{tabular}

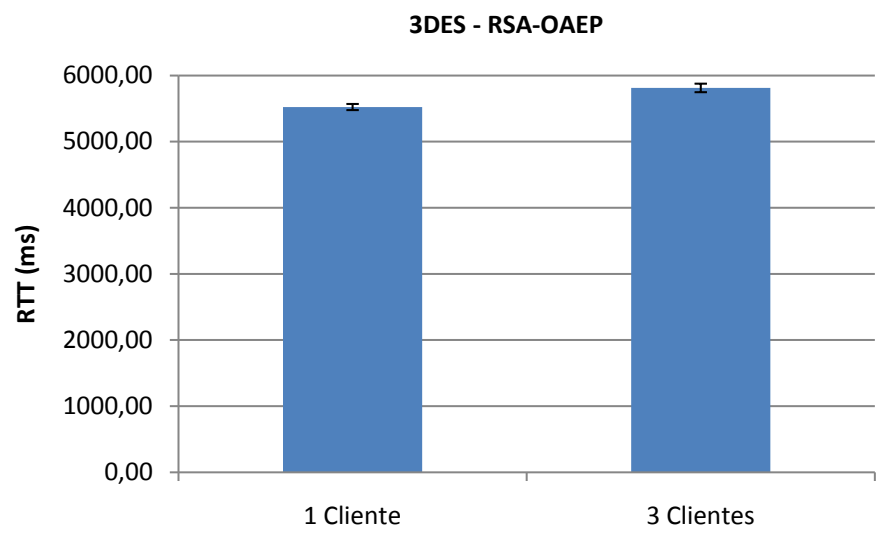

Figura 6.19: RTT - 3DES - RSA-OAEP.

Ainda com relação à comparação entre 1 e 3 clientes, na Tabela 6.23 e no gráfico da Figura 6.20 são apresentados os resultados do AES 192 com RSA 1.5. Os valores do AES 256 com RSA 1.5 são apresentados na Tabela 6.24 e no gráfico da Figura 6.21. E por fim, os resultados do 3DES com RSA 1.5 são comparados na Tabela 6.25 e no gráfico da Figura 6.22. Com o aumento da quantidade de clientes, a redução no desempenho do AES 192 com RSA 1.5 é de 2,21\%. A degradação do desempenho do AES 256 com RSA 1.5 é de 6\% e do 3DES com RSA 1.5 é de $6,07 \%$. Novamente, os resultados mostrados são estatisticamente diferentes, pois os intervalos de confiança não estão sobrepostos. Baseado nestes resultados, conclui-se que quando se pretende expandir a quantidade de clientes, tendo ainda a preocupação com o desempenho, deve-se dar preferência à utilização do AES 192. Pois, na medida em que o comprimento da chave aumenta, certamente haverá uma redução de desempenho que possivelmente causará um impacto negativo no funcionamento apropriado da aplicação.

Tabela 6.23: RTT - AES192 - RSA1.5.

\begin{tabular}{|c|c|c|c|}
\hline Qtde. Clientes & RTT & Desv. Padrão & Int. Confiança \\
\hline 1 & 4998,93 & 147,43 & 52,76 \\
\hline 3 & 5109,30 & 108,20 & 38,72 \\
\hline
\end{tabular}

Tabela 6.24: RTT - AES256 - RSA1.5.

\begin{tabular}{|c|c|c|c|}
\hline Qtde. Clientes & RTT & Desv. Padrão & Int. Confiança \\
\hline 1 & 5025,37 & 131,79 & 47,16 \\
\hline 3 & 5326,71 & 124,12 & 44,42 \\
\hline
\end{tabular}




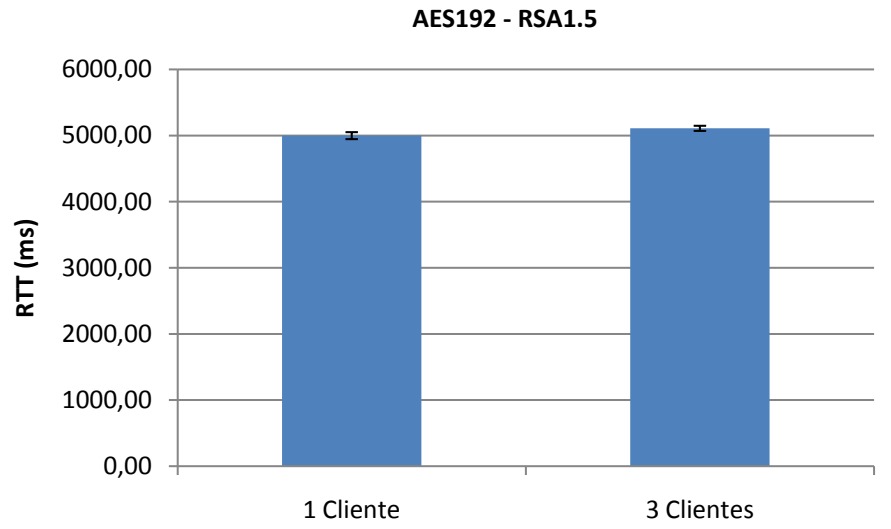

Figura 6.20: RTT - AES192 - RSA1.5.

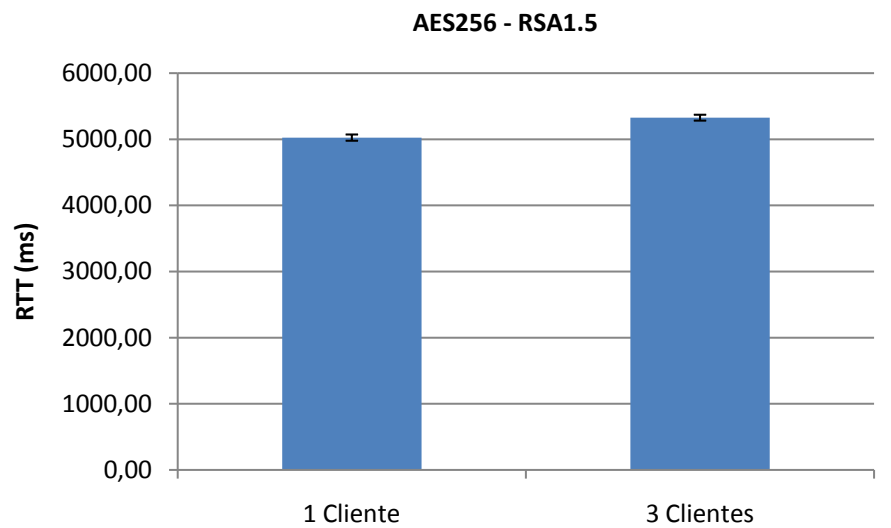

Figura 6.21: RTT - AES256 - RSA1.5.

Tabela 6.25: RTT - 3DES - RSA1.5.

\begin{tabular}{|c|c|c|c|}
\hline Qtde. Clientes & RTT & Desv. Padrão & Int. Confiança \\
\hline 1 & 5545,13 & 105,63 & 37,80 \\
\hline 3 & 5881,92 & 186,28 & 66,66 \\
\hline
\end{tabular}

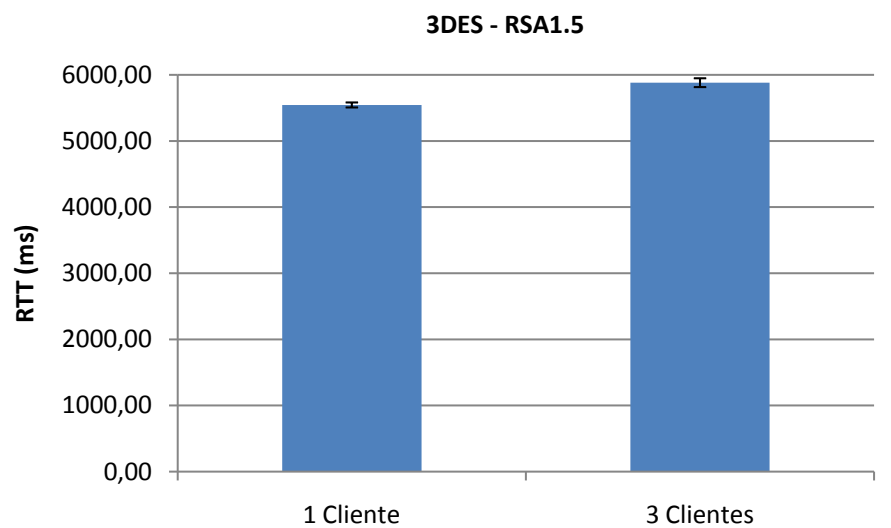

Figura 6.22: RTT - 3DES - RSA1.5.

\section{Análise da Influência dos Fatores}

Assim como no estudo de caso anterior, esta etapa da avaliação consiste em determinar quais fatores exercem mais influência nos resultados, além de verificar se há alguma influência signi- 
ficativa na interação entre os fatores. A análise presente nesta seção realiza uma comparação da influência dos algoritmos de chave simétrica entre AES 192 e AES 256, AES 192 e 3DES e, por fim, AES 256 e 3DES em relação aos outros dois fatores considerados. Os gráficos apresentados a seguir ilustram a porcentagem de influência da cada um dos fatores, sendo estes representados pelas letras A, B e C, e as interações entre os fatores representadas pelas combinações das letras.

No gráfico da Figura 6.23 é ilustrada a influência dos fatores para os resultados obtidos com os algoritmos de chave simétrica AES 192 e AES 256. Pode-se notar que o fator clientes (C) exerce a maior influência, com 59,74\%. Em seguida vem o fator algoritmo de chave simétrica (A) com $24,5 \%$ de influência. A terceira maior influência pertence à interação entre os fatores algoritmo de chave simétrica e clientes (AC) com 14,83\%. Os demais fatores e interações não possuem influências relevantes, não alcançando sequer $1 \%$. Neste caso pode-se perceber que devido à pequena diferença entre os RTTs do AES 192 e do AES 256, a quantidade de clientes apresenta a maior influência nos resultados.

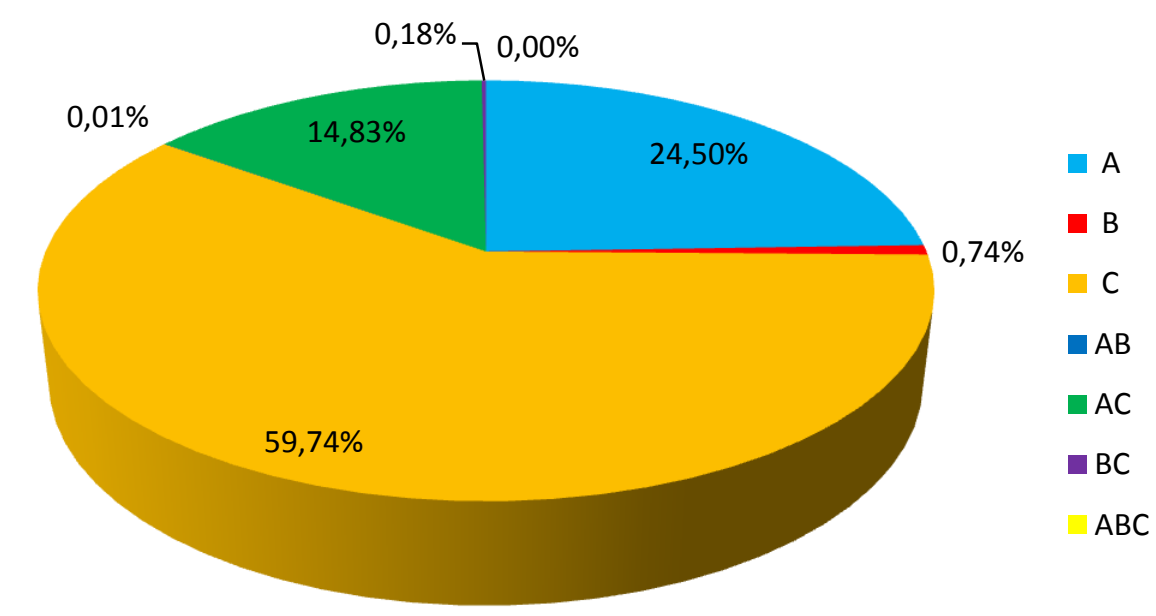

A: algoritmo de chave simétrica B: algoritmo de chave pública C: clientes

Figura 6.23: AES 192 vs. AES 256.

A influência dos fatores para os valores obtidos com os algoritmos AES 192 e 3DES é ilustrada na Figura 6.24. É possível observar que a maior influência pertence ao fator algoritmo de chave simétrica (A) com 88,37\%, seguido pelo fator clientes (C) com 8,85\%. A interação entre os fatores algoritmo de chave simétrica e clientes (AC) possui 2,42\% de influência. Os fatores e interações restantes ficaram abaixo de $1 \%$ e não apresentam influência significativa. Devido ao RTT alto do 3DES e, consequentemente, a maior diferença entre os RTTs do AES 192 e do 3DES, o algoritmo de chave simétrica torna-se o fator mais influente.

No gráfico da Figura 6.25 é exibida a influência de fatores para os valores coletados com os algoritmos AES 256 e 3DES. No gráfico é possível notar que o fator mais influente é o algoritmo de chave simétrica (A) com 74,65\%. Logo após vem o fator clientes (C) com 24,89\% de influência. Os demais fatores e interações não atingiram $1 \%$ e por isso não possuem influência significativa. Com o AES 256, a diferença entre o seu RTT e o do 3DES torna-se menor, com a consequente 


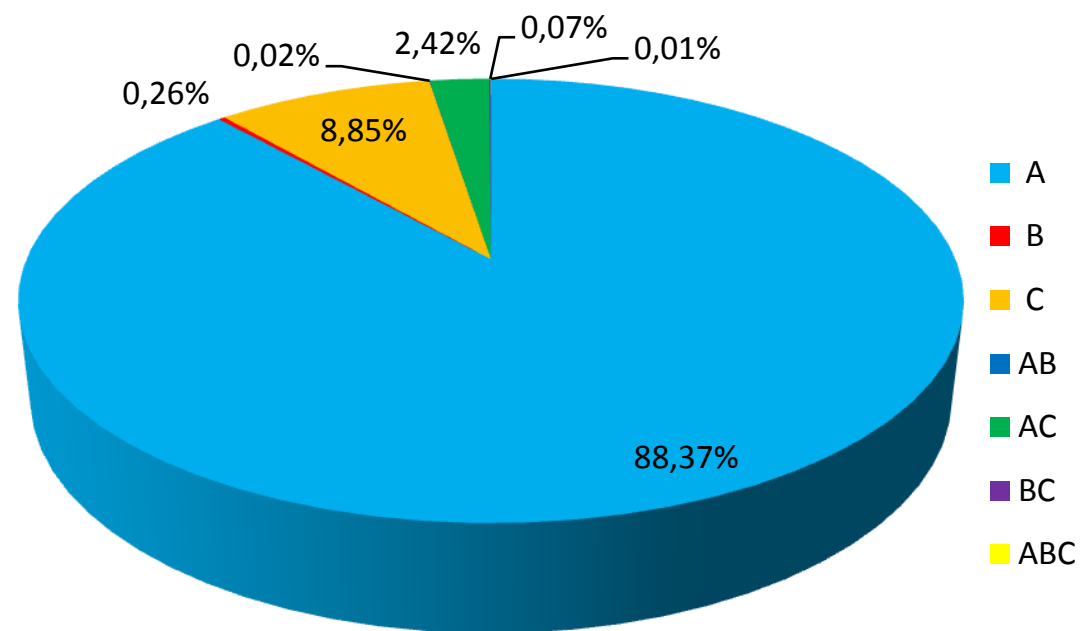

A: algoritmo de chave simétrica $\mathbf{B}$ : algoritmo de chave pública $\mathbf{C}$ : clientes

Figura 6.24: AES 192 vs. 3DES.

diminuição da influência do algoritmo de chave simétrica nos resultados, embora ainda permaneça como o fator mais influente.

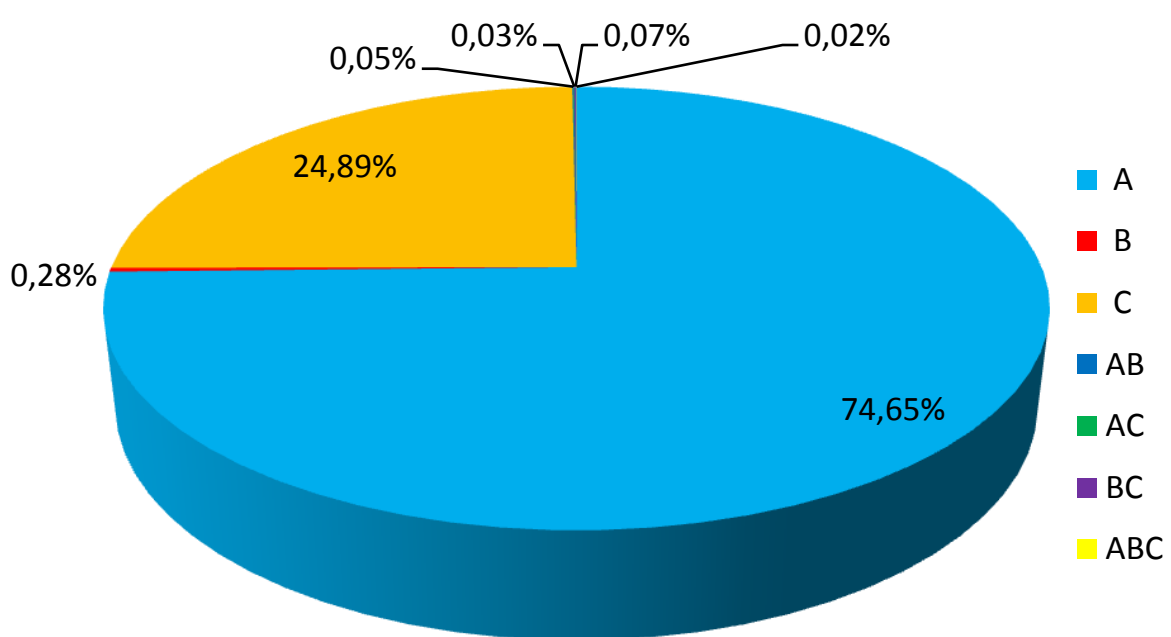

A: algoritmo de chave simétrica B: algoritmo de chave pública C: clientes

Figura 6.25: AES 256 vs. 3DES.

Com a análise da influência dos fatores, torna-se evidente que os fatores de maior influência são o algoritmo de chave simétrica e a quantidade de clientes. Diferentemente do algoritmo de chave simétrica, o fator algoritmo de chave pública causa pouca influência nos resultados, devido à sua utilização ser restrita à criptografia da chave secreta, ou seja, pequenas quantidades de dados.

\section{Discussões Finais}

Fundamentado nas análises dos resultados obtidos, é possível afirmar que dentre os algoritmos de chave simétrica avaliados, o AES 192 exibe o melhor desempenho em termos de velocidade. No entanto, em alguns casos apresentados, seu desempenho não possui diferença estatística em relação ao AES 256, o qual provê um maior nível de segurança a um custo relativamente semelhante no 
desempenho. Portanto, nestes casos, o algoritmo AES 256 pode ser considerado a melhor escolha. O 3DES, por sua vez, é o mais lento, devido ao seu modo de funcionamento.

Em relação aos algoritmos de chave pública, deve-se preferir o uso do RSA-OAEP em detrimento do RSA 1.5, pois além de apresentar os menores RTTs, o RSA-OAEP ainda possui a função de prevenir contra ataques de texto cifrado escolhido.

Ainda de acordo com os resultados obtidos, quando se eleva o número de clientes de um Web service, o algoritmo de chave simétrica que menos sofre degradação em seu desempenho é o AES 192, principalmente quando combinado com o algoritmo de chave pública RSA-OAEP.

Para finalizar, quando se deseja um equilíbrio entre segurança e desempenho, as escolhas mais indicadas são o AES 192 ou AES 256 (dependendo da quantidade de clientes) como algoritmos de chave simétrica e o RSA-OAEP como algoritmo de chave pública.

\subsection{Considerações Finais}

Em ambos os estudos de caso, a completa avaliação de desempenho exibida neste capítulo abordou desde o domínio da aplicação, passando pela configuração do ambiente de experimentos e planejamento de experimentos, até a análise crítica dos resultados obtidos.

No capítulo seguinte são apresentadas as conclusões. Adicionalmente, são discutidas as dificuldades encontradas durante o desenvolvimento deste projeto, assim como as contribuições, a produção científica e os trabalhos futuros. 
Os problemas relacionados à adição de segurança em Web services já são bem conhecidos, tanto pelas operações de segurança e seu inerente custo de processamento, quanto pelo aumento de complexidade nas mensagens XML/SOAP devido à inserção de elementos de segurança, causando, consequentemente, maior consumo de largura de banda da rede para transportar a mensagem e maior utilização de CPU para processamento da mesma. Além disso, é sabido que as técnicas de segurança da camada de transporte, como o SSL, não são recomendadas para Web services, pois não garantem segurança fim-a-fim.

Neste contexto, um dos objetivos desta dissertação de mestrado foi estudar e analisar as especificações de segurança para Web services visando à implantação de uma arquitetura que provesse segurança fim-a-fim para este tipo de aplicação. Com a implantação desta arquitetura, experimentações puderam ser realizadas com o objetivo de avaliar o desempenho de técnicas de segurança em Web services, como criptografia e assinatura digital. Posteriormente, foram realizados experimentos com diferentes algoritmos de criptografia de chave simétrica e de chave pública, variando também o comprimento das chaves utilizadas, com o propósito de analisar os algoritmos avaliados e inferir quais deles causam a menor degradação em termos de desempenho, quais oferecem um maior nível de segurança e, principalmente, quais são os mais indicados quando se pretende balancear os níveis de desempenho e de segurança em determinadas situações. Adicionalmente, foram realizadas análises de influência dos fatores avaliados, as quais apontam os fatores que mais exerceram influência nos resultados dos experimentos realizados. Desta forma, os objetivos da avaliação de desempenho das técnicas e dos algoritmos de segurança também foram alcançados, uma vez que a análise dos resultados obtidos permitiu apontar a degradação no desempenho causada pelos mesmos. 


\subsection{Dificuldades Relacionadas ao Projeto}

Inúmeras foram as dificuldades encontradas durante o desenvolvimento deste projeto de mestrado, e algumas delas podem ser destacadas:

- Na fase inicial do desenvolvimento, foi descoberto que a versão 1.4 do módulo Rampart (utilizada no primeiro estudo de caso) não continha uma biblioteca utilizada na criptografia de chave pública. Para resolver tal problema, foi utilizada a biblioteca existente na versão 1.3. Vale ressaltar que esta biblioteca foi adicionada novamente nas versões posteriores.

- Outro problema diz respeito à compatibilidade das versões do Axis2 e do Rampart. Durante a realização do projeto foram testadas várias combinações entre as versões destes dois softwares e percebeu-se que algumas delas não permitiam a realização de criptografia somente, porém era possível realizar assinatura seguida de criptografia. Além disso, existem combinações que simplesmente não funcionam, ou seja, não permitem nem criptografia, nem assinatura e tampouco a junção de ambas. Para o estudo de caso 1, foram utilizadas as versões funcionais mais recentes na época, ou seja, o Axis2 1.4.1 e o Rampart 1.4. Por sua vez, o estudo de caso 2 não apresentou tais problemas, pois as versões mais atualizadas dos softwares na época (Axis2 1.5.4 e Rampart 1.5.1) funcionaram corretamente quando combinadas.

- Na fase final do projeto, durante a realização da criptografia com os algoritmos de chave simétrica AES 192 e AES 256 ocorriam erros relacionados ao tamanho de chave. Estes erros eram causados, provavelmente, pela máquina virtual Java e foram resolvidos com a inclusão de duas bibliotecas relacionadas à JCE (Java Cryptography Extension) (JCE, 2002) no diretório de segurança da JRE (Java Runtime Environment).

- Também na etapa final, pretendia-se avaliar o algoritmo SHA-256, mas descobriu-se que o mesmo não funcionava apropriadamente, conforme descrito anteriormente na Seção 6.2.3. Desta forma, tal algoritmo foi descartado na avaliação de desempenho realizada.

\subsection{Contribuições}

O projeto de mestrado apresentado nesta dissertação apresenta algumas contribuições não somente para a área de avaliação de desempenho de Web services seguros com WS-Security, mas também para a área de segurança em SOA. Dentre elas destacam-se:

- Avaliação de desempenho em uma aplicação real. Pois este tipo de aplicação normalmente requer uma escolha entre segurança e desempenho. Neste contexto, ainda deve existir a possibilidade de balancear estes dois fatores. 
- Desenvolvimento e implementação de Web services seguros. Esta contribuição está registrada por meio da publicação de um capitulo de livro apresentado na ERI 2010 e de um minicurso apresentado na AppSec 2009, conforme relacionado posteriormente na Seção 7.3.2.

- A partir das implementações realizadas e dos resultados obtidos, pode-se propor meios para a especificação e o desenvolvimento de uma ferramenta que determine automaticamente as melhores técnicas/algoritmos dentro de um determinado escopo, como descrito posteriormente na Seção 7.4 .

- Detecção de problemas nos algoritmos disponíveis, uma vez que os mesmos aparentam não ter implementação padronizada. Pois ocorreram problemas, como na utilização do algoritmo SHA-256, o qual apresentava resultados que não faziam sentido. Após muita investigação foi descoberto que na verdade o algoritmo que estava sendo executado era o SHA-1.

- Análise dos ataques proferidos contra Web services, provendo uma ampla averiguação dos tipos de ataques e as contramedidas que podem ser utilizadas. Tal contribuição tangencia a avaliação de desempenho apresentada neste trabalho e por isso pode ser encontrada apenas no capítulo de livro publicado pela IGI Global (maiores detalhes posteriormente na Seção 7.3.2).

\subsection{Produção Científica}

Esta seção visa relacionar a produção científica proveniente deste projeto de mestrado (trabalhos aceitos e publicados), assim como trabalhos de iniciação científica correlacionados.

\subsubsection{Artigos}

- Rodrigues, D.; Estrella, J. C.; Branco, K. R. L. J. C. “Security vs. Performance in SOA Environment". International Conference on Convergence and Hybrid Information Technology (ICHIT 2010), 2010.

- Rodrigues, D.; Estrella, J. C.; Branco, K. R. L. J. C. "Analysis of Security and Performance Aspects in Service-Oriented Architectures". International Journal of Security and Its Applications, v. 5, p. 13-30, 2011.

\subsubsection{Capítulos de Livro}

- Rodrigues, D.; Estrella, J. C.; Branco, K. R. L. J. C. "Segurança Computacional no Desenvolvimento de Web Services”. VII Escola Regional de Informática - São Paulo/Oeste 2010. Bauru: SBC, 2010, p. 59-82. 
- Rodrigues, D.; Estrella, J. C.; Branco, K. R. L. J. C.; Vieira, M. "Engineering Secure Web Services”. Performance and Dependability in Service Computing: Concepts, Techniques and Research Directions. IGI Global, 2011.

\subsubsection{Minicursos Apresentados}

- Estrella, J. C.; Rodrigues, D.; Branco, K. R. L. J. C.; Santana, R. H. C.; Santana, M. J. "Segurança Computacional no Desenvolvimento de Web Services”. I Conferência Internacional de Segurança de Aplicações (AppSec Brasil), 2009.

\subsubsection{Resumos}

- Martins, J. S.; Branco, K. R. L. J. C.; Rodrigues, D.; Estrella, J. C. “Diretrizes para a Incorporação de Segurança em Web Services”. In: XVII Congresso de Iniciação Científica - $8^{\mathrm{a}}$ Jornada Científica e Tecnológica da UFSCar, 2009, São Carlos.

- Martins, J. S.; Rodrigues, D.; Estrella, J. C.; Branco, K. R. L. J. C. "Incorporação de Segurança em Web Services". In: $17^{\circ}$ Simpósio Internacional de Iniciação Científica da USP SIICUSP, 2009, São Carlos.

\subsection{Trabalhos Futuros}

Por se tratar de um trabalho amplo, a avaliação de desempenho de Web services seguros apresentada neste trabalho pode ser estendida. As sugestões para trabalhos futuros são:

- Realização de uma avaliação de desempenho incluindo a especificação de segurança WSSecureConversation, a qual estabelece sessões que possibilitam a troca de mensagens SOAP sem que seja necessário verificar a autenticação e autorização de cada uma delas. O WSSecureConversation poderia ser comparado ao WS-Security, pois teoricamente o primeiro possui potencial para ser mais eficiente. Outras especificações de segurança com a mesma finalidade também poderiam ser comparadas.

- Um ex-aluno de doutorado do Grupo de Sistemas Distribuídos e Programação Concorrente do ICMC-USP propôs uma arquitetura denominada WSARCH (Estrella, 2010). A WSARCH é uma arquitetura que visa prover qualidade de serviço aos Web services. Portanto, uma extensão da avaliação de desempenho realizada seria interessante focando a segurança nesta arquitetura.

- Avaliação de desempenho comparando as técnicas de segurança utilizadas neste trabalho com técnicas de segurança aperfeiçoadas em outros trabalhos, tal como em (Engelen e 
Zhang, 2008b), o qual apresenta um novo sumário de mensagem baseado em caching visando à melhoria do desempenho da assinatura digital com WS-Security.

- Visto a grande quantidade de ataques específicos em Web services apresentada em (Jensen et al., 2007), seria de grande interesse realizar alguns destes ataques nos Web services seguros implementados com o objetivo de efetuar uma avaliação de segurança.

- Desenvolvimento e implementação de uma ferramenta que automatize a determinação das melhores técnicas/algoritmos que poderão ser utilizadas em um escopo específico, visando à troca de mensagens seguras entre Web services. Esta ferramenta deve englobar os tipos de algoritmos criptográficos disponíveis nas especificações de segurança para Web services, bem como os tamanhos das chaves e outros. 

Alrouh, B.; Ghinea, G. A performance evaluation of security mechanisms for web services. In: Proceedings of the 2009 Fifth International Conference on Information Assurance and Security - Volume 02, Washington, DC, USA: IEEE Computer Society, 2009, p. 715-718.

Andresen, D.; Sexton, D.; Devaram, K.; Ranganath, V. Lye: A high-performance caching soap implementation. In: International Conference on Parallel Processing, 2004. ICPP 2004, 2004, p. 143-150 vol.1.

APACHE Wrong signaturemethod and digestmethod generated in request in case of algoritm suite having sha256 hashing algorithm (example: Basic256sha256). The Apache Software Foundation. Disponível em: https: / / issues. apache.org/jira/browse/RAMPART-216. Último acesso: 12/04/2011, 2009.

ApACHE Apache axis2/java. The Apache Software Foundation. Disponível em: http:// axis. apache.org/axis2/java/core/. Último acesso: 25/02/2011, 2010.

APACHE Apache rampart - axis2 security module. The Apache Software Foundation. Disponível em: http://axis.apache.org/axis2/java/rampart/. Último acesso: 25/02/2011, 2011a.

APACHE Apache tomcat. The Apache Software Foundation. Disponível em: http:// tomcat . apache.org/. Último acesso: 25/02/2011, 2011 b.

BARRY, D. K.; GANNON, P. J. Web services and service-oriented architecture: The savvy manager's guide. San Francisco, CA, USA: Morgan Kaufmann Publishers Inc., 2003.

Bellare, M.; Rogaway, P. Optimal asymmetric encryption - how to encrypt with rsa. In: Advances in Cryptology - EUROCRYPT'94, Springer-Verlag, 1995, p. 92-111.

BISHop, M. A. Computer security: Art and science. Boston, MA, USA: Addison-Wesley Longman Publishing Co., Inc., 2002. 
Boldyreva, A.; Imai, H.; Kobara, K. How to strengthen the security of rsa-oaep. IEEE Transactions on Information Theory, v. 56, n. 11, p. 5876-5886, 2010.

Burnett, S.; PAine, S. Rsa security's official guide to cryptography. Berkeley, CA, USA: Osborne/McGraw-Hill, 2001.

Chen, S.; ZIC, J.; TANG, K.; LEVy, D. Performance evaluation and modeling of web services security. IEEE International Conference on Web Services, v. 0, p. 431-438, 2007.

Chou, D. C.; Yurov, K. Security development in web services environment. Computer Standards \& Interfaces, v. 27, n. 3, p. 233-240, 2005.

Cohen, F. Discover soap encoding's impact on web service performance. IBM Corporation. Disponível em: http://www.ibm.com/developerworks/webservices / library/ws-soapenc/. Último acesso: 03/02/2011, 2003.

Colan, M. Service-oriented architecture expands the vision of web services, part 1. IBM Corporation. Disponível em: http://www.ibm.com/developerworks/library/ ws-soaintro.html. Último acesso: 21/02/2011, 2004.

Coulouris, G.; Dollimore, J.; Kindberg, T. Distributed systems: Concepts and design (4th edition). Addison Wesley, 2005.

DAEmen, J.; RiJmen, V. The block cipher rijndael. In: CARDIS '98: Proceedings of the The International Conference on Smart Card Research and Applications, London, UK: SpringerVerlag, 2000, p. 277-284.

Dierks, T.; Allen, C. The tls protocol version 1.0. RFC 2246. Disponível em: http: / / www. ietf.org/rfc/rfc2246.txt. Último acesso: 29/03/2011, 1999.

Diffie, W.; Hellman, M. E. New directions in cryptography. IEEE Transactions on Information Theory, v. IT-22, n. 6, p. 644-654, 1976.

ENGELEN, R.; ZHANG, W. Identifying opportunities for web services security performance optimizations. In: IEEE Congress on Services - Part I, 2008, 2008a, p. 209-210.

Engelen, R.; ZHANG, W. An overview and evaluation of web services security performance optimizations. In: IEEE International Conference on Web Services, 2008. ICWS ’08, 2008b, p. 137-144.

ERL, T. Service-oriented architecture: A field guide to integrating xml and web services. Upper Saddle River, NJ, USA: Prentice Hall PTR, 2004.

ERL, T. Service-oriented architecture: Concepts, technology, and design. Upper Saddle River, NJ, USA: Prentice Hall PTR, 2005. 
ERRADi, A.; MAheshwARI, P. A broker-based approach for improving web services reliability. In: ICWS '05: Proceedings of the IEEE International Conference on Web Services, Washington, DC, USA: IEEE Computer Society, 2005, p. 355-362.

ESTRElla, J. C. Wsarch: Uma arquitetura para a provisão de web services com qualidade de serviço. Tese de doutorado, ICMC-USP, São Carlos, SP, 2010.

Estrella, J. C.; Endo, A. T.; Toyohara, R. K. T.; Santana, R. H. C.; Santana, M. J.; BRUSCHI, S. M. A performance evaluation study for web services attachments. IEEE International Conference on Web Services, v. 0, p. 799-806, 2009.

Feldhofer, M.; Dominikus, S.; Wolkerstorfer, J. Strong authentication for rfid systems using the aes algorithm. Cryptographic Hardware and Embedded Systems - CHES 2004, p. 357-370, 2004.

FERNANDO, R. Setting up keystores for a client and a service. WSO2. Disponível em: http: / / wso2 . org/library/174. Último acesso: 18/03/2011, 2006.

Freier, A. O.; Karlton, P.; Kocher, P. C. The ssl protocol version 3.0. Internet Draft. Disponível em: http://www.mozilla.org/projects/security/pki/ nss/ssl/draft 302 . txt. Último acesso: 29/03/2011, 1996.

Gruschka, N.; Jensen, M.; Iacono, L.; Luttenberger, N. Server-side streaming processing of ws-security. IEEE Transactions on Services Computing, v. PP, n. 99, p. 1-14, 2011.

HolgersSON, J.; SÖDERSTROM, E. Web service security - vulnerabilities and threats within the context of ws-security. The 4th Conference on Standardization and Innovation in Information Technology, p. 138-146, 2005.

Hollar, R.; Murphy, R. Enterprise web services security. Rockland, MA, USA: Charles River Media, Inc., 2006.

Housley, R. Use of the rsaes-oaep key transport algorithm in the cryptographic message syntax (cms). RFC 3560. Disponível em: http: //www. ietf.org/rfc/rfc3560.txt. Último acesso: 11/04/2011, 2003.

IBM Standards and web services. Disponível em: http://www.i.bm.com/ developerworks/webservices/standards/. Último acesso: 26/01/2011, 2009.

JAIN, R. K. The art of computer systems performance analysis: Techniques for experimental design, measurement, simulation, and modeling. Wiley, 1991.

JCE Java cryptography extension (jce) reference guide. Oracle. Disponível em: http://download.oracle.com/javase/1.4.2/docs/guide/security/ jce/JCERefGuide.html. Último acesso: 18/04/2011, 2002. 
Jensen, M.; GruschKa, N.; Herkenhoner, R.; LutTenberger, N. Soa and web services: New technologies, new standards - new attacks. In: ECOWS '07: Proceedings of the Fifth European Conference on Web Services, Washington, DC, USA: IEEE Computer Society, 2007, p. $35-44$.

Josuttis, N. Soa in practice: The art of distributed system design. O'Reilly Media, Inc., 2007.

Juric, M. B.; Rozman, I.; Brumen, B.; Colnaric, M.; Hericko, M. Comparison of performance of web services, ws-security, rmi, and rmi-ssl. The Journal of Systems and Software, v. 79, p. 689-700, 2006.

KALISKI, B. Pkcs \#1: Rsa encryption version 1.5. RFC 2313. Disponível em: http: / / www . ietf.org/rfc/rfc2313.txt. Último acesso: 09/04/2011, 1998.

Kanneganti, R.; Chodavarapu, P. Soa security. Greenwich, CT, USA: Manning Publications Co., 2008.

Keytool Keytool - key and certificate management tool. Oracle. Disponível em: http://download.oracle.com/javase/6/docs/technotes/tools/ windows/keytool .html. Último acesso: 18/03/2011, 2010.

KnAP, T.; MlÝnKová, I. Towards more secure web services: Pitfalls of various approaches to $\mathrm{xml}$ signature verification process. In: ICWS '09: Proceedings of the 2009 IEEE International Conference on Web Services, Washington, DC, USA: IEEE Computer Society, 2009, p. 543550.

Kocher, P.; Lee, R.; McGraw, G.; Raghunathan, A. Security as a new dimension in embedded system design. In: DAC '04: Proceedings of the 41st Annual Design Automation Conference, New York, NY, USA: ACM, 2004, p. 753-760.

Kurose, J. F.; Ross, K. W. Computer networking: A top-down approach. 5 ed. Addison Wesley, 2009.

LANDWEHR, C. E. Computer security. International Journal of Information Security, v. 1, p. 3-13, 2001.

LiU, H.; Pallickara, S.; Fox, G. Performance of web service security. In: Proceedings of 13th Annual Mardi Gras Conference, Baton Rouge, Louisiana, 2005, p. 1-8.

LIU, J.; LI, J. A novel key exchange protocol based on rsa-oaep. In: 10th International Conference on Advanced Communication Technology, 2008. ICACT 2008, 2008, p. 1641-1643.

Mahmoud, Q. H. Service-oriented architecture (soa) and web services: The road to enterprise application integration (eai). Sun Microsystems. Disponível em: http: / java.sun.com/ 
developer/technicalArticles/WebServices/soa/. Último acesso: 20/01/2011, 2005.

Martin-Flatin, J. P.; LÖWE, W. Special issue on recent advances in web services. World Wide Web, v. 10, n. 3, p. 205-209, 2007.

Mashood, M.; WiKramanayake, G. Architecting secure web services through policies. In: International Conference on Industrial and Information Systems, 2007. ICIIS 2007, 2007, p. 5-10.

McGovern, J.; Tyagi, S.; Stevens, M.; Mathew, S. Java web services architecture. Morgan Kaufmann, 2003.

Merrill, D.; Grimshaw, A. Profiles for conveying the secure communication requirements of web services. Concurrency and Computation: Practice \& Experience, v. 21, n. 8, p. 991-1011, 2009.

Mi, Z.; ZUNPING, C.; ZIJI, M.; BINYU, Z. A security model design in web service environment. International Conference on Computer and Information Technology, v. 0, p. 736-740, 2005.

MicRosofT Security in a web services world: A proposed architecture and roadmap. Disponível em: http://msdn.microsoft.com/en-us/library/ms977312.aspx. Último acesso: 25/02/2011, 2002.

MiHINDUKULASOORIYA, N. Understanding ws-security policy language. WSO2. Disponível em: http: / / wso2 .org/library/3132. Último acesso: 25/02/2011, 2008.

Mogollon, M. Cryptography and security services: Mechanisms and applications. IGI Global, 2008.

Moreno, E. D.; Pereira, F. D.; Chiaramonte, R. B. Criptografia em software e hardware. Novatec Editora, 2005.

Nagappan, R.; Skoczylas, R.; SRIgAnesh, R. P. Developing java web services. New York, NY, USA: John Wiley \& Sons, Inc., 2003.

NG, C. W.; NG, T. S.; YIP, K. W. A unified architecture of md5 and ripemd-160 hash algorithms. ISCAS '04. Proceedings of the 2004 International Symposium on Circuits and Systems, 2004, v. 2, p. II - 889-92 Vol.2, 2004.

Nordbotten, N. A. Xml and web services security standards. IEEE Communications Surveys Tutorials, v. 11, n. 3, p. 4-21, 2009.

OASIS Uddi specification tc. Disponível em: http://www.oasis-open.org/ committees/tc_home.php?wg_abbrev=uddi-spec. Último acesso: 02/02/2011, 2004a. 
OASIS Web services reliable messaging (wsrm) tc. Disponível em: http://www . oasis-open.org/committees/tc_home.php?wg_abbrev=wsrm. Último acesso: 28/01/2011, 2004b.

OASIS Web services security (wss) tc. Disponível em: http://www.oasis-open.org/ committees/tc_home.php?wg_abbrev=wss. Último acesso: 18/02/2011, 2006a.

OASIS Web services distributed management (wsdm) tc. Disponível em: http://www . oasis-open.org/committees/tc_home.php?wg_abbrev=wsdm. Último acesso: 28/01/2011, 2006b.

OASIS Ws-securitypolicy 1.2. Disponível em: http://docs.oasis-open.org/ ws-sx/ws-securitypolicy/v1.2/ws-securitypolicy.html. Último acesso: 18/02/2011, 2007a.

OASIS Web services business process execution language (wsbpel) tc. Disponível em: http: //www.oasis-open.org/committees/tc_home.php?wg_abbrev=wsbpel. Último acesso: 28/01/2011, 2007b.

OASIS Ws-trust 1.3. Disponível em: http://docs.oasis-open.org/ws-sx/ ws-trust/200512. Último acesso: 18/02/2011, 2007c.

OASIS Ws-secureconversation 1.3. Disponível em: http://docs.oasis-open.org/ ws-sx/ws-secureconversation/v1.3/ws-secureconversation.html. Último acesso: 18/02/2011, 2007d.

OASIS Security services (saml) tc. Disponível em: http://www.oasis-open.org/ committees/tc_home.php?wg_abbrev=security. Último acesso: 28/01/2011, 2008a.

OASIS Web services federation (wsfed) tc. Disponível em: http://www.oasis-open . org/committees/tc_home.php?wg_abbrev=wsfed. Último acesso: 18/02/2011, $2008 b$.

OASIS Web services atomic transaction (ws-atomictransaction). Disponível em: http:// docs.oasis-open.org/ws-tx/wsat/2006/06. Último acesso: 25/02/2011, 2009a.

OASIS Web services business activity (ws-businessactivity). Disponível em: http: / / docs . oasis-open.org/ws-tx/wsba/2006/06. Último acesso: 28/01/2011, 2009b.

O’NeILL, M. Web services security. New York, NY, USA: McGraw-Hill, Inc., 2003.

OPENSSL Openssl cryptography and ssl/tls toolkit. The OpenSSL Project. Disponível em: http: / /www . openssl.org/. Último acesso: 18/03/2011, 2011. 
ORT, E. Service-oriented architecture and web services: Concepts, technologies, and tools. Sun Microsystems. Disponível em: http://java.sun.com/developer/ technicalArticles/WebServices/soa2/. Último acesso: 25/02/2011, 2005.

Papazoglou, M. P. Service-oriented computing: Concepts, characteristics and directions. In: WISE '03: Proceedings of the Fourth International Conference on Web Information Systems Engineering, Washington, DC, USA: IEEE Computer Society, 2003, p. 3-12.

Pointcheval, D. How to encrypt properly with rsa. CryptoBytes, v. 5, n. 1, p. 10-19, 2002.

Ravi, S.; Raghunathan, A.; Kocher, P.; Hattangady, S. Security in embedded systems: Design challenges. ACM Transactions on Embedded Computing Systems, v. 3, n. 3, p. 461-491, 2004.

Rodrigues, D.; Estrella, J. C.; Branco, K. R. L. J. C. Security vs. performance in soa environment. In: ICHIT '10: Proceedings of the 2010 International Conference on Hybrid Information Technology, New York, NY, USA: ACM, 2010, p. 1-7.

Rodrigues, D.; Estrella, J. C.; Branco, K. R. L. J. C. Analysis of security and performance aspects in service-oriented architectures. International Journal of Security and Its Applications, v. 5, p. 13-30, 2011.

Rosenberg, J.; Remy, D. Securing web services with ws-security: Demystifying ws-security, ws-policy, saml, xml signature, and xml encryption. Pearson Higher Education, 2004.

SCRIBner, K.; STIVER, M. Applied soap: Implementing .net xml web services. Indianapolis, IN, USA: Sams, 2001.

SIDDIQUI, B. Exploring $\mathrm{xml}$ encryption, part 1. IBM Corporation. Disponível em: http: / /www.ibm.com/developerworks/xml/library/x-encrypt/. Último acesso: 15/02/2011, 2002.

SIDHARTH, N.; LIU, J. Intrusion resistant soap messaging with iapf. In: APSCC '08: Proceedings of the 2008 IEEE Asia-Pacific Services Computing Conference, Washington, DC, USA: IEEE Computer Society, 2008, p. 856-862.

Silva, F. O.; RosA, P. F. The quest for the web services stack: a fast trip. In: ICWE '06: Proceedings of the 6th International Conference on Web Engineering, New York, NY, USA: ACM, 2006, p. 93-94.

SosnOSKI, D. Java web services: Axis2 ws-security signing and encryption. IBM Corporation. Disponível em: http://www.ibm.com/developerworks/java/library/ j-jws5/. Último acesso: 12/02/2011, 2009. 
Stallings, W. Cryptography and network security. Upper Saddle River, NJ, USA: PrenticeHall, Inc., 2005.

Sugita, M.; Kawazoe, M.; Imai, H. Constructing new differential path and algebraic cryptanalysis for full-sha-1. In: IEICE Technical Reports, Gifu, 2009, p. 1-8 (ISEC2009-51, v.109).

Tanenbaum, A. S. Computer networks. Prentice Hall Professional Technical Reference, 2003.

TANG, K.; Chen, S.; LeVy, D.; ZIC, J.; YAN, B. A performance evaluation of web services security. In: 10th IEEE International Enterprise Distributed Object Computing Conference, 2006. EDOC' '06, 2006, p. 67-74.

VIEGA, J.; EPSTEIN, J. Why applying standards to web services is not enough. IEEE Security Privacy, v. 4, n. 4, p. 25-31, 2006.

W3C Xml encryption syntax and processing. Disponível em: http://www.w3.org/TR/ xmlenc-core/. Último acesso: 15/02/2011, 2002.

W3C Web services architecture. Disponível em: http://Www.w3.org/TR/ws-arch/. Último acesso: 25/01/2011, 2004.

W3C Xml key management specification (xkms 2.0). Disponível em: http://www.w3. org/TR/xkms2/. Último acesso: 17/02/2011, 2005.

W3C Latest soap versions. Disponível em: http://www.w3.org/TR/soap/. Último acesso: 02/02/2011, 2007a.

W3C Web services description language (wsdl) version 2.0 part 1: Core language. Disponível em: http: / /www.w3.org/TR/wsdl20/. Último acesso: 31/01/2011, 2007b.

W3C Web services policy 1.5 - framework. Disponível em: http://WwW.w3.org/TR/ ws-policy/. Último acesso: 18/02/2011, 2007c.

W3C Extensible markup language (xml). Disponível em: http://www.w3.org/XML/. Último acesso: 29/01/2011, 2008a.

W3C Xml signature syntax and processing (second edition). Disponível em: http: //Www . w3. org/TR/xmldsig-core/. Último acesso: 16/02/2011, 2008b.

Weerawarana, S.; Curbera, F.; Leymann, F.; Storey, T.; Ferguson, D. F. Web services platform architecture: Soap, wsdl,ws-policy, ws-addressing, ws-bpel, ws-reliable messaging and more. Upper Saddle River, NJ, USA: Prentice Hall PTR, 2005.

WEIS, B. The use of rsa/sha-1 signatures within encapsulating security payload (esp) and authentication header (ah). RFC 4359. Disponível em: http://www. ietf.org/rfc/ rfc4359.txt. Último acesso: 09/04/2011, 2006. 
Yamany, H. F.; Capretz, M. A. M.; Allison, D. S. Quality of security service for web services within soa. In: SERVICES '09: Proceedings of the 2009 Congress on Services - I, Washington, DC, USA: IEEE Computer Society, 2009, p. 653-660.

YAU, S. S.; Yin, Y.; AN, H. G. An adaptive tradeoff model for service performance and security in service-based systems. In: ICWS '09: Proceedings of the 2009 IEEE International Conference on Web Services, Washington, DC, USA: IEEE Computer Society, 2009, p. 287294.

Ying, Y.; HuAnG, Y.; WAlKeR, D. W. A performance evaluation of using soap with attachments for e-science. In: In Proceedings of the UK e-Science All Hands Meeting, 2005, p. 796-803.

Yu, Q.; Liu, X.; Bouguettaya, A.; Medjahed, B. Deploying and managing web services: Issues, solutions, and directions. The VLDB Journal, v. 17, n. 3, p. 537-572, 2008.

Yu, Y.; Lu, J.; FernandeZ-RAmil, J.; YUAn, P. Comparing web services with other software components. IEEE International Conference on Web Services, v. 0, p. 388-397, 2007.

YUE-ShENG, G.; BAO-JiAn, Z.; WU, X. Research and realization of web services security based on xml signature. International Conference on Networking and Digital Society, v. 2, p. 116-118, 2009.

Zhang, D.; Coddington, P.; Wendelborn, A. Binary data transfer performance over highlatency networks using web service attachments. International Conference on e-Science and Grid Computing, v. 0, p. 261-269, 2007. 